\title{
Immune Abnormalities in Autism Spectrum Disorder-Could They Hold Promise for Causative Treatment?
}

\author{
Dominika Gładysz $^{1}$ - Amanda Krzywdzińska ${ }^{1}$ - Kamil K. Hozyasz ${ }^{1}$
}

Received: 19 June 2017 / Accepted: 5 November 2017 /Published online: 6 January 2018

(C) The Author(s) 2018. This article is an open access publication

\begin{abstract}
Autism spectrum disorders (ASD) are characterized by impairments in language and communication development, social behavior, and the occurrence of stereotypic patterns of behavior and interests. Despite substantial speculation about causes of ASD, its exact etiology remains unknown. Recent studies highlight a link between immune dysfunction and behavioral traits. Various immune anomalies, including humoral and cellular immunity along with abnormalities at the molecular level, have been reported. There is evidence of altered immune function both in cerebrospinal fluid and peripheral blood. Several studies hypothesize a role for neuroinflammation in ASD and are supported by brain tissue and cerebrospinal fluid analysis, as well as evidence of microglial activation. It has been shown that immune abnormalities occur in a substantial number of individuals with ASD. Identifying subgroups with immune system dysregulation and linking specific cellular immunophenotypes to different symptoms would be key to defining a group of patients with immune abnormalities as a major etiology underlying behavioral symptoms. These determinations would provide the opportunity to investigate causative treatments for a defined patient group that may specifically benefit from such an approach. This review summarizes recent insights into immune system dysfunction in individuals with ASD and discusses the potential implications for future therapies.
\end{abstract}

Electronic supplementary material The online version of this article (https://doi.org/10.1007/s12035-017-0822-x) contains supplementary material, which is available to authorized users.

Kamil K. Hozyasz

khozyasz@verco.com.pl; kamil.hozyasz@imid.med.pl

1 Department of Pediatrics, Institute of Mother and Child, Warsaw, Poland
Keywords ASD · Autism · Cytokine · Chemokine · Lymphocytes $\cdot$ Immune system

"The human body is a machine which winds its own springs"

Julien Offray de La Mettrie (eighteenth-century French physician and philosopher)

Autism spectrum disorders (ASD), according to the International Statistical Classification of Diseases and Related Health Problems and the 5th edition of the Diagnostic and Statistical Manual of Mental Disorders [1, 2] criteria, belong to pervasive developmental disorders (PDD) and are characterized by the coexistence of primary symptoms across several areas: improper or impaired language and communication development, difficulties in social attachment and interactions, and occurrence of rigid, stereotypic and repetitive patterns of behavior and interests. ASD children require comprehensive care and the support of specialists from various fields [2-5]. Incidence rates of ASD are controverted and dependent on diagnostic criteria. The Centers for Disease Control and Prevention calculated that the overall prevalence of ASD in children aged 8 years in the USA equaled 1 out of 68 children [6]. It is a serious social problem and an increasing global burden with implications for public health services [7].

Numerous attempts to determine the etiology of ASD have been conducted; nonetheless, it remains largely elusive. It is considered that genetic, neurological, immunological, and environmental factors play a role in the development of ASD. Growing attention is being paid to neuroimmunology as dysregulation of immune responses may lead to impairments in 
neurodevelopment and numerous findings of altered immune system function in ASD individuals have been reported [8].

\section{Immunological background of ASD}

The first suggestion of a link between the immune system and ASD was formed by Stubbs in 1976 because of undetectable rubella antibody titers after a rubella vaccine challenge in autistic children [9]. Several studies in animal models confirmed that an immune challenge during pregnancy results in behavioral abnormalities. Maternal immune activation was shown to activate a macrophage inflammatory state with increased M1 polarization [10], lead to up-regulation of interferongamma (IFN- $\gamma$ ) and interleukin (IL) 17 a secreted by $\mathrm{CD}^{+}$ $\mathrm{T}$ cells [11], and cause a systemic deficit of $\mathrm{T}$ regulatory cells (Tregs) [12].

Mice injected with valproic acid during their gestational period were found to have reduced social interactions and therefore are proposed as a mouse model of ASD. They have chronic glial activation and present with an inflammatory response as evidenced by increasing numbers of microglia and production of higher levels of proinflammatory cytokines when stimulated with lipopolysaccharides (LPS) [13].

Presence of maternal anti-fetal brain autoantibodies has been reported to play a role in ASD as well [14-20]. Monkeys exposed prenatally to human immunoglobulin $G$ (IgG) derived from mothers of ASD children were found to exhibit stereotypies, hyperactivity [21], or impaired social behavior [22]. Similar results were observed in mice [23]. BTBR mice (as a mouse model of ASD) were found to have higher levels of serum $\mathrm{IgG}$, immunoglobulin $\mathrm{E}$ (IgE), and anti-brain antibodies along with up-regulation of several cytokines [24].

Family history of autoimmunity has been reported as a risk factor for ASD in multiple studies [25-39]. A meta-analysis on this topic identified hypothyroidism, type 1 diabetes, rheumatoid arthritis, and psoriasis as a major family history burden [29, 38]. Maternal autoimmune diseases beginning during pregnancy can strongly impact risk of ASD in offspring as well [39].

An association between some alleles of human leukocyte antigens (HLA) and autoimmune diseases has been established. Several studies have revealed links between HLA and ASD, where autistic children were found to have a higher frequency of HLA-DRB $1 * 11$ allele and lower frequency of HLA-DRB $1 * 03$ allele [40]. Several other investigators reported on an association between HLA and ASD in different populations including Caucasian [41-45], Thai [46], Saudi Arabian [47], and Chinese [48]. An interesting association of HLA-G polymorphism with ASD, likely a consequence of prenatal immune activation, was reported by Guerini et al. [49]. HLA-DR4 in mothers was also reported as the ASD risk factor for their offspring [50]. Consideration of genetic polymorphisms in the HLA region is advised when studying immunopathology of the disease [51].

A presence of brain autoantibodies in children with ASD also suggests immunological involvement [52-63]. Severity of ASD, measured with Childhood Autism Rating Scale (CARS), was found to be correlated with serum antineuronal [54] and anti-ganglioside M1 antibodies [63]. Antibrain antibodies have been found to correlate with more impaired cognitive functions, motor stereotypies [52, 57], irritability, and lower expressive language skills [53, 57].

An accumulation of evidence in favor of an immune pathomechanism has led to studies of neonatal and midgestational cytokines as early markers of ASD (Table 1). In a population-based case-control study, monocyte chemotactic protein-1 (MCP-1) was elevated and the chemokine RANTES (for regulated upon activation, normal T-cell expressed and secreted) was decreased in newborn peripheral blood retrieved from archives that collected dried bloodspots for screening purposes (obtained 24-48 h after birth). RANTES was also found to be down-regulated in children with developmental delays other than ASD along with macrophage inflammatory protein- $1 \alpha$ (MIP-1 $\alpha)$ [66]. Another approach to identify children at risk for ASD was proposed by Goines et al. [71], who showed that increased IFN- $\gamma$, IL-4, and IL-5 in pregnant women at 15 to 19 weeks of gestation was associated with increased risk of bearing a child with ASD. A study from the same center revealed that mid-gestational concentration of cytokines and chemokines (especially granulocyte macrophage colony-stimulating factor-GM-CSF, IFN- $\gamma$, IL- $1 \alpha$, and IL-6) was highest in mothers of ASD children with intellectual disability [64]. A high concentration of IL-4 was found to be associated with increased risk of severe ASD, while IL$1 \beta$ correlated with mild to moderate ASD [65]. A series of studies by Abdallah et al. [67-70] demonstrated a strong association of multiple cytokines detected in material from newborn screening, as well as several chemokines (MCP-1, MIP$1 \alpha$, RANTES) and growth factors (brain-derived neurotrophic factor-BDNF, neurotrophin-NT, transforming growth factor-beta-TGF- $\beta$ ), in both neonatal dried bloodspots and amniotic fluid [70]. Down-regulation of NT in dried bloodspots of ASD children was confirmed by Nelson et al. [72]. The search for potential ASD biomarkers is well underway [73, 74]; for an excellent review, see Anderson [75].

ASD is very complex and heterogeneous. The question of whether immune dysregulation is a primary cause or secondary consequence is still open. Even if immune system integrity turns out to be a key player in ASD pathogenesis, it surely will not be the sole factor responsible for behavioral abnormalities. However, evidence for an immunological component is strong. It is worth noting that all published studies on neonatal and gestational immune mediators have succeeded in detecting some abnormalities in comparison to typically developing controls. However, attention should be given to some 


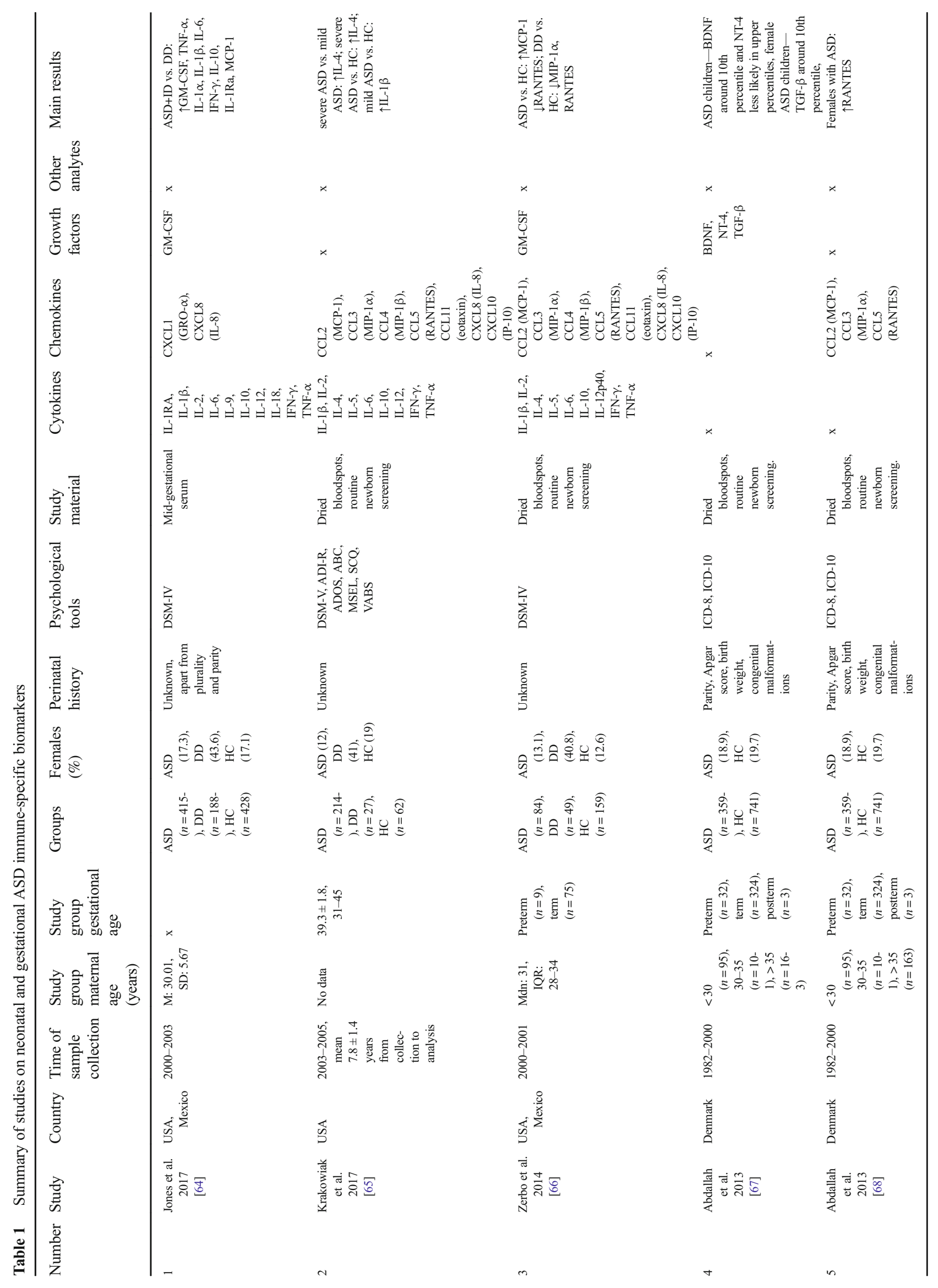




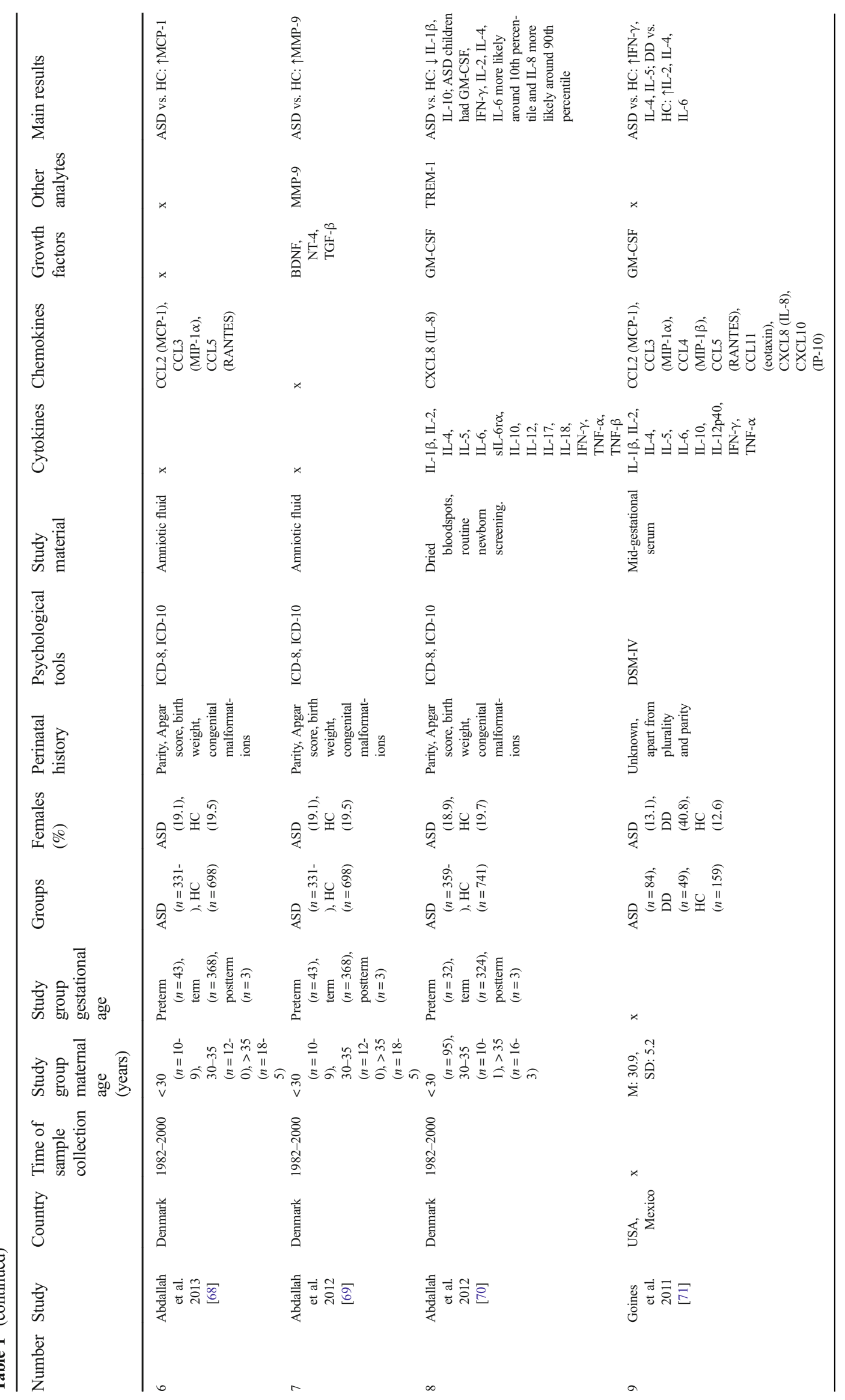




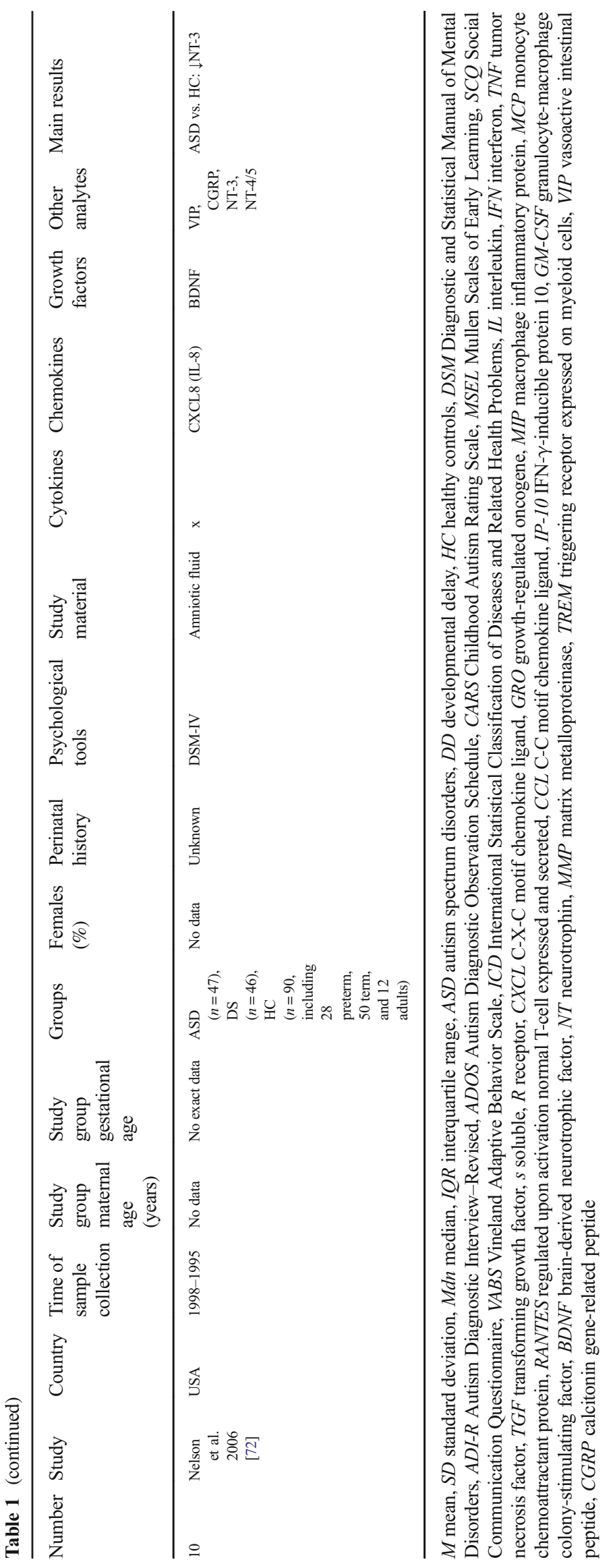


methodological concerns, such as lengthy times from sample collection to analysis, incomplete perinatal histories, lack of details on behavioral abnormalities, and cases of no clinical confirmation of ASD. Only the Krakowiak et al. study [65] confirmed ASD diagnoses and made an effort to evaluate behavioral traits. Interestingly, besides mediators classically associated with inflammation, an elevation of Th-2 cytokines was noted. An up-regulated concentration of serum midgestational IL-10 in mothers of autistic children was reported by Jones et al. [64]. These results should be interpreted with caution, however, as IL-10 is known to be physiologically elevated during pregnancy $[76,77]$ and its concentration was normal in another study from the same biological sample [71], and was not elevated $[65,66]$ or even down-regulated [70] in three other studies that utilized dried bloodspots from newborn screening. Surprisingly, another Th2 cytokine, IL-4, was found to be elevated in newborn dried bloodspots (acquired from children that were determined to have ASD) by Krakowiak et al. [65] who conducted the study with the best methodological quality. Moreover, high IL-4 level was connected with severe ASD. Another study found elevated IL-4 concentration in mid-gestational serum from mothers of children with ASD, which could be partially attributed to changes during pregnancy [76]. One of two experiments based on dried bloodspots did not detect any abnormalities [66], while another revealed tendency toward lower IL-4 concentrations in neonates that developed ASD [70]. Clearly, the purpose of these studies was to identify biomarkers that could precede occurrence of autistic traits. However, this task is very hard or nearly impossible due to several other perinatal factors that can alter results and due to methodological difficulties, particularly in confirming ASD diagnosis and finding connections between behavioral abnormalities and immune disturbances.

\section{Lymphocytes}

One of the first clues concerning lymphocyte pathology in ASD was described by Stubbs and Crawford who found decreased lymphocyte response to stimulation with phytohemagglutinin (PHA) in children with ASD [78]. One of the first studies on lymphocyte subsets in ASD was carried out by Warren et al. in 1986 [79]. The investigators found a decreased number of $\mathrm{T}$ lymphocytes, reduced response to stimulation with PHA, concanavalin A, and pokeweed mitogen, and an imbalanced ratio of helper/suppressor cells. Another study confirmed lower helper/suppressor ratio with a decreased percentage of helper-inducer cells and decreased percentage of cells with expression of IL-2R after mitogenic stimulation being inversely correlated with severity of autistic traits [80].

Another early study on lymphocytes in ASD showed lower numbers of total lymphocytes in peripheral blood of ASD children compared to sibling and healthy controls, along with a significantly lower percentage and number of $\mathrm{CD}^{+}{ }^{+}$helper $\mathrm{T}$ cells [81]. Ashwood et al. [82] reported significantly higher number of B cells in children with ASD aged 4-6 years in comparison with age- and sex-matched typically developing controls. The study protocol involved 64 three-color cellular assays that revealed higher counts of activated and mature B cells and higher numbers of cellular activation markers such as HLA-DR and CD26. The investigators further divided children into low and high functioning individuals according to intelligence quotient (IQ) measured with Stanford-Binet Intelligence Scale; however, there were no differences within subgroups. Ferrante et al. [83] observed a significant increase in $\mathrm{CD}^{+}$memory and decrease in $\mathrm{CD} 4^{+}$naïve $\mathrm{T}$ cells associated with HLA A2-DR11. Warren et al.'s studies [84, 85] on lymphocyte subpopulations revealed incomplete T cell activation, decreased numbers of lymphocytes and $\mathrm{CD} 4{ }^{+} \mathrm{CD} 45 \mathrm{RA}^{+}$ cells, and normal levels of $\mathrm{B}, \mathrm{NK}$, and other T cells. Abnormalities regarding suppressor-inducer $\mathrm{T}$ cells have shifted researchers' attention to T-cell biology in ASD.

Tregs play a key role in regulation of immune responses. A study on Egyptian children [86] revealed lower numbers of $\mathrm{CD} 4{ }^{+} \mathrm{CD} 25^{\text {high }}$ Tregs in the blood of autistic children. Moreover, allergic problems and family history of autoimmunity turned out to be risk factors for the lowest number of $\mathrm{CD} 4^{+} \mathrm{CD} 25^{\text {high }}$ Tregs. The study was conducted on 30 patients and 30 age- and sex-matched healthy controls.

Dysregulation of Th1, Th2, Th17, and Treg-related transcription factors has also been described. Mononuclear cells derived from peripheral blood (PB-MNC) of autistic children and typically developing controls were stimulated and subsequently assessed for expression of mRNA and proteins of major transcription factors involved in neurodevelopment and differentiation of T cells. A deficit of forkhead box protein $3^{+}$Tregs was found along with up-regulation of Th1/Th2/ Th17-related transcription factors [87].

An imbalance of cytokines produced by $\mathrm{CD}^{+}$and $\mathrm{CD} 8^{+}$ $\mathrm{T}$ cells with skewing toward Th2 response was found in 1997 by Gupta et al. [88]. Proportions of $\mathrm{CD}^{+}$and $\mathrm{CD} 8^{+}$ $\mathrm{T}$ cells producing IFN- $\gamma$ and IL-2 were reduced in opposition to $\mathrm{T}$ cells that produced IL-4. Further insight into Th2 response was provided by a study that concentrated on Th2 lymphocyte receptor ligands of 56 ASD children with 32 matched controls. Serum levels of macrophage-derived chemokine (MDC) and thymus and activation-regulated chemokine (TARC) were elevated and significantly correlated with intensification of autistic behaviors [89]. A higher percentage of $\mathrm{CD}^{+} \mathrm{T}$ cells $(21.68 \%$ vs. $16.48 \%)$ and $\mathrm{B}$ cells $(8.17 \%$ vs. $6.97 \%)$ and a decrease of $\mathrm{CD} 4^{+} / \mathrm{CD}^{+}$ratio (3.01 vs. 3.97) was reported in 59 adult patients with ASD with a mean age of about 24 years versus a control group composed of 26 individuals, two of which were first-degree relatives, with no significant differences regarding age and gender of study participants [90]. 
Immune dysfunction is also observed in healthy siblings of ASD children, their immunophenotype is closer to their relatives than to typically developing matched controls. They have been found to have a higher concentration of cytokineproducing lymphocytes and $\mathrm{CD} 8^{+}$naïve $\mathrm{T}$ lymphocytes along with a down-regulation of $\mathrm{CD}^{+}$effector memory and $\mathrm{CD} 4^{+}$ terminally differentiated lymphocytes [91].

Th17 $\mathrm{CD}^{+} \mathrm{T}$ cells are thought to be important players in autoimmune and neuroinflammatory diseases. Their product, IL-17A, is known to be up-regulated in several autoimmune diseases such as multiple sclerosis, systemic lupus erythematosus, and rheumatoid arthritis [92]. A cross-sectional study by Al-Ayadhi and Mostafa [93] on 45 children with ASD aged 6-11 years revealed a positive correlation of IL-17A with ASD severity. Nearly $50 \%$ of autistic children had elevated serum IL-17A levels, including $67.9 \%$ of children with severe and $17 \%$ of children with mild to moderate ASD. Upregulation of IL-17 was also found in ASD children with concomitant asthma after T-cell stimulation with PHA [94]. A strong association of ASD with Th17 cells has also been demonstrated in animal studies, where effector cytokine IL17 a was essential for maternal immune activation and subsequent behavioral abnormalities [95]. IL-23, known to increase Th17 cell production of IL-17, was found to be down-regulated, especially in children with new-onset ASD, with no concomitant differences in IL-17 levels. Stimulation with PHA altered secretion of IL-23, which was found to be significantly lower than in typically developing controls and associated with more impaired behavioral scores $[96,97]$.

A BTBR mouse model of ASD was found to have upregulated IgG production with IgG brain deposits and antibrain IgG antibodies [98]. Several studies in humans have assessed concentrations of serum immunoglobulins and their subclasses in ASD individuals with discrepant results. A study on 15 subjects with ASD, 5 of whom underwent cerebrospinal fluid (CSF) immunoglobulin analysis, found no abnormalities [99]. Serum immunoglobulin A (IgA) deficiency was found by Warren et al. [100] in 40 individuals with ASD, both children and adults. Eight of 40 studied ASD patients had IgA levels below normal range adjusted for age, while in control groups there were no abnormalities. Mean serum IgA level of autistic individuals was significantly lower than in the control group (105 mg/100 mL vs. $143 \mathrm{mg} / 100 \mathrm{~mL}$ ). Similar observations were made by Wasilewska et al. [101] who reported on lower IgA levels and up-regulated expression of CD23 on B lymphocytes derived from children with regressive ASD aged 3-6 years old. The studied groups consisted of 24 ageand gender-matched individuals with no differences regarding demographics and perinatal history.

In a study on 31 patients with selective IgA deficiency, 1 had a diagnosis of ASD [102]. The researchers focused on the offspring and siblings of the abovementioned group. Out of 87 children born to individuals with $\operatorname{IgA}$ deficiency, 3 had a diagnosis of ASD in comparison to 1 child out of 193 children born to subjects with normal IgA concentration. ASD was diagnosed in $2 \%$ of siblings (2/99 individuals) of IgAdeficient patients in contrast with $0.5 \%$ of siblings $(1 / 217$ individuals) in the control group. However, the abovementioned results did not reach statistical significance [102].

Analysis of plasma levels of immunoglobulins in over 100 individuals with ASD revealed reduced levels of IgG and immunoglobulin $\mathrm{M}(\operatorname{IgM})$ that inversely correlated with scores on the Aberrant Behavior Checklist (ABC), with lethargy being especially pronounced in children with the lowest IgG [103]. The mean IgG level in ASD individuals equaled $5.39 \mathrm{mg} / \mathrm{mL}$ in contrast to $7.72 \mathrm{mg} / \mathrm{mL}$ in typically developing co6ntrols, and $8.23 \mathrm{mg} / \mathrm{mL}$ in children with developmental delay. IgM level was less evident; however, it was statistically significant $(0.67 \mathrm{mg} / \mathrm{mL}$ in comparison to $0.79 \mathrm{mg} / \mathrm{mL}$ in healthy controls).

Further in-depth studies revealed that the detected abnormalities were not a result of B-cell dysfunction. There were no differences in the number of naïve, memory IgG or IgM cells, no abnormalities in response to antigenic stimulation, and production of immunoglobulins after in vitro stimulation was detected. The authors hypothesized that the lower level of immunoglobulins is caused by either a defect in another immune cell type that takes part in immunoglobulin production or a defect during immune system development [104].

Plasma concentration of IgM as well as IgG, especially $\mathrm{IgG4}$, was reported to be increased in ASD patients in comparison to healthy siblings. Moreover, IgG1 subclass was found to be increased in comparison with healthy siblings of the same gender [105]. Higher concentrations of IgA, IgG, and IgE food-specific antibodies in individuals with ASD in comparison to their siblings were also described [106]. Spiroski et al.'s study [107] of immunoglobulins in Macedonian children with ASD revealed alterations in concentration of $\operatorname{IgA}, \operatorname{IgG} 2$, and $\operatorname{IgG} 3$ between ASD children and healthy family members. The study was a retrospective analysis that included 30 autistic children with mean age of 10 ; the control groups consisted of mothers, fathers, and siblings of affected children. No exact demographical data was given. Because of multiple comparison testing and lack of precise characteristics of examined subjects, study results should be interpreted with caution.

According to Croonenberghs et al. [108], autistic individuals had higher concentrations of total serum proteins with increased concentrations of albumin and gamma-globulins, especially $\operatorname{IgG} 2(305 \mathrm{md} / \mathrm{dL}$ vs. $216 \mathrm{md} / \mathrm{dL})$ and $\operatorname{IgG} 4$ $(76 \mathrm{md} / \mathrm{dL}$ vs. $48 \mathrm{md} / \mathrm{dL})$. The authors hypothesize that alteration of IgG subclasses may be associated with a cytokinerelated influence on autoimmune B cells. Unfortunately, the study was carried out on a small number of subjects (18 with ASD and 22 controls). However, increased IgG4 levels in 
ASD children in comparison to typically developing controls and children with non-autistic developmental delay were confirmed in another study [109].

A higher frequency of D8/17 B lymphocytes was found in ASD subjects, especially in subjects with repetitive behaviors [110]. This antigen is associated with Tourette syndrome, rheumatic fever, and pediatric autoimmune neuropsychiatric disorders associated with streptococcal infections [111-114]. B cells were found to be hypersensitive to thimerosal [115]. Wei et al.'s study [116] on B-lymphocyte function in eight ASD individuals found altered cell migration and adhesion as well as improper immunoglobulin formation and secretion. The authors concluded that B-cell abnormalities were caused by disturbed integrin-FAK-Src signaling and reduced paxillin activity. However, the majority of studies assessing B-cell number and function did not detect any abnormalities [79, $80,85,117]$.

Overall data is suggestive that altered lymphocyte function, especially T-cell subpopulations, occurs in a substantial number of ASD individuals. Multiple studies have reported on lymphocyte pathology and imbalances between lymphocyte subpopulations. The key consistent findings include decreased response to stimulation [78-80], abnormal activation $[80,84,85]$, improper ratio of $\mathrm{T}$ helper and suppressor cells [79, 80, 83], down-regulation of Th cells [81], and systemic deficit of Tregs $[86,87]$ in ASD subjects. These results, along with cytokine abnormalities, provide a broader view of a possible basis for observed ASD aberrations.

\section{Natural killer cells}

Natural killer (NK) cells constitute about $15 \%$ of circulating lymphocytes and play a pivotal role in the innate immune system [118]. They are characterized by a lack of CD3 surface antigen, expression of CD56, and their function is exerted by production of immunomodulatory cytokines such as IFN $-\gamma$, tumor necrosis factor-alpha (TNF- $\alpha$ ), and IL-10. They also have cytolytic activity and mediate cellular cytotoxicity and surveillance immune function through crosstalk with dendritic cells $[119,120]$. Imbalances between their activation and inhibitory states could play a role in autoimmune diseases; however, the specific underlying mechanisms are not yet fully understood [121]. Roles for NK cells have already been described in the pathogenesis of neurological disorders such as multiple sclerosis [122], schizophrenia [123], Tourette syndrome [124], and Rett syndrome [125].

A previously described study by Ashwood et al. [82] reported higher absolute numbers of NK cells in peripheral blood of autistic individuals ( 161 cells $/ \mu \mathrm{L}$ vs. 117 cells $/ \mu \mathrm{L}$ ). Reduced NK cell activity associated with ASD was first reported by Warren et al. in 1987 [126]. The study was carried out using K562 tumor cells, from 31 patients with ASD, as target cells and found that cells from 12 of the ASD patients had significantly reduced cytotoxic activity. Enstrom et al.'s study [127] on NK cells revealed an increased expression of NK cell receptor RNA, along with an up-regulated number of NK cells $\left(21.24 \pm 3.40 \times 10^{4}\right.$ cells $/ \mathrm{mL}$ vs. $14.45 \pm 1.98 \times 10^{4}$ cells $/ \mathrm{mL}$ ), and production of perforin, granzyme B, and IFN- $\gamma$ in blood samples from ASD children compared to typically developing controls. Cellular studies were carried out on 17 autistic individuals aged $2-5$ years, and 16 age- and sexmatched controls, while gene expression profile was conducted on 35 ASD children and 11 healthy controls. Cytotoxicity in response to stimulation was reduced in the ASD group. Similar abnormalities were not found in typically developing children. No differences in frequency of CD56 ${ }^{\text {Dim }}$ (cytotoxic properties) or CD56 ${ }^{\text {Bright }}$ (interleukin-producing cells) cells were noted. These results are concordant with previous studies that reported abnormalities in NK cell activity $[126,128]$ and molecular changes in differentially expressed genes [129]. According to Vojdani et al. [128], who analyzed peripheral blood samples from over 1000 children, NK cell activity is decreased due to low levels of its stimulants, IL-2 and IL-15. They found no correlation between NK cell absolute number and cytotoxic activity, in opposition to the previously mentioned hypothesis. However, the investigators found a relationship between cell function and low intracellular level of glutathione. They also showed that NK cell activity was higher after co-culture with glutathione, IL-2, and IL-15. However, serum concentrations of those interleukins and subpopulations of CD56 ${ }^{\text {Dim }}$ and CD56 ${ }^{\text {Bright }}$ were not assessed. In 59 adult ASD patients, significantly lower numbers of NKT cells, with normal numbers of NK cells, and increased numbers of stimulated NKT and NK cells expressing $\mathrm{CD} 25^{+}$were described [90].

Another approach for NK cell analysis was proposed by Torres et al. [130] and Guerini et al. [131] who focused on molecular changes by studying killer immunoglobulin receptors (KIR), MHC I class-binding receptors, that are expressed on NK cell surfaces and modulate NK cell function [132]. Both activation and inhibition states of KIR have been associated with various diseases including autoimmune disorders [133]. Torres et al. [130] found up-regulation of KIRactivating genes in patients with ASD. Another study [131] suggested that KIR might play a role in in utero ASD pathogenesis as activating KIR/HLA complexes were found to be increased in ASD, detectable in both children with ASD and their mothers.

The implications of NK cell pathology in ASD remain unknown, and they seem to be a secondary cause of proinflammatory processes and immune imbalances. Chronic inflammation at the cellular level could lead to persistent activation of NK cells, subsequent reduction of their cytotoxic activity, and compensatory up-regulation of their total number. Increased numbers of NK cells associated with ASD was 
confirmed in two $[82,127]$ out of five studies $[82,126-128$, 134]. One study demonstrated the opposite result; however, the study and control group were broader in age demographics (respectively from 3 to 22 years old and from 1 to 12 years old). Abnormal NK cell functional activity was confirmed in both experiments that utilized cytotoxic ability analysis [127, 128]. One might suspect that either unnaturally low levels of NK cell stimulants (such as IL-15, IL-2, IL-12, IL-18, and IL21) or that excessively high levels of the stimulants would be observed if the inflammatory milieu leads to NK cell pathogenic activation and loss of cytotoxic properties through exhaustion. Interestingly, abnormalities of these cytokines were scarcely, if ever, found. A major NK cell stimulant, IL-15, was explored in 7 of 57 conducted studies [135-141] and found significantly up-regulated only in children with ASD who presented with gastrointestinal (GI) disturbances [137]. IL-2 was more well studied $[88,91,135,136,138-149]$ and turned out to be significantly altered in 4 out of 16 experiments. It was found to be up-regulated in comparison to control group in two studies [91, 149] and in one study it was increased among ASD children with GI issues and correlated with impaired adaptive behavior [138]. CD- $4^{+}$IL-2-secreting cells were found decreased in one of the earliest studies [88]. IL12 was vastly explored in nearly half of the conducted studies $[73,91,135,136,138-142,144,145,147,150-160]$ and found frequently increased in ASD subjects in comparison to healthy controls [135, 140,141, 145, 152, 157, 160]. Interestingly, stimulation in different conditions downregulated IL-12 concentration [144, 153, 154] apart from stimulation with dietary proteins [157]. IL-12 high concentration turned out to be associated with abnormal EEG [135], GI complaints [158], low IQ [138], and prominent aberrant behavior [144, 145]. IL-18 was explored in four studies [140-142, 159] and found elevated in adult males with ASD in comparison to neurotypical controls [140], while IL-21 was studied in one experiment and found significantly increased in autistic children compared to normal controls [162]. None of the studies assessed NK cell count and function in addition to cytokine levels.

\section{Monocytes}

Abnormal monocyte count or function was described in ASD by several investigators $[151,155,161]$. Sweeten et al. [161] reported a high monocyte count in children with ASD, which was not confirmed in later studies. The difference was small $\left(0.588 \times 10^{3}\right.$ cells $/ \mathrm{mm}^{3}$ vs. $0.491 \times 10^{3}$ cells $\left./ \mathrm{mm}^{3}\right)$, but statistically significant. Monocytes in children with ASD were also found to be positive for a surface receptor that is thought to be expressed on cells susceptible to apoptosis [90]. Enstrom et al. [155], in a small study on 17 ASD children and 16 healthy controls, stimulated monocytes with Toll-like receptor (TLR) ligands and observed differences between cytokine profiles in autistic and healthy children. Following different LTR stimulations, several cytokines were increased (IL-1 $\beta$, IL-6, TNF- $\alpha$ ) or decreased (IL-1 $\beta$, IL-6, GM-CSF, and TNF- $\alpha$ ) in ASD individuals. However, no difference in number of monocytes was observed. In children with ASD, stimulation with TLR2 and TLR4 led to a high proinflammatory response, while TLR9-induced stimulation resulted in poor production of cytokines and ineffective reaction. Authors concluded that such abnormalities may have an impact on neuronal activity and developing autoimmunity. Jyonouchi et al. [151] proposed an interesting study on monocyte cytokine profiles in six groups of patients with and without ASD, including an "inflammatory subtype of ASD" group - patients who presented with symptoms indicating immune dysregulation and GI complaints (other groups included ASD children without non-IgE-mediated food allergy, typically developing controls with non-IgE-mediated food allergy, children with pediatric acute-onset neuropsychiatric syndrome, and healthy controls). The proinflammatory cytokine profile in this group was upregulated both before and after stimuli. Additionally, children who manifested irritability, lethargy, or hyperactivity were found to produce higher amounts of proinflammatory and lower amounts of anti-inflammatory cytokines (Tables 2 and 3). It is worth underlying that cytokine pattern in acute-onset neuropsychiatric syndrome was different than that observed in ASD.

Monocytes are a part of an innate immune system that differentiate into macrophages and migrate into the surrounding tissue where they present antigens to lymphocytes [186]. State-of-the-art research has shown that current understanding of monocyte and macrophage biology is insufficient and should undergo revision [187]. Monocytes in an inflammatory milieu have been known to secrete proinflammatory mediators such as IL- $1 \beta$, IL- 8 , or TNF- $\alpha$, and their prolonged activation has been found to be relevant in the course of rheumatoid arthritis [188], Alzheimer's [189], and Parkinson's disease [190]. Changes in monocyte function observed in ASD may not be causative, as studies suggest that monocytes are in an activated state and their proinflammatory activity could add on to existing immune imbalances, exacerbating behavioral symptoms.

\section{Microglia}

Microglia, resident innate immune cells of the brain, are specialized tissue macrophages of the CNS that monitor brain homeostasis [191]. They are known to play an important role in the pathogenesis of neuropsychiatric disorders including ASD [192-195]. During brain development, microglia take part in synaptic and neuronal development and regulation of stem cell proliferation [196]. In autistic children, microglia are 


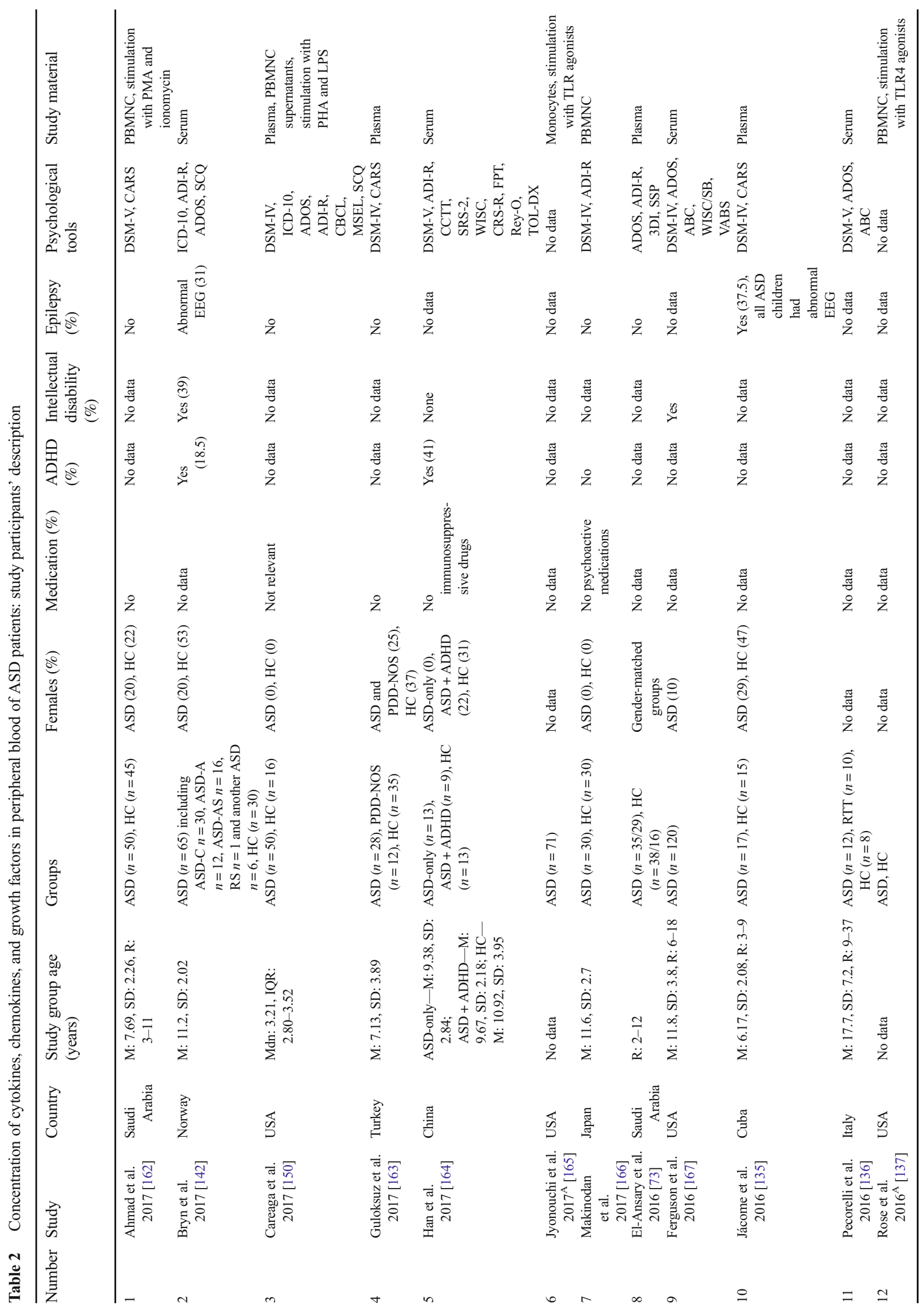




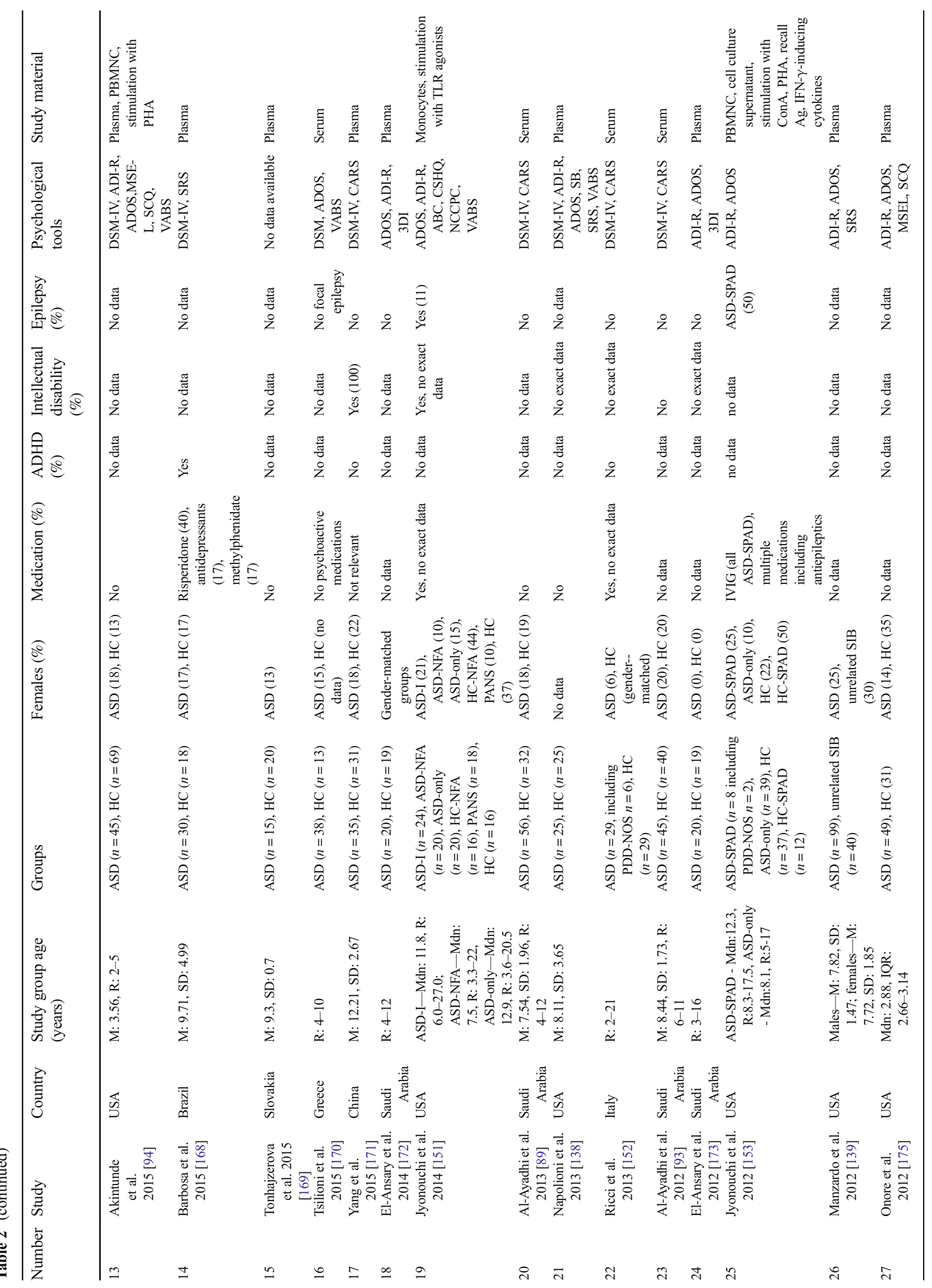




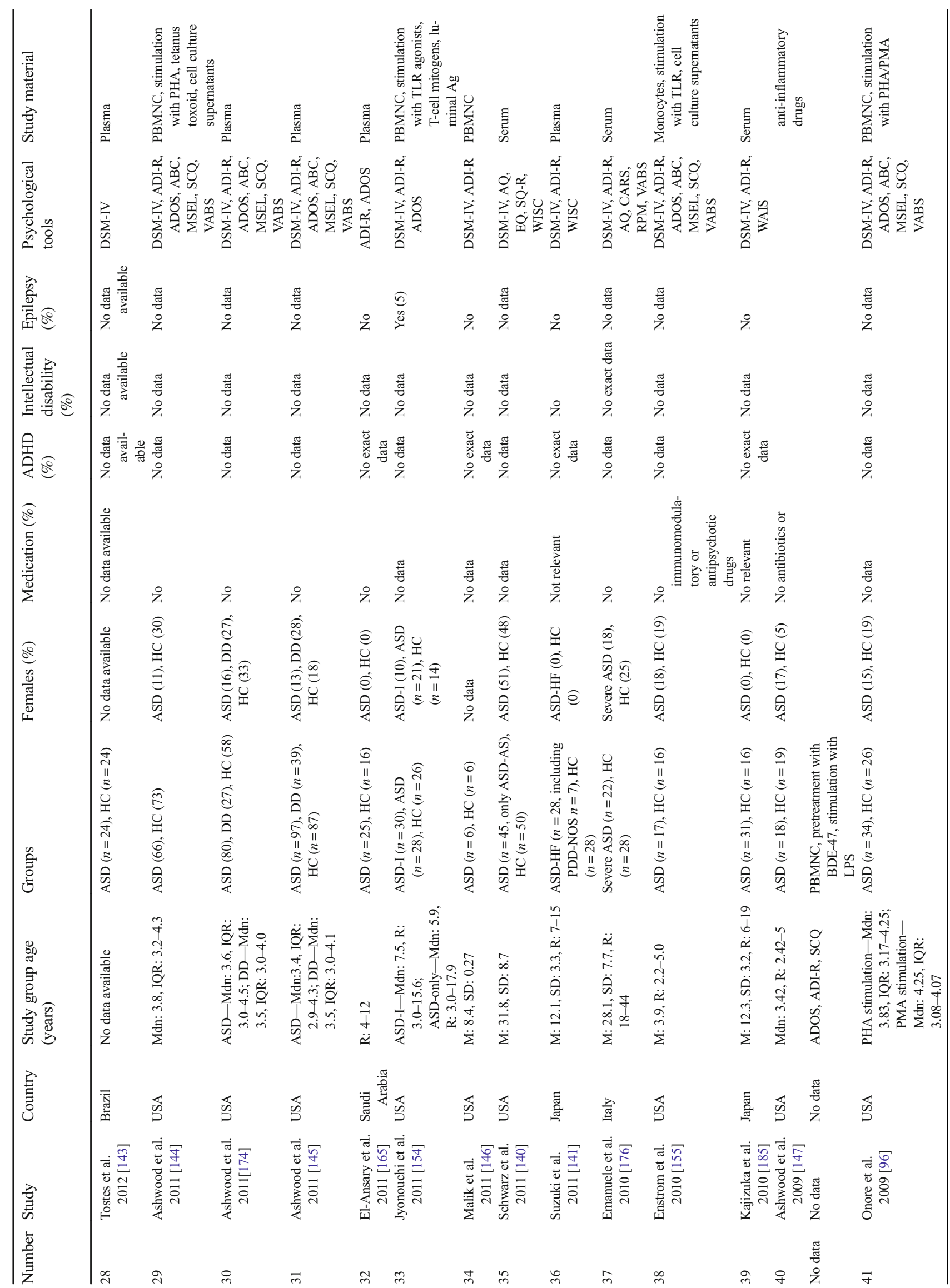




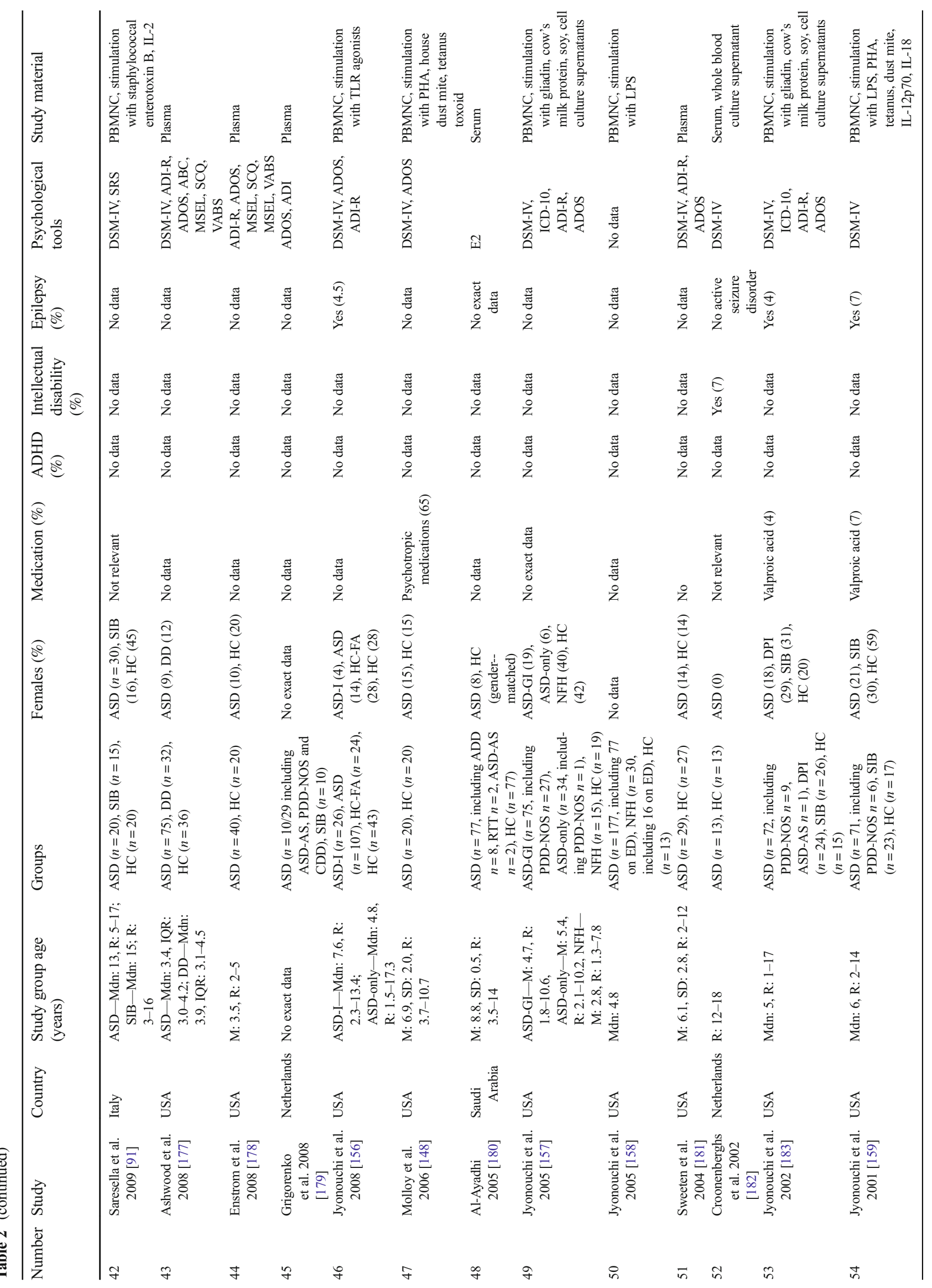




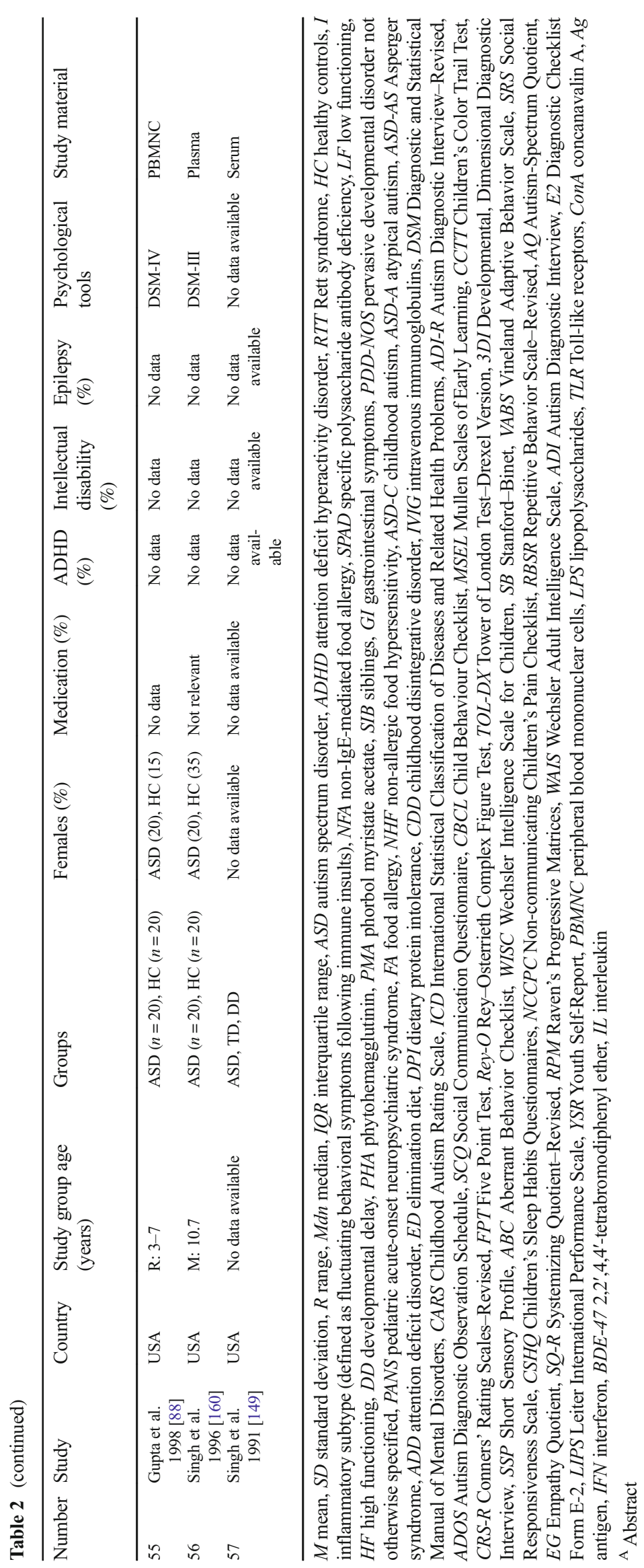




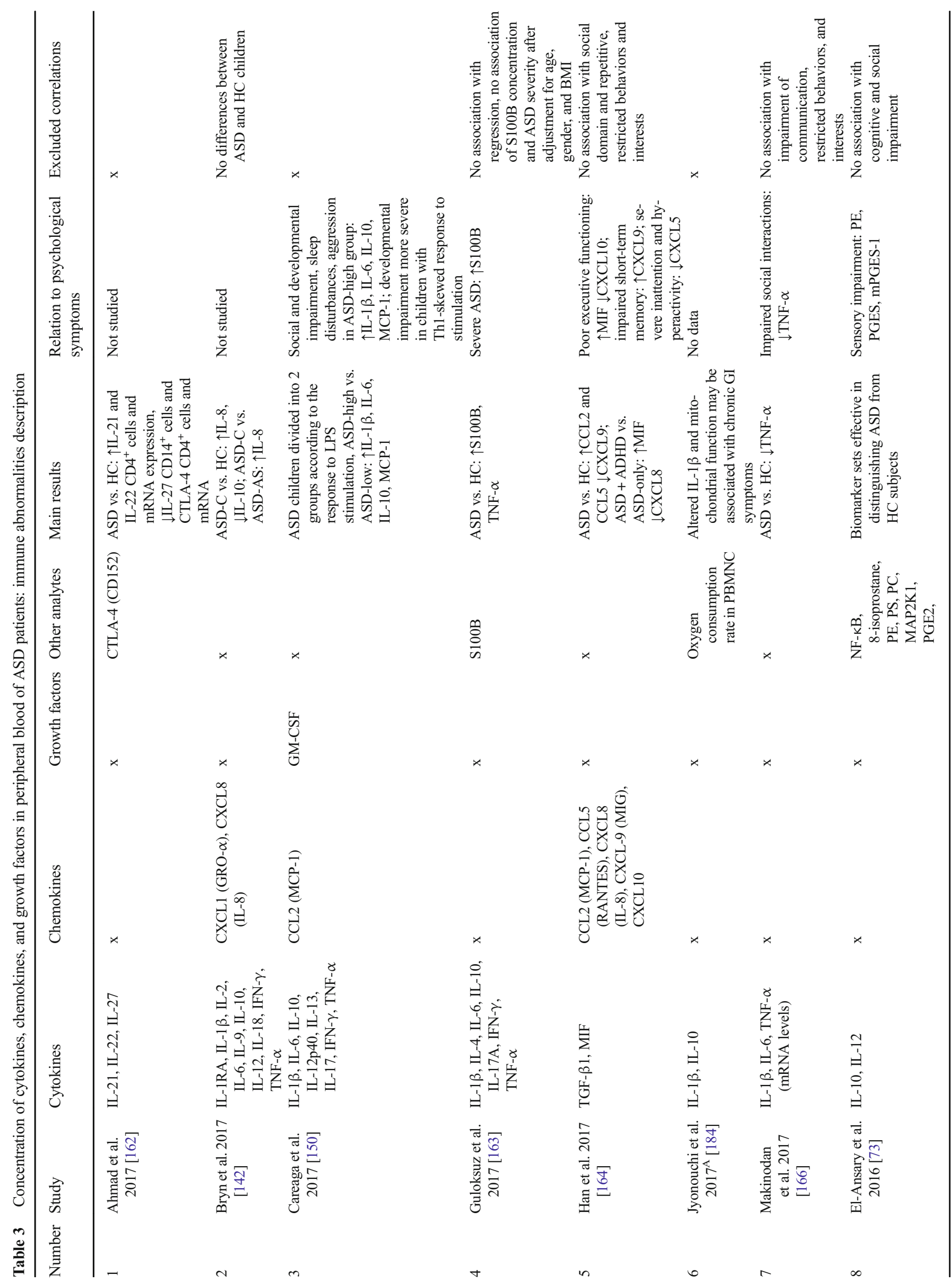




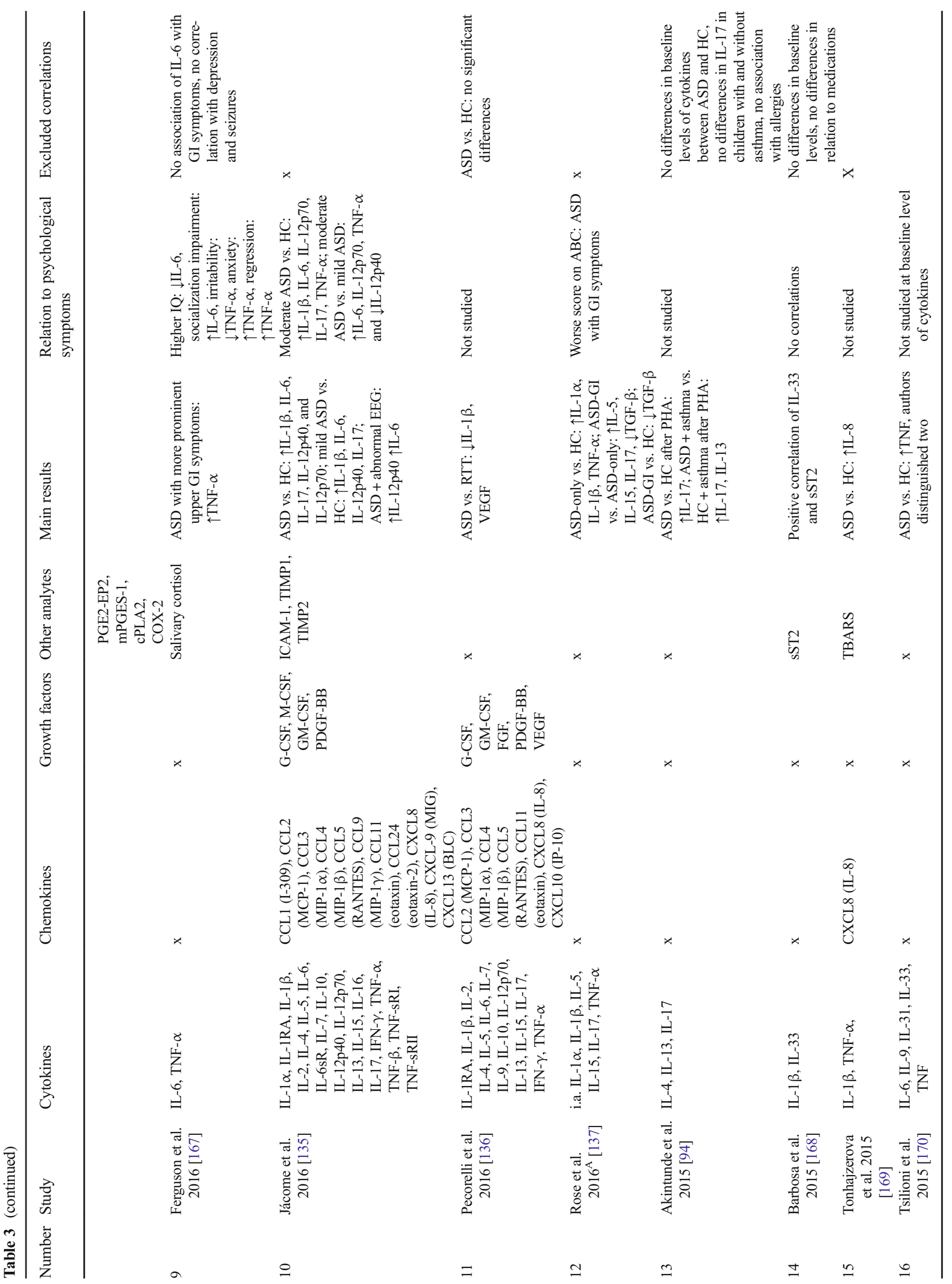




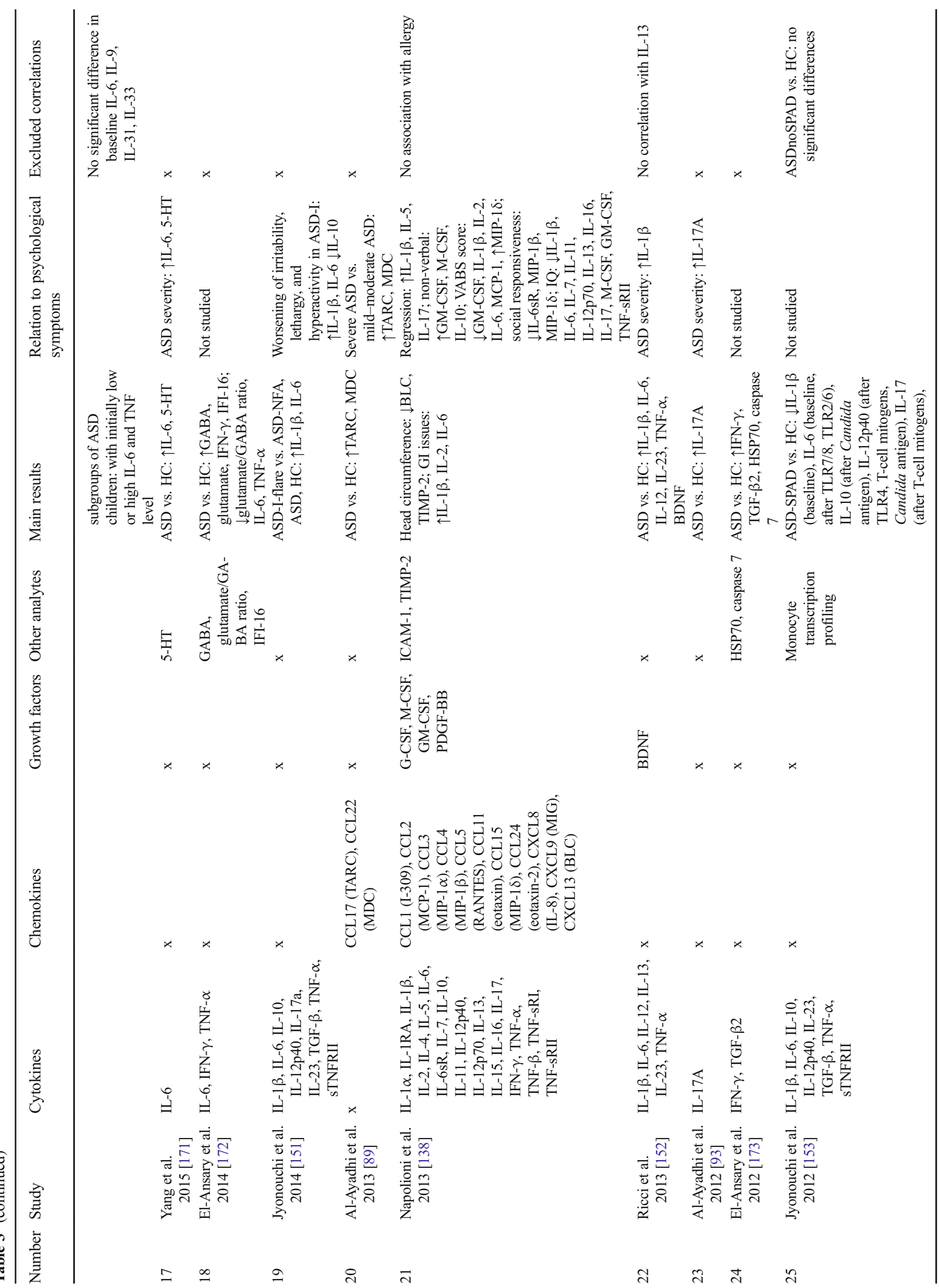




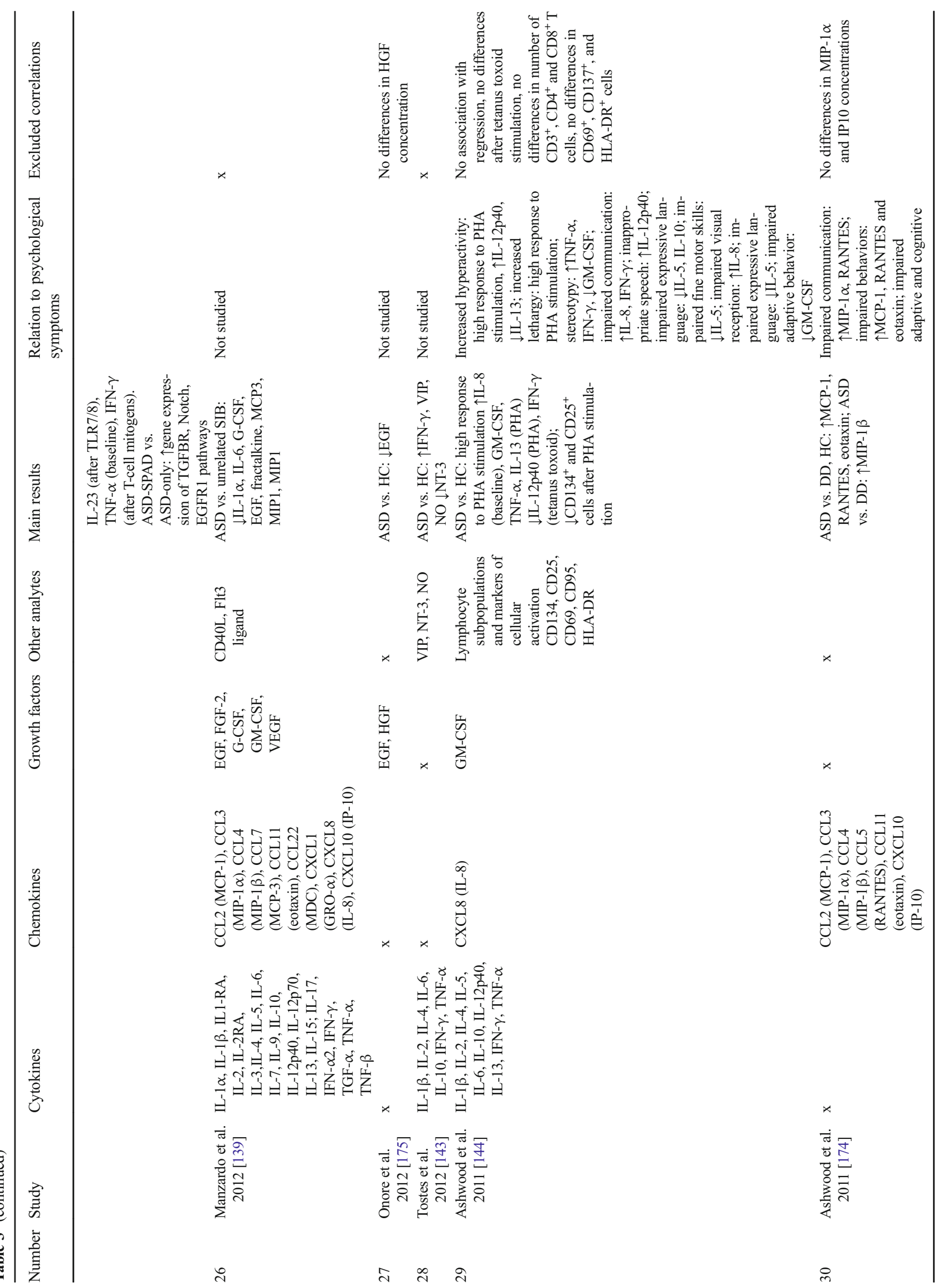




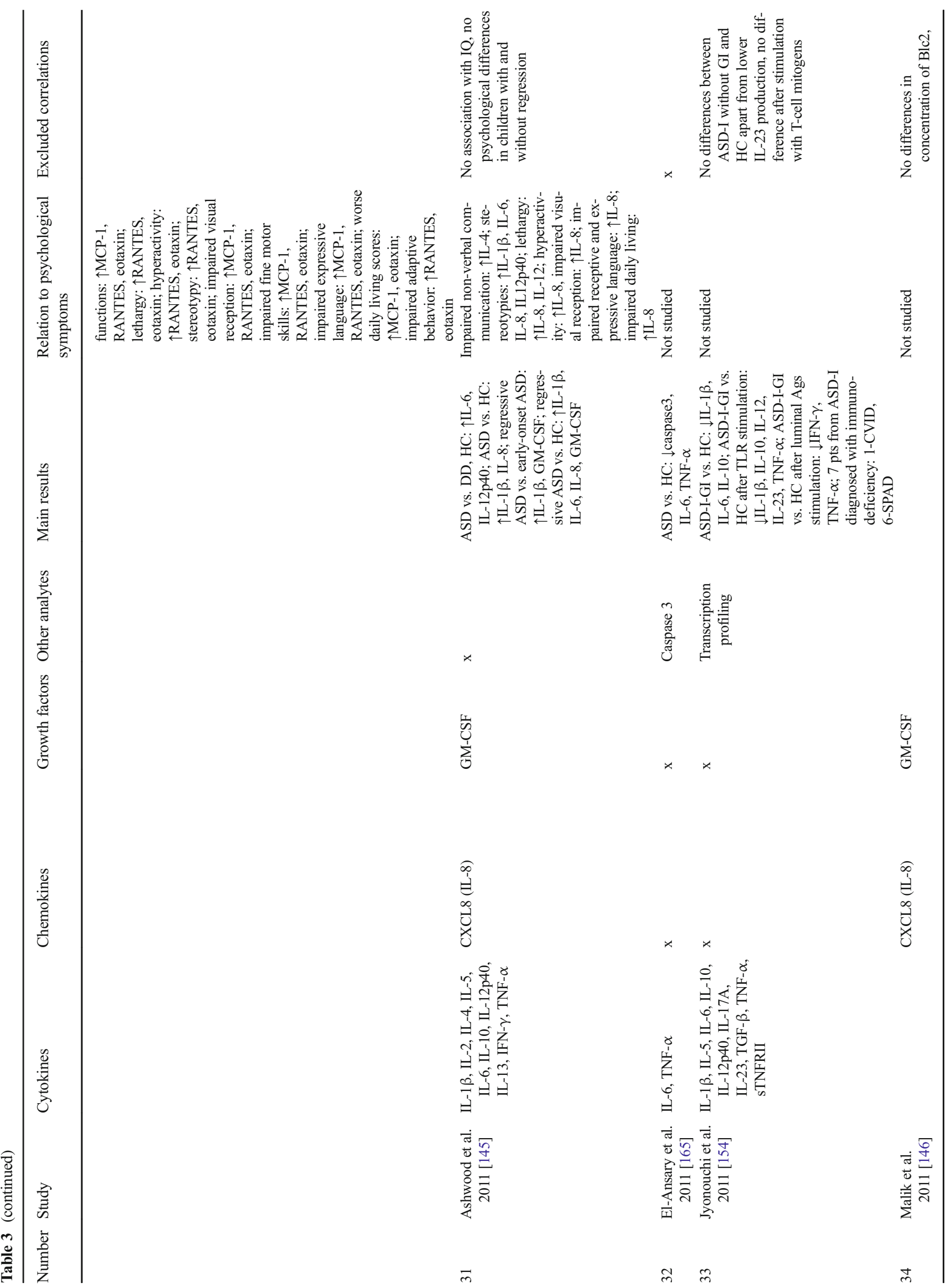




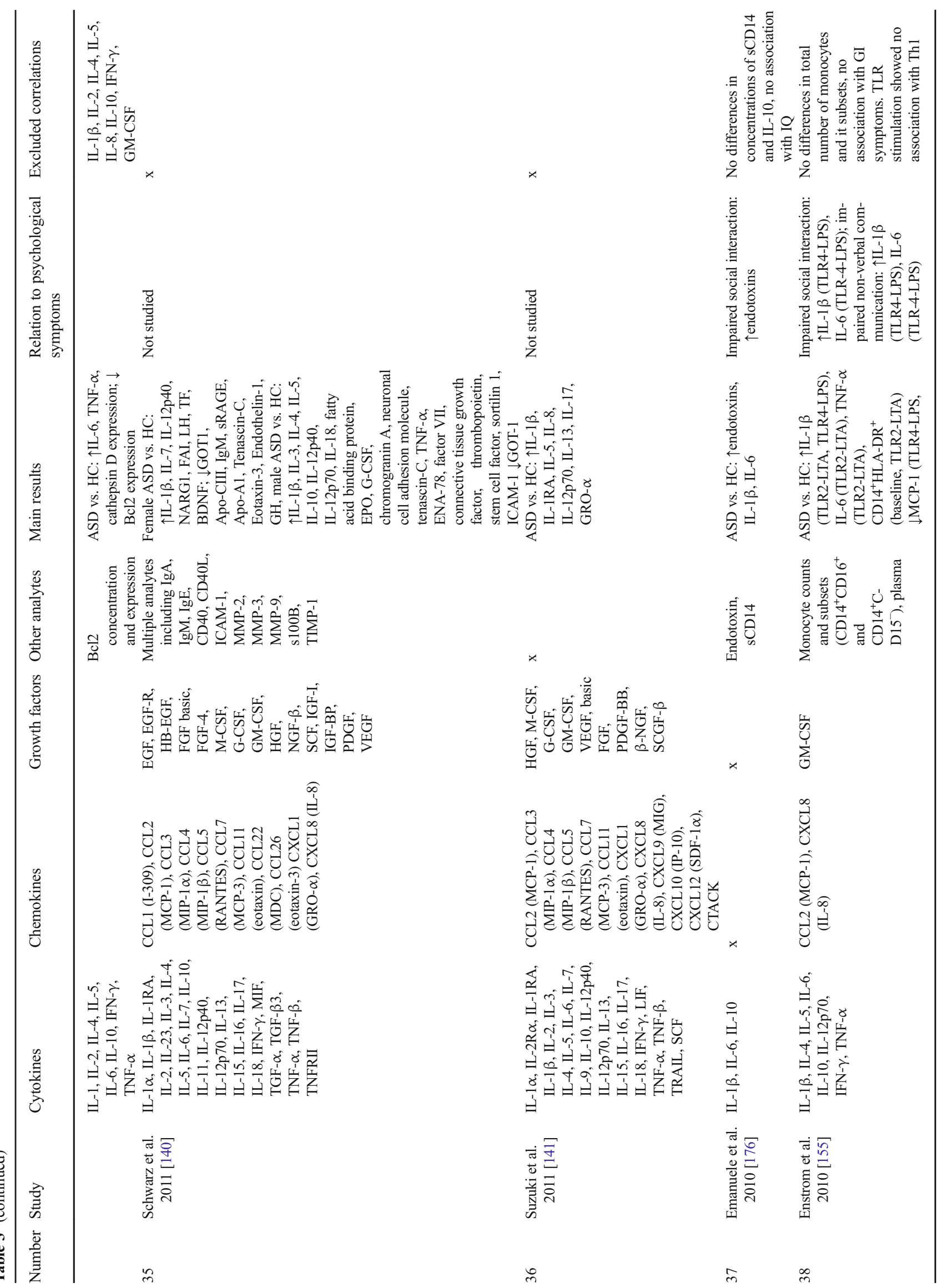




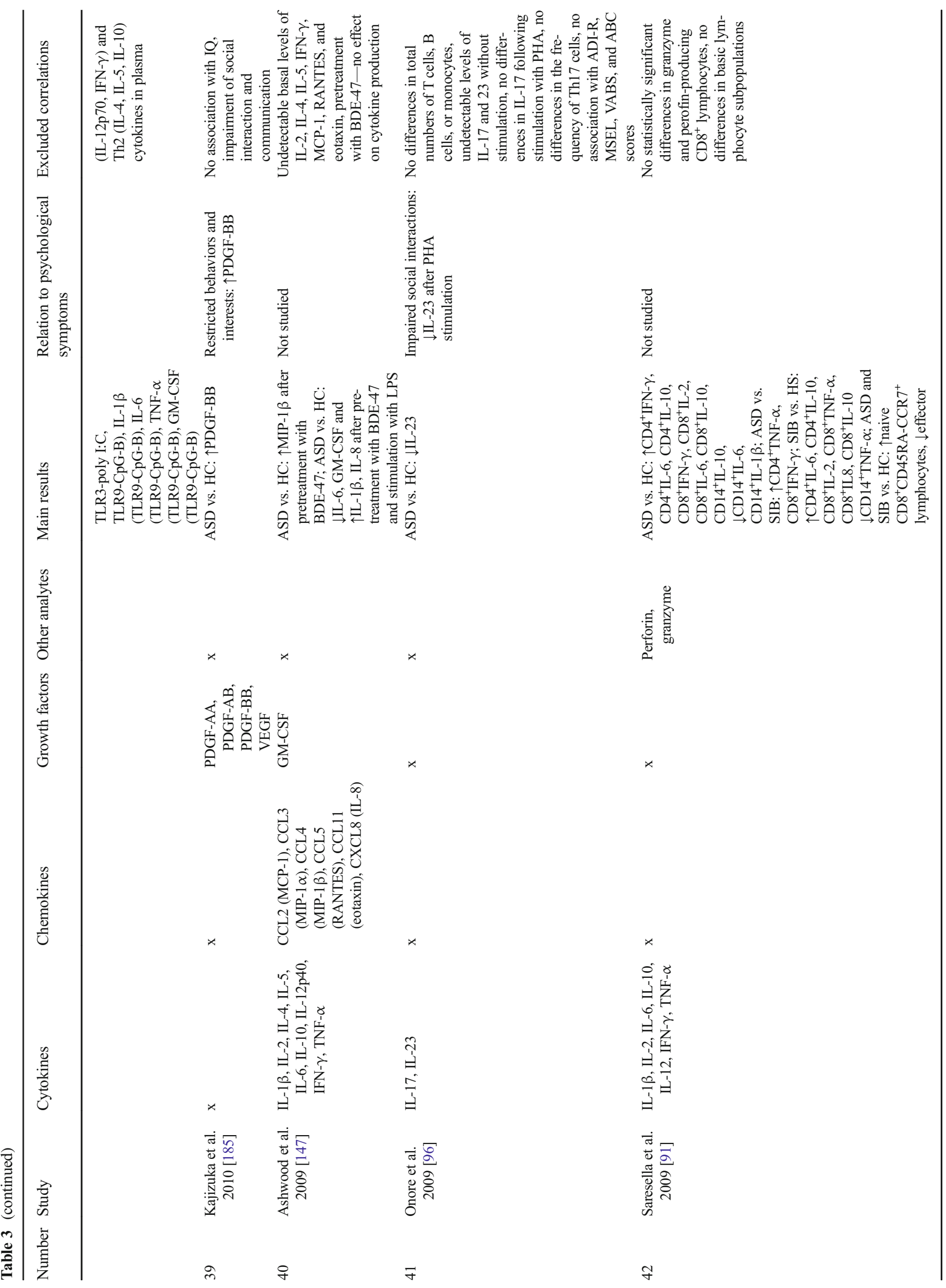




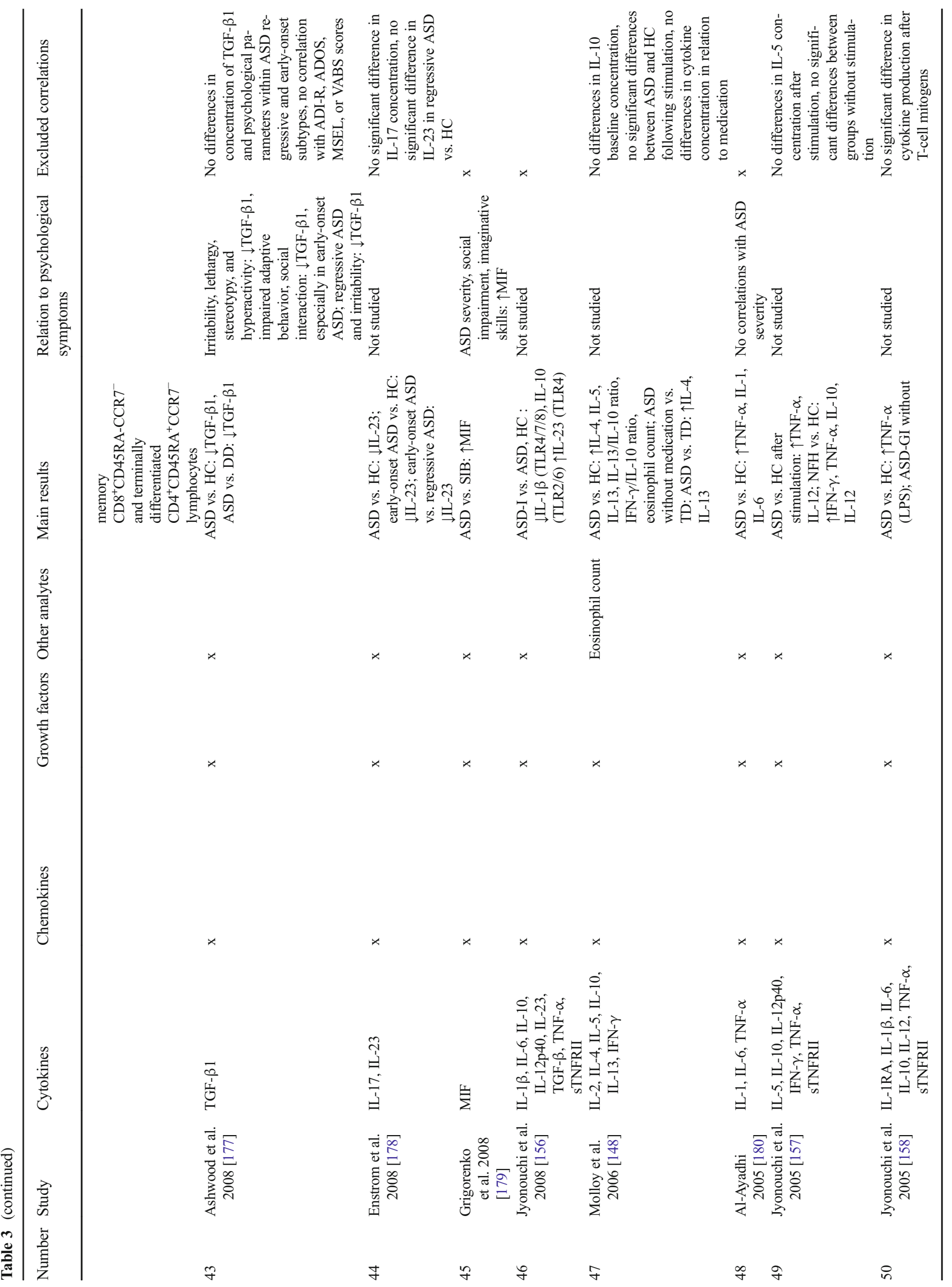




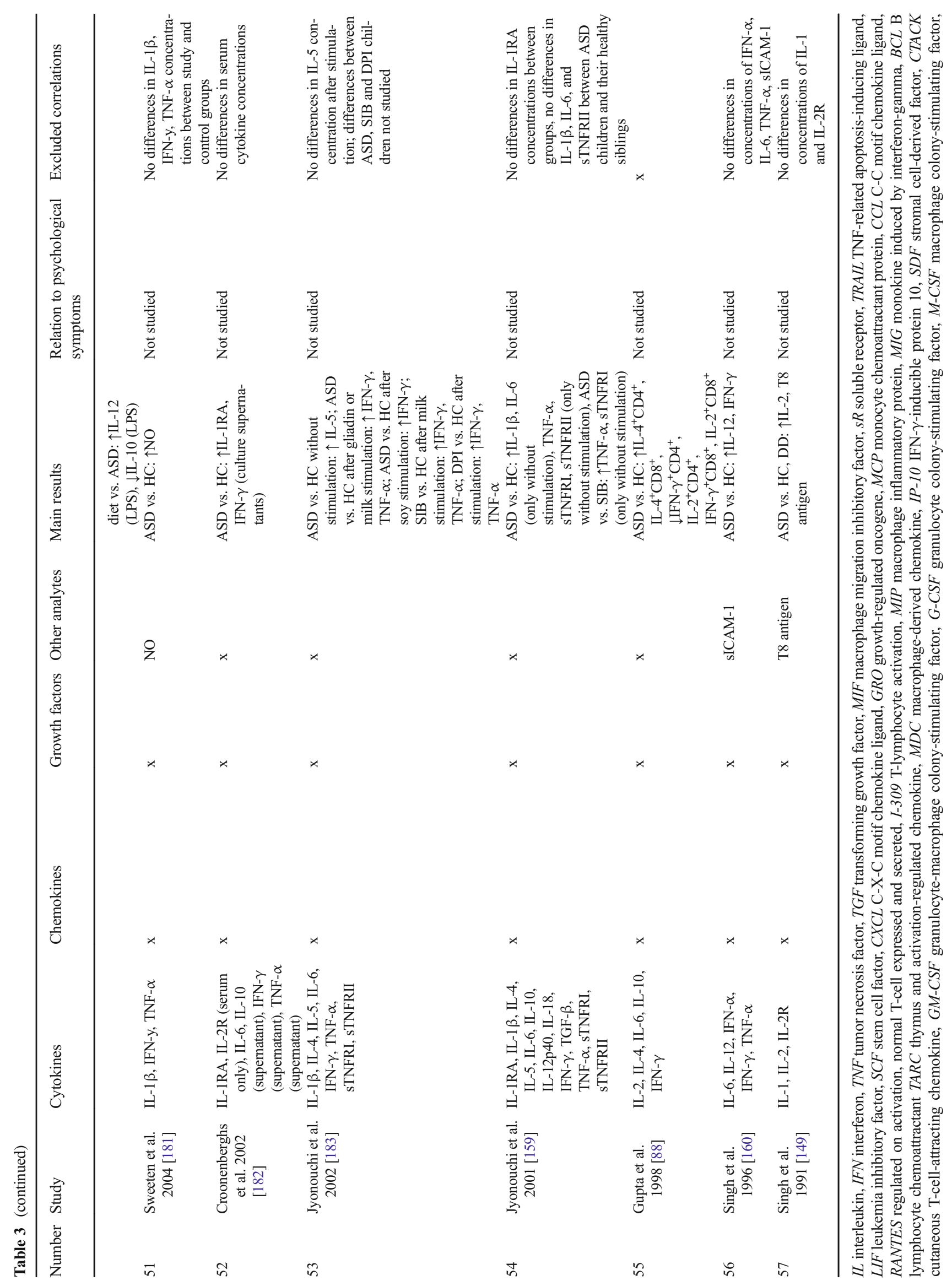




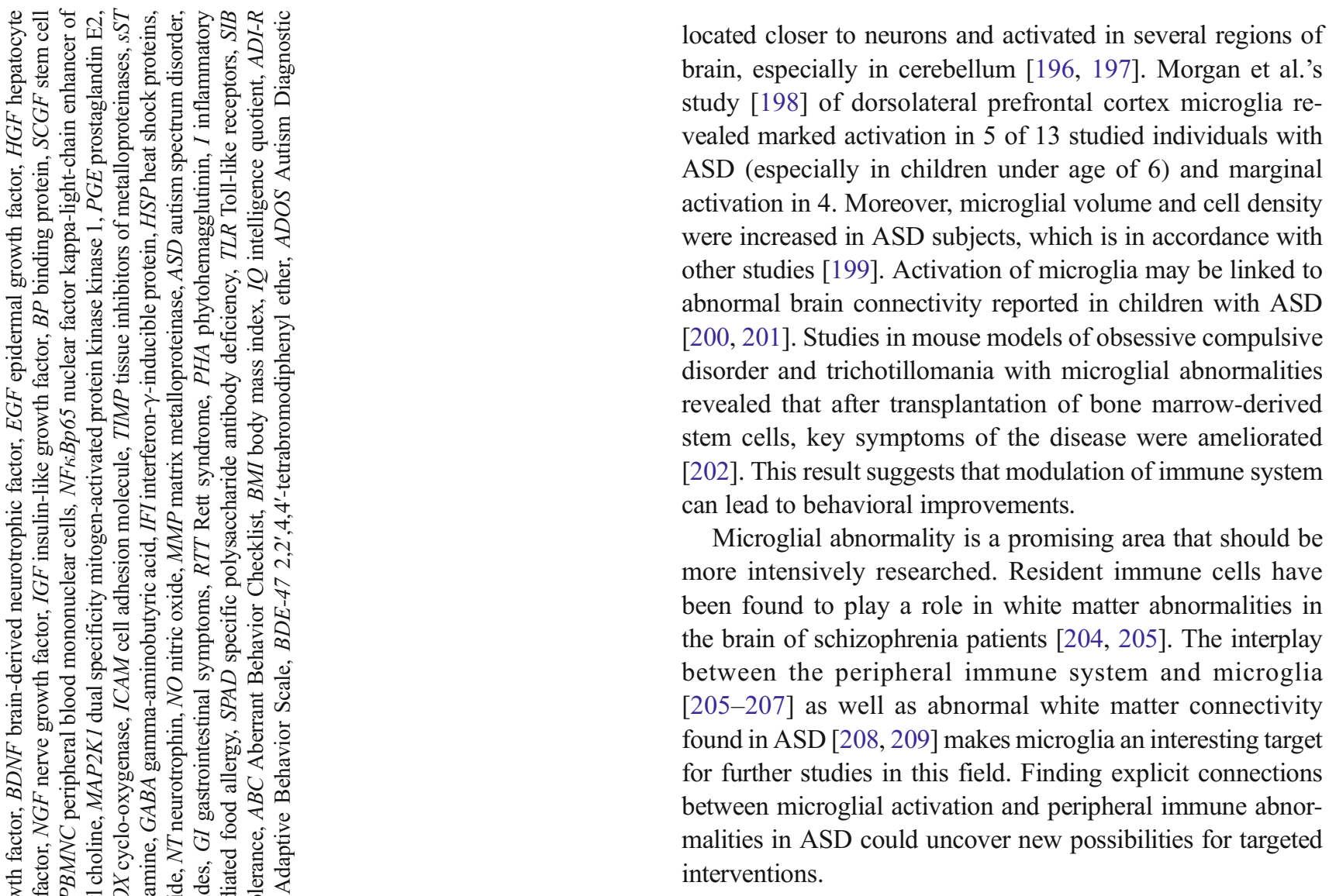

\section{Cytokines and chemokines in brain tissue and cerebrospinal fluid}

A tremendous insight into ASD pathogenesis was achieved through cytokine studies on autistic brains. Frozen tissue lysates of front cerebral cortex from eight ASD patients and matched individuals were compared for concentrations of several cytokines. The subjects were aged 4-37 years (mean age of 12) and included five males and three females with moderate to severe ASD. The control group was age- and sexmatched and included individuals that had been diagnosed with asthma, heart disease, or other injuries. TNF- $\alpha$, IL-6, granulocyte colony-stimulating factor (G-CSF), IFN- $\gamma$, and IL-8 were increased in the brain of ASD patients. There were no differences in IL-1 $\beta$, IL-2, IL-4, IL-5, or IL-10. The study revealed that proinflammatory and Th1 cytokines as well as Th1/Th2 ratio (measured as IFN- $\gamma /$ IL-10 ratio) and IL- 8 were up-regulated in comparison with control group [210]. Vargas et al. [211] studied cytokine profiles in both brain and CSF. The brain tissue was sampled from middle frontal gyrus, anterior cingulate gyrus, and cerebellar hemisphere. The study group was composed of 15 patients ( 3 females) aged 5-44; most had been diagnosed with mental retardation $(12 / 15)$ and some with epilepsy (6/15). The control group consisted of 12 individuals, including 3 females, aged 5-46, with no 
neurological disorders. The causes of death in both groups were non-neurological. The expression of 79 proteins, including cytokines, chemokines, and growth and differentiation factors, was measured on seven autistic brains and controls by protein array studies and confirmed with ELISA array for the most significant proteins. The most prominent changes were captured in anterior cingulate gyrus; however, several proteins turned out to be up-regulated in all studied regions (MCP-1, TARC,TGF- $\beta 1$ ) and one in CSF as well (MCP-1). Proteins up-regulated in CSF included IL-6, INF- $\gamma$, and IL10. Interestingly, immunocytochemical staining was carried out to detect structures responsible for increased cytokine concentration and revealed that astrocytes localized in the cerebellum and cortical and subcortical white matter regions were the main source of MCP-1 and IL-6. Moreover, Vargas et al. [211] found that microglia and astroglia activation was most prominent in the cerebellum. However, interpretation of this study should be careful due to the co-existing pathologies of epilepsy and mental retardation. Elevated concentration of IL6 was also found by another study that examined cerebellar brain tissue derived from six ASD individuals compared to six control subjects [212]. Zimmerman et al.'s study [213] aimed to examine CSF. They obtained CSF and serum from 12 patients with moderate to severe ASD, including 2 females, aged 2.7-10 years, most with regression, and some with epilepsy or abnormal EEG results. The study revealed an increased concentration of biopterin and a decreased concentration of quinolinic acid and neopterin (indicators for immune activation) in comparison with control group; however, those changes could be due to the fact that control group was composed of patients with central nervous system diseases. Cytokine profile showed a higher serum soluble TNF- $\alpha$ receptor II concentration in children with ASD compared with siblings, normal children, and patients with central nervous system diseases. No other abnormalities were detected. No correlation between serum and CSF concentration was observed and presence of regression did not seem to influence results in any manner. The authors concluded that decreased quinolinic acid and neopterin along with increased biopterin in CSF might be a result of metabolic pathway dysmaturation in the absence of co-existing infection or due to expression localized to microglia. Another study [214] that examined pterin compounds in CSF found 7,8-dihydroneopterin and 6R-5,6,7,8tetrahydrobiopterin to be significantly down-regulated in comparison with controls. Several other investigators have raised the issue of elevated pterins in both serum and urine as a sign of cellular immunity activation, stimulated by IFN- $\gamma$ and TNF- $\alpha$ with conflicting results $[161,215-218]$. The earliest study on 16 ASD children and 12 typically developing controls found decreased plasma and urinary levels of neopterin and monapterin accompanied by normal tetrahydrobiopterin level [218]. In contrast, two other studies on urinary pterins revealed that both neopterin and biopterin were elevated in ASD individuals in comparison to healthy controls [216, 217]. High plasma neopterin in ASD individuals was also confirmed in two other studies [161,215]. Several attempts to treat ASD with tetrahydrobiopterin and sapropterin have been carried out demonstrating potentially positive effects, including three clinical trials [219-224]. However, molecular studies on ASD individuals revealed only one marginal association with a gene responsible for tetrahydrobiopterin synthesis [225]. Currently, there are no open clinical trials in this area.

An elevation of NF- $\mathrm{KB}$ in neurons and microglia was found to be significant in orbitofrontal cortex of ASD individuals [226]. Chez et al. [227] evaluated the concentration of TNF- $\alpha$ simultaneously in both serum and CSF of 10 male patients aged 2.5-9.7 with regressive ASD. The study's results must be interpreted cautiously since 7 out of 10 patients were on medications, including valproic acid and risperidone, which are thought to have anti-inflammatory and potentially immunomodulatory properties [228-231]. Four patients had received treatment for autoimmunity in the past, but no details concerning timeframe of treatment were provided. The ratio of TNF- $\alpha$ in CSF and serum ranged between 1.7 and 275, with an average value of 41.6 , and the concentration of TNF- $\alpha$ in $\mathrm{CSF}$ and the $\mathrm{CSF} /$ serum ratio were higher in patients who did not undergo immunomodulatory therapy. The authors hypothesized they may have observed a unique CNS response, as no apparent correlation exists between CSF and serum and the $\mathrm{CSF} /$ serum ratio described in other diseases (HIV, ischemic stroke, traumatic brain injury, multiple sclerosis, systemic lupus erythematosus, frontotemporal dementia) is close to $1: 1$. A similar hypothesis concerning lack of association between different protein concentration in CSF and serum was confirmed by Pardo et al. [232]. The results of studies conducted on CSF and brain tissue are summarized in Table 4.

It is worth noting that though all of the described studies detected abnormalities in CSF or brain tissue of ASD patients, high variability between subjects, small samples, and lack of correlation between clinical symptoms and laboratory results hinder interpretation. Only three studies [213, 227, 232] focused on both CSF and peripheral blood and did not confirm any correlation between the same proteins in those two samples. It would be highly beneficial to conduct larger studies, simultaneously evaluating concentrations of proteins in both CSF and peripheral blood. It is understandable that lumbar puncture for scientific purposes might be unacceptable to some patients' parents as it is connected with high levels of child stress and/or administration of premedication or anesthetics. However, ASD children often undergo MRI scans under general anesthesia for diagnostic purposes and CSF sampling could be done at that time and preserved for further studies. Understanding differences and interactions between the periphery and CNS is crucial for determining novel therapeutic strategies. 


\section{Peripheral blood cytokines, chemokines, and growth factors}

The first studies on plasma cytokine levels in individuals with ASD showed increased levels of IFN- $\gamma$, IL-2, and IL-12 and thus concluded that ASD may be linked to pathological stimulation of Th1 cells. No difference between the study and control group was found for IFN- $\alpha$, IL-1, IL-6, TNF- $\alpha$, or soluble intercellular adhesion molecule-1 [149, 160]. An increase in the Th1 inflammatory response was also found by Croonenberghs et al. [182] who studied production of IL-6, IL-10, interleukin-1 receptor antagonist (IL-1RA), IFN- $\gamma$, and TNF- $\alpha$ in whole blood and IL-6, interleukin-2 receptor (IL$2 \mathrm{R}$ ), and IL-1RA in serum of ASD individuals. The study revealed increased levels of IFN- $\gamma$ and IL-1RA in the supernatant of ASD group whole blood cultures. A relationship between Th1 and Th2 cytokines was also studied by Gupta et al. [88]. They found an imbalance between Th1 and Th2 cytokines with increased IL- $4^{+} \mathrm{CD} 4^{+} \mathrm{T}$ cells and IL- $4^{+} \mathrm{CD} 8^{+} \mathrm{T}$ cells and decreased proportions of IFN $-\gamma^{+} \mathrm{CD} 4^{+} \mathrm{T}$ cells, IL$2^{+} \mathrm{CD}^{+}{ }^{+}$cells, and IFN $-\gamma^{+} \mathrm{CD} 8^{+}$and $\mathrm{IL}-2^{+} \mathrm{CD} 8^{+} \mathrm{T}$ cells in children with autism. Molloy et al. [148] compared production of several cytokines (IL-2, IL-4, IL-5, IL-10, IL-13, IFN- $\gamma$ ) in PB-MNC of ASD children and healthy controls and found a predominance of $\mathrm{Th} 2$ response with an imbalance in Th1/Th2 cytokine subsets in the ASD children MNC. Production of TNF- $\alpha$, IL- $1 \beta$, and IL- 6 by PB-MNC was significantly increased with and without stimuli (PHA, tetanus, IL-12p70, IL-18) [159] in the ASD group. The same investigators measured cytokine production against common dietary proteins and found increased proinflammatory cytokine responses (IFN- $\gamma$ and TNF- $\alpha$ ) that might predispose ASD individuals to GI inflammation and worsen disease behavioral symptoms [157]. In another study, both children with ASD and nonallergic food hypersensitivity had elevated cytokine production after stimulation with common dietary proteins and similar cytokine profiles. Both groups had high TNF- $\alpha$ and IL-12 concentrations and individuals with non-allergic food hypersensitivity also had elevated IFN- $\gamma$ and IL-10 levels [183] (Table 3).

Suzuki et al. [141] measured concentration of multiple proteins in plasma of high-functioning male children with ASD aged 7-15. The study included 21 children with ASD disorder and 7 with pervasive developmental disorder-not otherwise specified (PDD-NOS). The investigators found that IL-1 $\beta$, IL-1RA, IL-5, IL-8, IL-12p70, IL-13, IL-17, and growthregulated oncogene- $\alpha$ were significantly elevated (1.5-2.5fold) in comparison to matched controls; however, no correlation between clinical profile and laboratory results was observed. An interesting contribution was made by Han et al. [164] who found distinct chemokine and cytokine profiles between ASD individuals and ASD children with comorbid diagnosis of attention deficit hyperactivity disorder (ADHD).
The study group consisted of children aged 6-17 years, 9 with ASD and ADHD, 13 with ASD only, and 13 typically developing controls matched by age, gender, and IQ. Investigators compared concentrations of several chemokines and two cytokines (TGF $\beta 1$ and macrophage migration inhibitory factor-MIF) of which MCP-1 and Th2-related RANTES were significantly higher and Th1-related C-X-C motif chemokine ligand (CXCL) 9 was lower in all children with ASD, in comparison to healthy controls. Moreover, an increased MIF and decreased CXCL10 concentration was found to correlate with lower executive functioning scores, while CXCL9 was inversely correlated with short-term memory function. Increased concentration of RANTES and decreased CXCL9 were associated with poor behavioral scores (social domain, repetitive behavior, and hyperactivity). Children with comorbid ADHD had higher MIF and lower IL- 8 concentration than ASD-only children. Individuals with ASD and ADHD were different from typically developing controls in concentration of MIF (higher) and in IL-8 and CXCL9 (lower).

Frequently, ASD individuals were reported to have a higher concentration of proinflammatory or lower concentration of anti-inflammatory cytokines [93, 135, 137, 141-143, $145,146,149,151,152,155,157-160,163,169-171,182$, 183 ] in comparison to healthy controls or other developmental delays, although some results are contradictory $[88,91,139$, 144, 147, 148, 153, 154, 156, 166, 172, 173, 177]. Interestingly, Tsilioni et al. [170] distinguished two autistic groups - with initially low or high IL-6 and TNF levels, whereas another study divided subjects according to response to LPS stimulation and found high levels of IL- $1 \beta$ and IL-6 in LPS responders [150]. One recent study focused on several soluble factors that have not previously been studied in ASD. Investigators researched IL-21, IL-22, IL-27, and cytotoxic Tlymphocyte-associated molecule- 4 as indicators of pro- and anti-inflammatory balance and revealed dysregulation of immune milieu [162]. Other differences between ASD subjects and healthy individuals included high MCP-1, RANTES, eotaxin [174], TARC, MDC [89], BDNF, and plateletderived growth factor (PDGF) concentrations [140, 152], low epidermal growth factor (EGF) $[139,175]$, and altered IL-23 [96, 152-154, 156, 178] and IL-8 [141, 142, 144, $145,147,169]$. Intriguingly, a few studies included normally developing siblings as one of the control groups and found that their biomarker profile was distinct from other normally developing children [91, 179, 183].

Several published studies did not confirm differences between ASD and healthy individuals in baseline or stimulated levels of cytokines, chemokines, or growth factors [94, 136, 142, 147, 153, 168, 170, 181].

Approximately half of the studies tried to correlate behavioral profile with laboratory abnormalities (Table 3). One of them did not find any correlation with clinical measures [168]; however, it evaluated only two cytokines (IL-1 $\beta$, IL-33), 


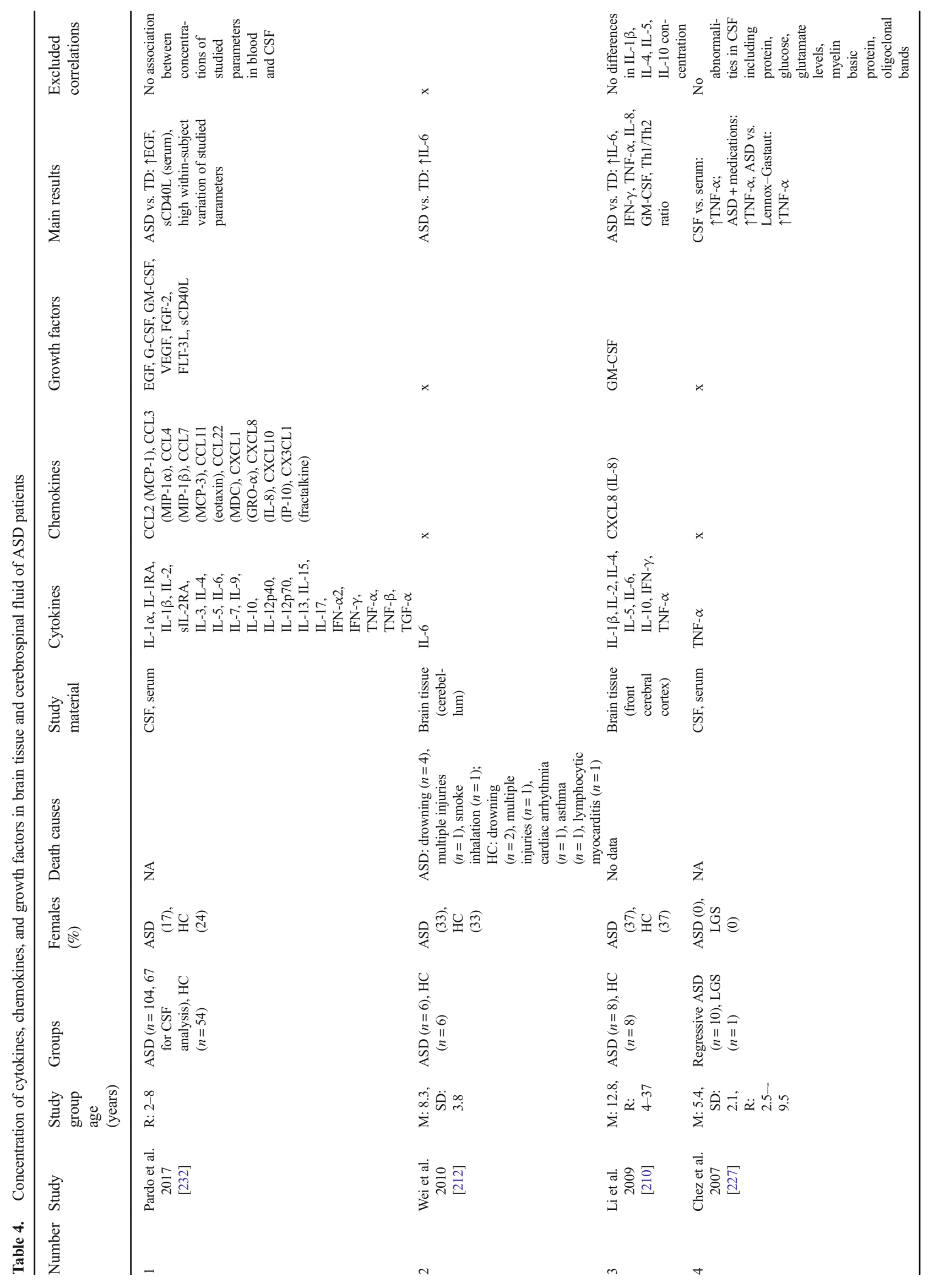




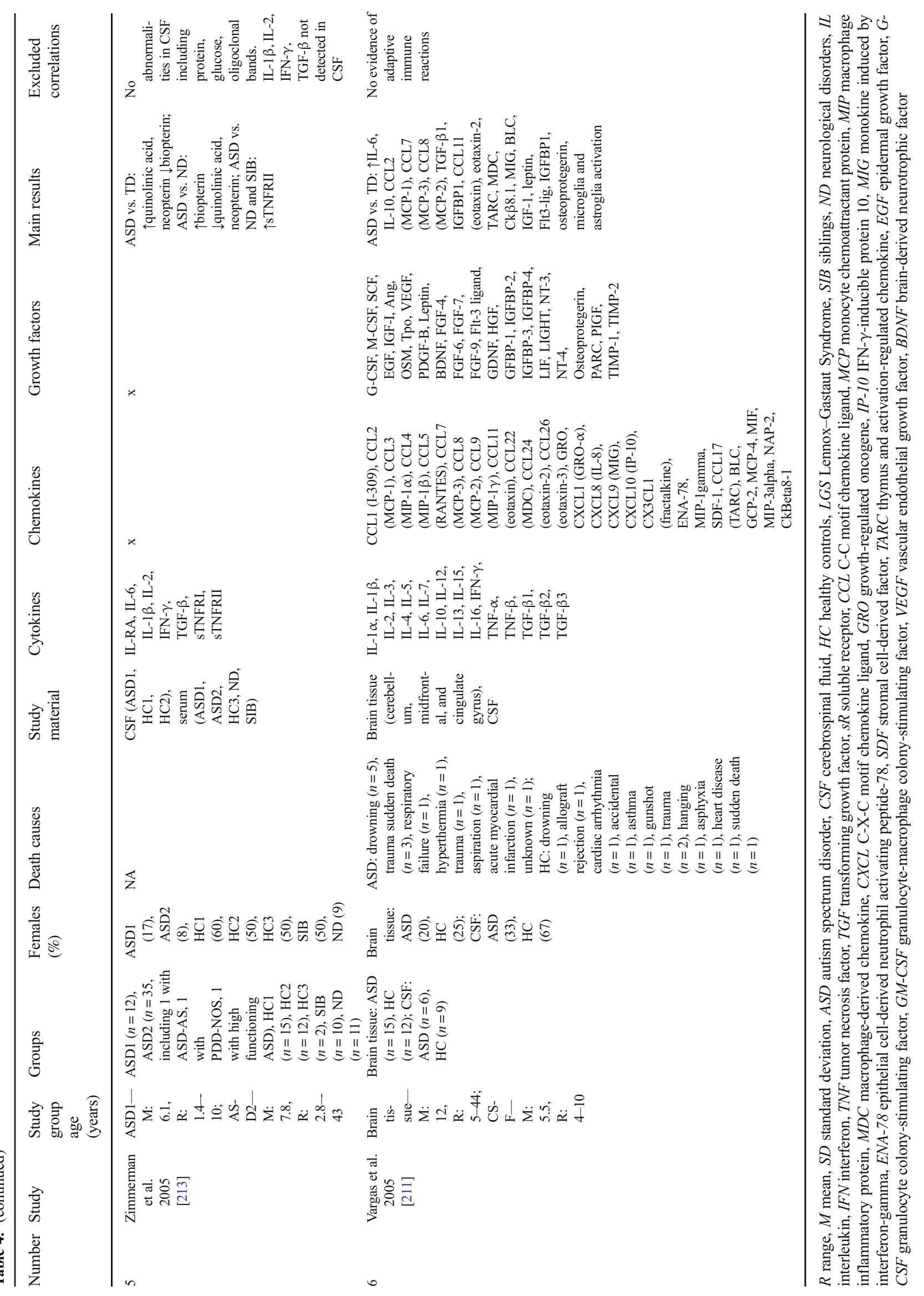


scored children with the Social Responsiveness Scale (SRS) alone, and included those also on psychotropic medication. However, there were no differences found between patients on and off medication.

A link between ASD severity and cytokine or chemokine abnormalities was sought for extensively. Increased concentration of IL-1 $\beta$ [150-152], IL-6 [135, 150, 171], IL-12p70 [135], IL-17A [93], TNF- $\alpha$ [135], MIF [179], MDC, and TARC [89] positively correlated with more severe behavioral symptoms. Only one out of seven studies on this topic failed to confirm a connection between peripheral blood cytokines (TNF- $\alpha$, IL-1, IL-6) and disease severity [180].

Several investigators identified a relationship between social sphere and concentration of several factors, out of which IL-6 was repeatedly found to be relevant. IL-6 correlated positively with social impairments both at baseline level $[150,167]$ and after stimulation [155]. Up-regulation of IL-1 $\beta$ [150, 155], IL10 [150], MCP-1 [150, 219], MIP-1 $\beta$ [138], MIP-1 [138], MIF [180], and endotoxins [177] and down-regulation of IL23 [96], TGF- $\beta 1$ [177], TNF- $\alpha$ [166], and GM-CSF [138] were also described in relation to social dysfunction.

In opposition to the above-described results, Han et al. [164] found no association of social domain with TGF- $\beta 1$ and MIF. Correlation with social impairment was also negative in two other experiments that focused on IL-10, IL-12 [73], PDGF, and vascular endothelial growth factor (VEGF) [185]. Poorer performance on Vineland Adaptive Behavior Scale was connected with low GM-CSF, IL-1 $\beta$, IL-2, IL-6, and MCP-1, with high MIP-1 $\delta$ [138], and no association was found with IL-17, IL-23, and TGF- $\beta 1$ [96, 177].

Deficits in communication and language were frequently found to be associated with an impaired protein profile, in particular higher concentration of IL-4, IL-8, IL12p40, IFN- $\gamma$ [144, 145], MIP-1 $\alpha$, and RANTES [174] and lower concentrations of IL-5 and IL-10 [144]. Concentration of PDGF and VEGF [185] and mRNA levels of IL-1 $\beta$, IL-6, and TNF- $\alpha$ [166] were found to be independent of communication skills. Poor verbal contact was linked with upregulation of IL-1 $\beta$ and IL-6 after stimulation [155] as well as high concentration of IL-10, GM-CSF, and M-CSF [138].

Stereotypic behavior seemed to correlate with downregulation of TGF- $\beta 1$ [177] and GM-CSF [144] as well as up-regulation of IL-1 $\beta$, IL-6, IL-8, IL12p40, TNF- $\alpha$, and IFN- $\gamma[144,145]$. Restricted patterns of behavior and interests were more pronounced in patients with high concentration of MCP-1, RANTES, eotaxin [174], and PDGF-BB [185].

Surprisingly, exacerbations of both hyperactivity and lethargy were found to be linked to low levels of antiinflammatory cytokines (IL-10, TGF- $\beta$ ), high levels of proinflammatory cytokines (IL-1 $\beta$, IL-6) $[145,151]$, several chemokines (IL-8, RANTES, eotaxin), and high response to PHA stimulation $[144,174]$. Hyperactivity was also associated with low levels of CXCL5 [164] and IL-13 and high levels of IL-12p40 [144]. Irritability was also associated with a similar balance of pro- and anti-inflammatory cytokines [151] apart from a low level of TNF- $\alpha$ [167] or TGF- $\beta 1$ [178].

Most of the studies did not reveal any association between IQ and soluble molecules profile [145, 176, 185] apart from low concentration of IL-6 in Ferguson et al. [167] study and Napolioni et al. research [138] in which a wide range of cytokines inversely correlated with IQ. Impaired short-term memory was associated with high CXCL9 [164].

An interesting observation about sleep disturbances and aggressive behavior was made by Careaga et al. who found up-regulation of IL-1 $\beta$, IL-6, IL-10, and MCP-1 in children whose PBMNC responded well to LPS stimulation [150]. Interestingly, Th-1 skewed response was associated with more severe developmental impairment.

Other studied areas included fine motor skills (down-regulated IL-5, up-regulated MCP-1, RANTES, and eotaxin), visual reception (up-regulated IL-8, MCP-1, RANTES, and eotaxin) $[144,176]$, executive functioning (high MIF, low CXCL10) [164], daily living abilities (high MCP-1, eotaxin), and adaptive and cognitive functions (high MCP-1, RANTES, and eotaxin, low TGF- $\beta 1$ and GM-CSF, and no association with IL-10 or IL-12) [73, 138, 144, 174, 177].

When analyzing various developmental patterns of ASD patients it would seem that children who lost abilities would present with different biological conditions. A few studies that researched a wide cytokine profile negated its connection with regression [144, 163]. However, Ashwood et al. [145] showed that children who regressed expressed higher levels of IL- $1 \beta$ in comparison to other ASD individuals and higher levels of IL$1 \beta$, IL-6, IL-8, and GM-CSF in comparison to healthy controls. IL-1 $\beta$ was also found significantly higher by Napolioni et al. [138] along with IL-5 and IL-17 in children with regressive ASD. A single study reported a connection between higher TNF- $\alpha$ concentration and occurrence of regression [167].

GI issues are frequently reported among autistic individuals [233]. PB-MNC from ASD individuals with GI problems were found to have altered concentration of several cytokines; however, results are inconsistent $[137,138,154,158,167$, 184]. ASD children with GI symptoms were also assessed for intracellular cytokines in $\mathrm{CD}^{+}$lymphocytes in both peripheral blood and mucosa. Peripheral blood levels of TNF- $\alpha$ were similar to typically developing children with Crohn disease and were increased in comparison to healthy controls. Similar observations were made for IFN- $\gamma$ both in peripheral blood and terminal ileum lymphocytes. IL-10 was downregulated in ASD children with GI symptoms in comparison to both healthy controls and children with Crohn disease in both peripheral blood and terminal ileum mucosa. The observed differences were maintained following stimulation [234]. Lymphocytic colitis in ASD children, especially those with GI symptoms and regression, was reported in several papers. A study on immunological aberrations in gut mucosa, 
based on duodenal, ileal, and colonic biopsies, revealed upregulation of $\mathrm{CD}^{+}{ }^{+} \mathrm{CD} 8^{+}$intraepithelial lymphocytes and $\mathrm{CD}^{+}$lamina propria lymphocytes with proinflammatory cytokine profile [234, 235]. Functional GI disorders in children with ASD were associated with elevation of several proinflammatory cytokines in rectal biopsy mucosa [236]. ASD children with GI complaints were found to have comparable levels of $\mathrm{CD}^{+}$lymphocyte intracellular cytokines [237] and even higher intraepithelial cell number and $\mathrm{CD} 8^{+}$density than children with Crohn disease [238].

Another study revealed epithelial IgG and complement deposition in almost all children with regressive ASD [239]. However, not all investigators were successful in determining abnormalities of intestinal biopsy specimens in ASD individuals [240].

An unusual approach was proposed in a double-blind, placebo-controlled trial with camel milk, assessing whether 2week administration of raw or boiled camel milk, instead of cow milk, would help to reduce serum levels of TARC and lessen autistic traits. Camel milk is said to have unique properties such as low molecular weight immunoglobulins. Investigators hypothesized that camel milk could downregulate synthesis and secretion of TARC leading to reduction of inflammatory processes. Best behavioral outcomes were observed with raw camel milk; however, the use of both forms of camel milk led to significant reduction of TARC levels [241].

Multiple studies have confirmed cytokine, chemokine, and growth factor abnormalities in ASD. For details concerning demographic details and medical history of analyzed patients, please refer to Table 2; for summarized results, please see Table 3 . The main results concern proinflammatory cytokines. IL-1 was found to be found up-regulated frequently and its high concentration was connected with regression [138, 145], ASD severity [152], deficits in social sphere [150, 155], impaired adaptive skills [138] and development [150], as well as hyperactivity, lethargy, and irritability [151]. IL-6 was strongly associated with ASD severity $[135,171]$ and deficits in social sphere [150, 155, 167]. Its up-regulation, analogous to IL-1, was found to be significantly correlated with hyperactivity, lethargy, and irritability [151]. Interestingly, higher IQ was connected with lower IL-6 level [138, 167]. For detailed summary, please refer to Table 5 .

\section{Pivotal role of immune system as a potential target for novel therapeutic methods}

The first attempt to treat ASD on the basis of immunological disturbances came in the form of intravenous immunoglobulin (IVIG) administration. According to current guidelines, such treatment is not recommended due to limited scientific rationale [243]. However, several papers reported on improvement after IVIG. Plioplys [244] reported on 10 children who received 4 IVIG infusions with 6-week intervals, out of which 5 were considered to have improved. Four children had a partial response to treatment with regard to improved attention span and reduced hyperactivity. One child was reported to have an amelioration of autistic symptoms that regressed after IVIG discontinuation. Gupta et al. [245] treated 10 patients out of which 5 had marked improvement in prominent eye contact, echolalia, speech, and behavior. DelGiudice-Asch et al. [246] did not find any beneficial effects; however, they carried out their study on seven subjects without previous indepth immune tests. Another study reported on 26 children who received IVIG and had improved ABC scores, and described that 22 regressed within 2-4 months after IVIG cessation [247]. An open-label study with oral encapsulated immunoglobulin therapy in ASD children with GI symptoms revealed that $50 \%$ of subjects had behavioral improvement measured with $\mathrm{ABC}$ and marked reduction of GI complaints [248]. However, a double-blind placebo-controlled trial showed no effectiveness of the abovementioned treatment [249]. IVIG exert an immunomodulatory effect and has been reported to be effective in several autoimmune and inflammatory disorders [250-252]. Although immunoglobulin administration has been shown to have an inhibitory effect on T-cell activation and down-regulate concentration of several cytokines [253, 254], it primarily acts on B-cell function and immunoglobulin repertoire [255]. On the basis of cellular mechanism studies and the results of human use, treatment with IVIG does not appear to hold strong potential as a diseasemodifying strategy.

Interestingly, corticosteroids which have been used to treat other disorders in ASD patients were found to lessen autistic features. A child with ASD who developed autoimmune lymphoproliferative disorder improved greatly in language development and behavior after oral prednisolone therapy [242]. A retrospective analysis showed that children with regressive autism benefited from steroid therapy in language development and behavioral spheres [256, 257]. Two other cases of behavioral improvement after corticosteroid therapy were reported in ASD and PDD [258, 259]. Limitations of steroid therapy include well-known side effects and lack of expected significant improvement in core ASD domains. To date, there is only one registered clinical trial registered using pregnenolone in an attempt to lessen irritability, sensory impairment, and social sphere in autistic individuals [NCT02627508].

The US Food and Drug Administration has approved two atypical antipsychotic medications for treatment of irritability related to ASD [260]. Both risperidone and aripiprazole display interesting immunological properties in in vitro experiments. They were found to reduce proinflammatory cytokines, promote anti-inflammatory pathways, and inhibit microglial activation [261-265]. However, results from in vivo studies on cytokine changes during treatment of schizophrenia patients are inconsistent [266-269]. In children with ASD, levels of 


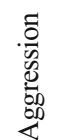

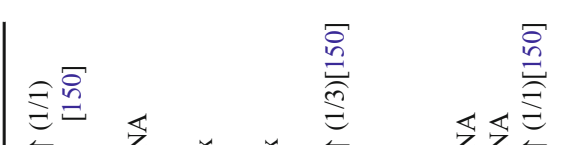

: $\stackrel{\rightleftarrows}{\rightleftarrows} \times \underset{\leftarrow}{\rightleftarrows}$

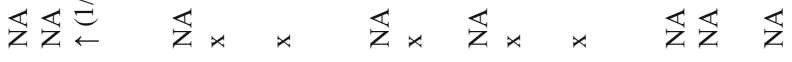

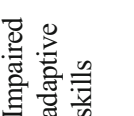

$\varangle$

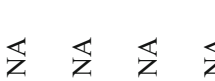
$\sqrt{\infty}+\infty \quad \leq \quad \leq$

总离递

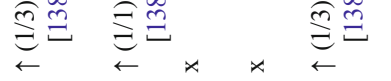

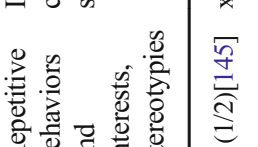
$\stackrel{x}{\exists}$

ส.

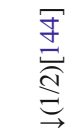

兽言

$\frac{5 \pi}{5} \cdot \frac{\pi}{8}$

吕. क

気

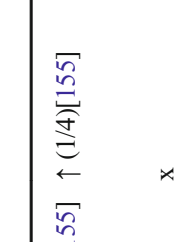

$\times \stackrel{\stackrel{\Xi}{\leftrightarrows}}{\leftrightarrows}$

$\times$

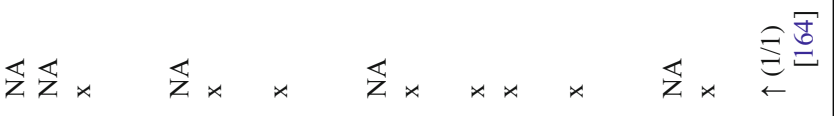

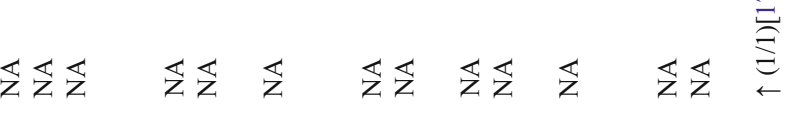

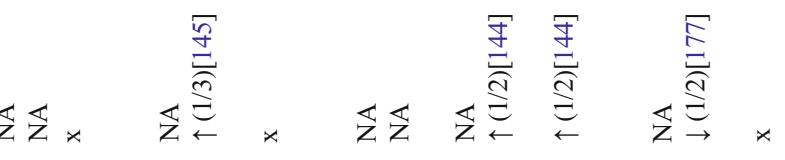

䒠总

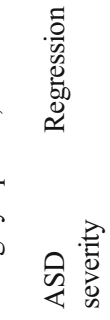

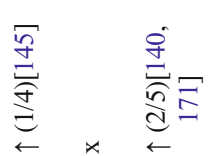

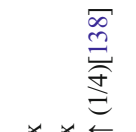

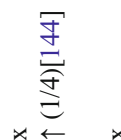

...

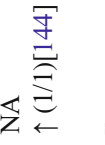

$n$

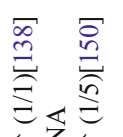

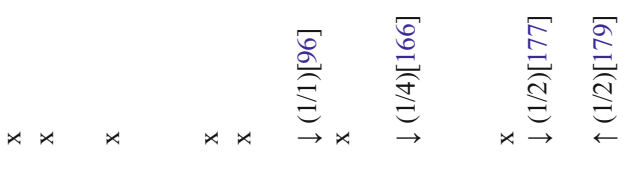

군

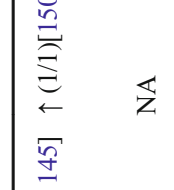

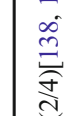

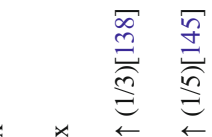

$x \times x$

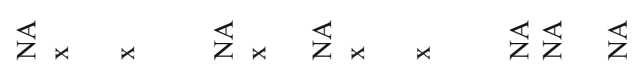

$\frac{0}{1}$

守过声。

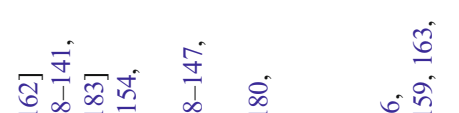

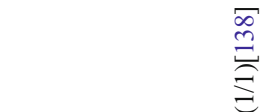

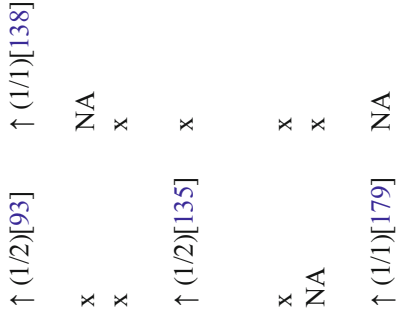

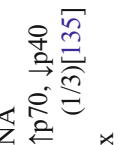

我

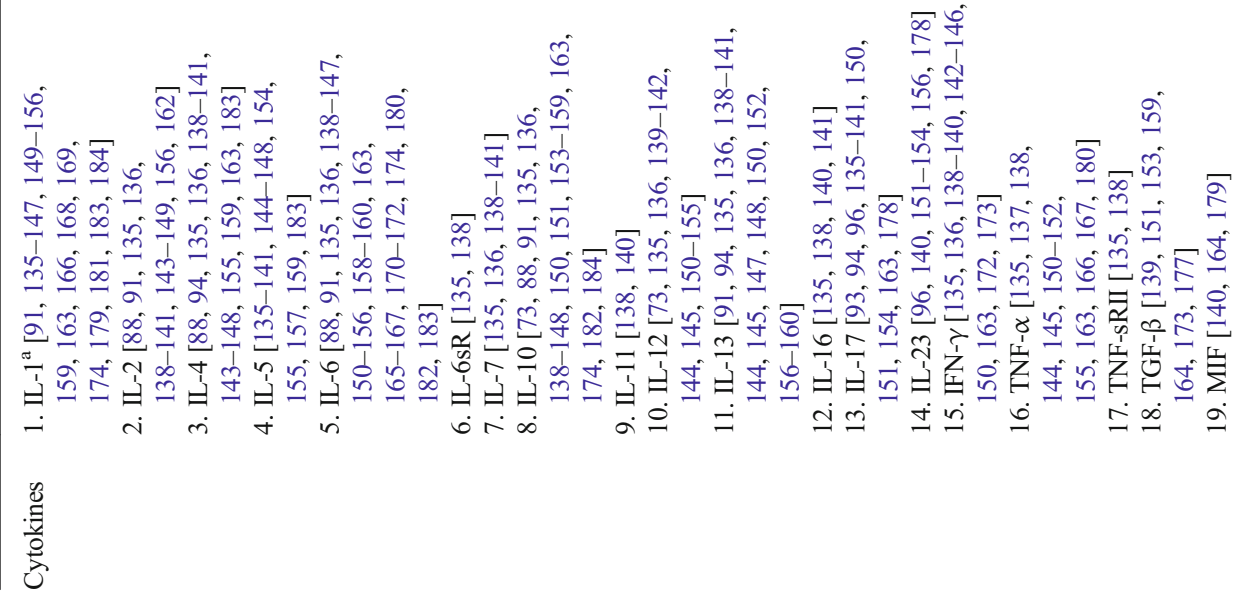




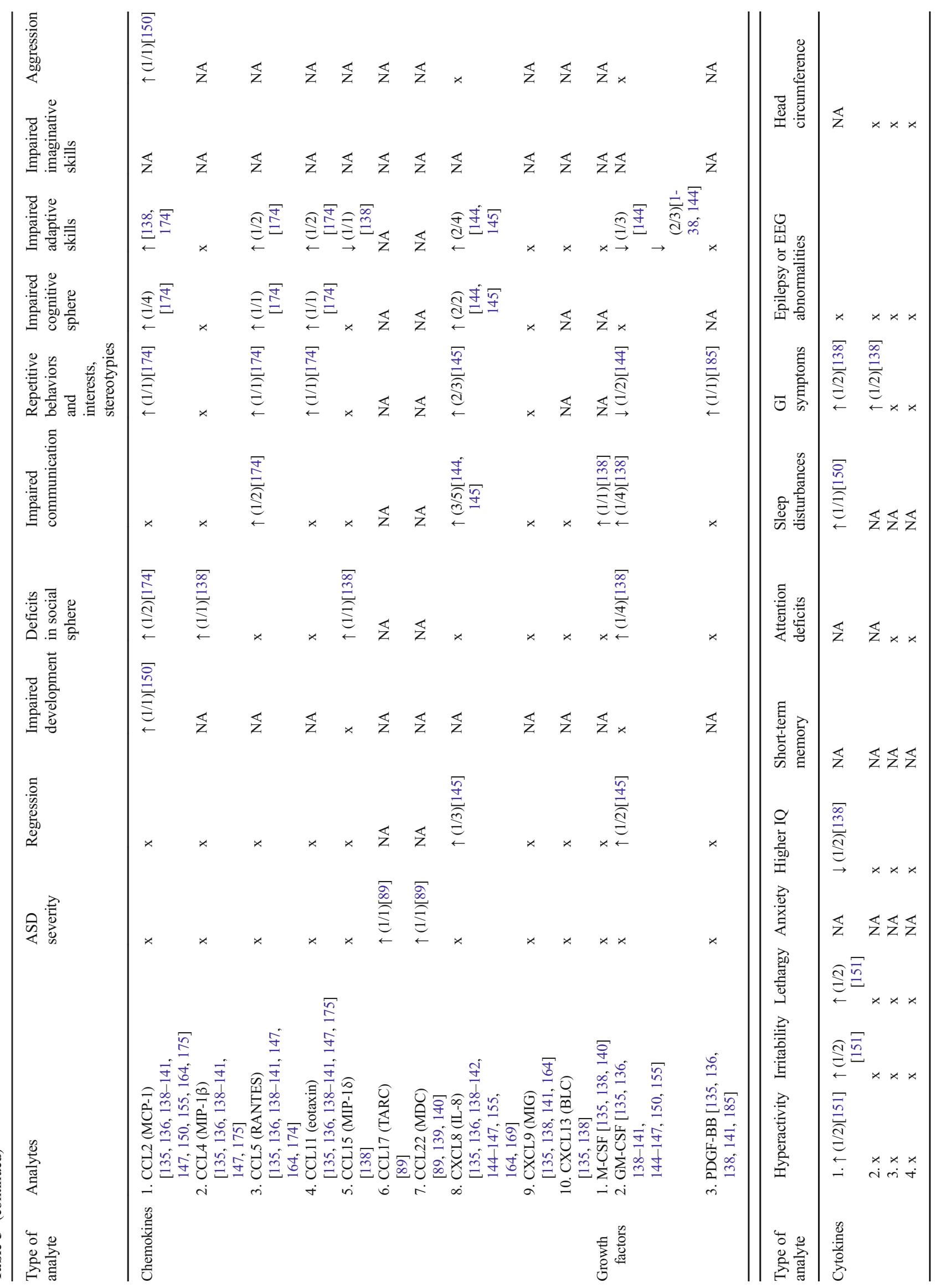




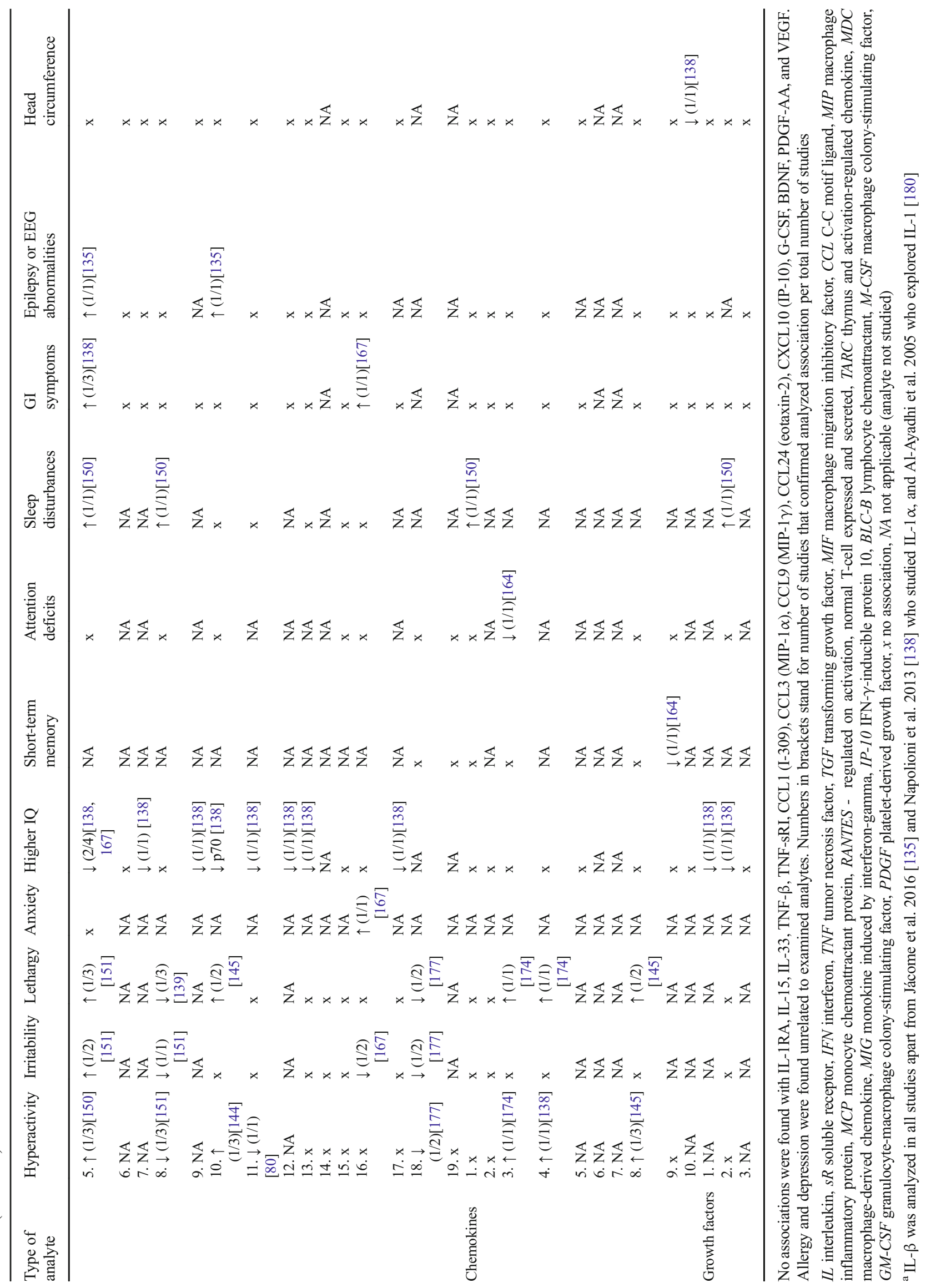


cytokine after 8 weeks of risperidone therapy were unchanged in one study [270], while Choi et al. [229] found significant reductions of two chemokines, MCP-1 and eotaxin, that have previously been reported as up-regulated. Multiple clinical trials with risperidone [NCT01171937, NCT00576732, NCT01333072, NCT00080145, NCT00584701, NCT00005014, NCT01624675, NCT00086645, NCT00374764, NCT00166595, NCT0014739] and aripiprazole [NCT00619190, NCT01333072, NCT00468130 NCT00208533 NCT00198107, NCT01028820, NCT01617447, NCT00332241, NCT00308074, NCT01227668, NCT01617460, NCT00337571, NCT00365859, NCT00198055, NCT00870727] were conducted. Other neuroleptics whose potential was explored in ASD include olanzapine [NCT00057408, NCT00183404], lurasidone [NCT01911442, NCT01620060, NCT01914393, NCT01731119], brexipiprazole [NCT03292848], and ziprasidone [NCT00208559]. Effects of neuroleptics on ASDassociated irritability and hyperactivity are promising, and though some studies report improvement in the social sphere or in stereotypy [271], most fail to address core ASD symptoms $[272,273]$. Their influence on immune abnormalities is probably much more pronounced in in vitro than in vivo conditions, and although MCP-1 was found to be correlated with deficits in social sphere [150], improper communication [174], and impaired adaptive skills $[138,174]$, none of the fields were influenced with risperidone treatment. The possible adverse effects of neuroleptics, such as increased appetite, weight gain, fatigue, and tremor, have to be taken into consideration before deciding on treatment initiation [271-274].

Donepezil, an acetylcholinesterase inhibitor, was proven to reduce inflammatory cytokine response [275] and attenuate M1 microglia polarization [276, 277]. It was also found to be beneficial in the BTBR mouse model of ASD and valproic acid-induced mouse model of ASD [278, 279]. However, despite promising preclinical data, administration of acetylcholinesterase inhibitors such as donepezil, galantamine, or rivastigmine failed to alter concentrations of proinflammatory cytokines in peripheral blood of patients with Alzheimer's disease [280]. In another study, four of eight patients with ASD improved on donepezil; however, the drug influenced only irritability and hyperactivity [281]. Donepezil failed to show efficacy in two double-blind, randomized clinical trials in children with ASD and Fragile X syndrome [282, 283]. Currently, there is one clinical trial open to evaluate acetylcholine esterase inhibitors [NCT01098383].

Minocycline, a tetracycline antibiotic that could potentially alter inflammation and microglia activity [284], failed to exert clinical effects despite detected changes of hepatocyte growth factor and IL-8 in serum and BDNF changes in both serum and CSF [285]. However, in a double-blind placebo-controlled trial, minocycline as an adjunctive therapy to risperidone showed reduction of hyperactivity and irritability [286].
One clinical trial with minocycline aimed at measuring microglia activity by PET imagining is currently open [NCT03117530].

Several other medications with potent immunomodulatory properties evidenced by in vitro studies are presently under clinical trials. Currently, there are over 60 ongoing interventional clinical trials with different pharmacologic approaches and more than 130 studies already completed with no drug registered for ASD core symptoms [287].

The most currently available data still fails to reveal the most efficient mechanism of action for addressing immune abnormalities found in ASD. Regulation of cytokine expression seems a natural candidate due to vast preclinical evidence of cytokine correlation with autistic traits. Cytokine administration was also found to induce behavioral abnormalities $[288,289]$. INF- $\alpha$, which is known to elicit proinflammatory mediators such as IL-1, IL-2, IL-6, IL-8, and MCP-1 [290, 291], has been used for treatment of cancer and chronic viral hepatitis [292, 293] with behavioral adverse effects such as depression, anxiety, mania, and psychosis [294]. Cytokines as a therapeutic agent should be used with the utmost caution, as in vitro studies are unable to predict immune responses in living organisms due to their complicated, pleiotropic actions. Unnaturally excessive immune activation can lead to cytokine-release syndrome, a potentially life-threatening adverse effect [295].

Interestingly, a recent study in a valproic acid-exposed rat model of ASD revealed that fingolimod, an immunomodulatory agent used in clinical trials in relapsing-remitting multiple sclerosis, improved learning disturbances, memory deficits, and social impairments. It was found to reduce microglial activation and down-regulate IL-1 $\beta$ and IL- 6 in the hippocampus [296].

Another approach is to explore the potential for utilizing stem cells in inducing immunomodulation. Recent robust research in the stem cell field revealed that stem cells have both immunomodulatory and neuroprotective potential [297]. The first clues to such association come from hematopoietic stem cell transplantation (HSCT). Interestingly, behavioral abnormalities are not transferred by bone marrow transplantation (BM-HSCT); however, they can be corrected by BM-HSCT from healthy individuals. Thus, restoring an immunophenotype could alter a disease course [12]. Stem cell intervention may be a way to correct immune system abnormalities and alternate core symptom domains of ASD.

Specific properties of mesenchymal stromal cells (MSC) make them an attractive cell source for regenerative therapy. MSCs are multipotent non-hematopoietic stem cells that display immunomodulatory properties [298]. They have been defined by the International Society for Cellular Therapy [299] as a plastic-adherent cell population with particular phenotype $\left(\mathrm{CD} 105^{+}, \mathrm{CD} 73^{+}, \mathrm{CD} 90^{+}, \mathrm{CD} 45, \mathrm{CD} 34^{-}, \mathrm{CD} 14\right.$,

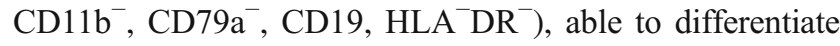


into osteoblasts, adipocytes, and chondroblasts. They can be transplanted across allogeneic barriers because of their low immunogenicity, as they do not express major histocompatibility complex class II antigens or co-stimulatory molecules [300].

Evidence for MSC effectiveness in a mouse model has accumulated. An animal model of maternal immune activation yields offspring with autistic traits that present with increased M1 polarization, up-regulation of inflammatory cytokines and $\mathrm{CD}^{+}$response, as well as systemic Treg deficit [10-12]. The BTBR mouse strain is considered an adequate animal model for ASD due to behavioral deficits in ASDrelated spheres [301]. Moreover, similar immune system abnormalities and an inflammatory phenotype are found in BTBR mice [302-304]. Intraventricular MSC transplantation in young BTBR mice ameliorated stereotypic behaviors and improved deficits in social and cognitive spheres; it is worth noting that it did alter core ASD-related symptoms. Histological analysis revealed increased neurogenesis in the hippocampal area and an elevated level of BDNF were noted. Six weeks after transplantation, MSC cells were detectable in the dorsal third ventricle [305]. Intriguingly, MSC cultured to express higher amount of BDNF were found to induce longterm effects on behavioral traits, superior to unmodified cells [306]. Intracerebral MSC administration protected mice from a social deficit induced by phencyclidine [307, 308], while adipose-derived stem cells alleviated behavioral abnormalities in a valproic acid-induced ASD model [309]. As previously mentioned, microglia in ASD individuals tend to be overly activated. Several investigators found MSC were able to inhibit microglial activation and induce neuroprotective $\mathrm{M} 2$ polarization [310-312]. MSC and microglial crosstalk was also investigated in vitro. MSC were found to act through expression of fractalkine (CX3CL1), which induces a neuroprotective microglia phenotype [313] and immunomodulates microglia through paracrine effects [314]. MSC are also known to express multiple neural genes and transcription factors and differentiate into neural cells after culture in a suitable media [315]. The overall safety profile from clinical applications is promising; however, it lacks long-term data [316].

A few clinical papers on stem cells use in autism have been published so far; for a summary, please see Supplementary Table 1. Firstly, a 14-year-old autistic boy [317] treated with autologous bone marrow-derived mononuclear stem cells (BMMNC) was described. The patient had been diagnosed with severe autism with co-existing self-injurious behavior. Brain MRI was normal, PET CT scan showed reduced metabolic activity in several regions, while on EEG bilateral episodic sharp and slow wave abnormalities were seen. The patient received $56 \times 10^{6}$ MNC intrathecally along with intensified rehabilitation. At 6 months, he was evaluated with CARS and PET CT. CARS showed substantial improvement as the boy scored 23.5 points (19-point change from the baseline), which is considered as "non-autistic." PET CT showed increased uptake in several regions which was considered to be improvement in comparison with previous result. At 12 months, the investigators reported on further improvement, especially concerning social sphere; however, the patient was not tested with tools dedicated to evaluate autistic children. The subsequent study by Sharma et al. [318] was an open-label, proof-of-concept study with 32 patients and similar study plan; however, the patients were evaluated with Indian Scale for Assessment of Autism, Clinical Global Impression scale (CGI), and scales designed to measure independence in daily living. In CGI-II scores, all patients but one were considered as improved, including 11 who were evaluated as "very much improved." The improvements were noted on all evaluated domains and were most pronounced in social sphere. The adverse effects related to the procedure included an increase in hyperactivity (transient in six patients, lasting over 6 months in one patient) and generalized tonic-clonic seizures in three patients that could be controlled with medications. Another study [319] used cord blood MNC along with Wharton's jelly-derived MSC (WJ-MSC) in one of three study arms. The study employed both an intravenous and intrathecal administration route. No serious adverse effects were observed. ASD children treated with WJ-MSC yielded better results on CARS, ABC, and $\mathrm{CGI}$ at 24 weeks after treatment. The results were compared with patients who received cord blood-derived MNC and rehabilitation only. Unfortunately, there were no patients who received WJ-MSC without MNC. An open-labeled study for children with ASD by Bradstreet et al. [320] used a controversial stem cell source-hematopoietic stem cells derived from fetal liver (delivered intravenously) and neuroprogenitors from fetal brain tissue (delivered subcutaneously). No serious adverse effects were noted. An improvement was noted on ABC and Autism Treatment Evaluation Checklist, especially concerning speech, social, and sensory domains. Lymphocyte subpopulations were assessed at baseline, 6, and 12 months after treatment. A significant up-regulation of $\mathrm{CD}^{+}$and $\mathrm{CD}^{+}{ }^{+} \mathrm{T}$ cells with reduced $\mathrm{B}$ cell count was observed. Recently, a case series of three patients treated with human embryonic stem cells was published [321]. The patients received cells intramuscularly (once/day with a dose of approximately $4 \times 10^{6}$ ), intravenously (twice/week with a dose of approximately $16 \times 10^{6}$ ), and via other routes such as intrathecal administration (weekly, different dosages). Treatment was planned in 4 cycles within 4-8-month intervals. The patients were a 3-year-old boy with ASD and no other co-morbidities, a 4-year-old boy with co-existing developmental delay, and a 10year-old boy who was also diagnosed with pediatric acute-onset neuropsychiatric syndrome, Lyme disease, heavy metal toxicity, and obsessive-compulsive disorder. The investigator concluded that patients improved significantly in eye contact, communication, cognitive skills, and writing. No information about psychological tools used to assess children were given. PET-CT examination revealed significant improvement in brain blood perfusion in all treated patients. All those results should be interpreted 
with caution as improvements in communication or cognitive skills are typical for young children and should be expected also in ASD individuals. For a summary of currently ongoing or unpublished clinical trials, please refer to Supplementary Table 2.

Cord blood (CB) is a unique biological material known to contain several populations of cells including progenitor stem cells, MSC, endothelial precursor cells, and unrestricted somatic stem cells [322, 323]. CB was also found to contain neurotropic and immunomodulatory factors along with several anti-inflammatory cytokines [324, 325]. The first clinical use of CB was carried out in 1988 in a setting of allogeneic HSCT in a patient with Fanconi anemia [326]. Recent advances and in-depth studies of CB biology have shown that this material can be employed in brain injuries [327]. Autologous cord blood infusion has already been shown to be safe and promising in cerebral palsy and acquired brain disorders [328, 329]. Preclinical scientific rationale support CB immunomodulatory properties and potential to correct neuronal activity [330, 331]. A breakthrough clinical trial has shown promising potential for $\mathrm{CB}$ and hematopoietic stem cells in ASD [332]. A phase I, open-label trial included 25 children aged 2-6 years with a confirmed ASD diagnosis and banked autologous CB. The procedure turned out to be safe and well tolerated. Improvements were noted in communication skills, expressive vocabulary, eye-tracking measures, and overall assessment of ASD severity. Interestingly, greater improvements were seen in children with higher nonverbal IQ. Further studies are planned to explore this therapeutic method, including the use of allogeneic CB.

\section{Future directions}

The overall data suggests that there is substantial evidence for immune system dysregulation in at least some children with ASD. The challenge lies in defining the exact connection between ASD symptoms and the immunological background. The graphic idea of this association is presented presented on Figure 1.

Studies based on newborn screening are interesting as they refer to early markers of ASD. However, they might also be misleading. Discrepancies between results of various studies may be due to methodological differences and heterogeneity of studied populations. Six studies were based on dried bloodspots from neonatal screening [65-68, 70], two on amniotic fluid [69, 72], and two on mid-gestational serum [64, 71] (Table 1).

An additional problem arises from ASD over diagnosis. In many cases, achieving a diagnosis of ASD is desirable as it facilitates parents' ability to gain early support for children with developmental disorders [333]. Also, different periods

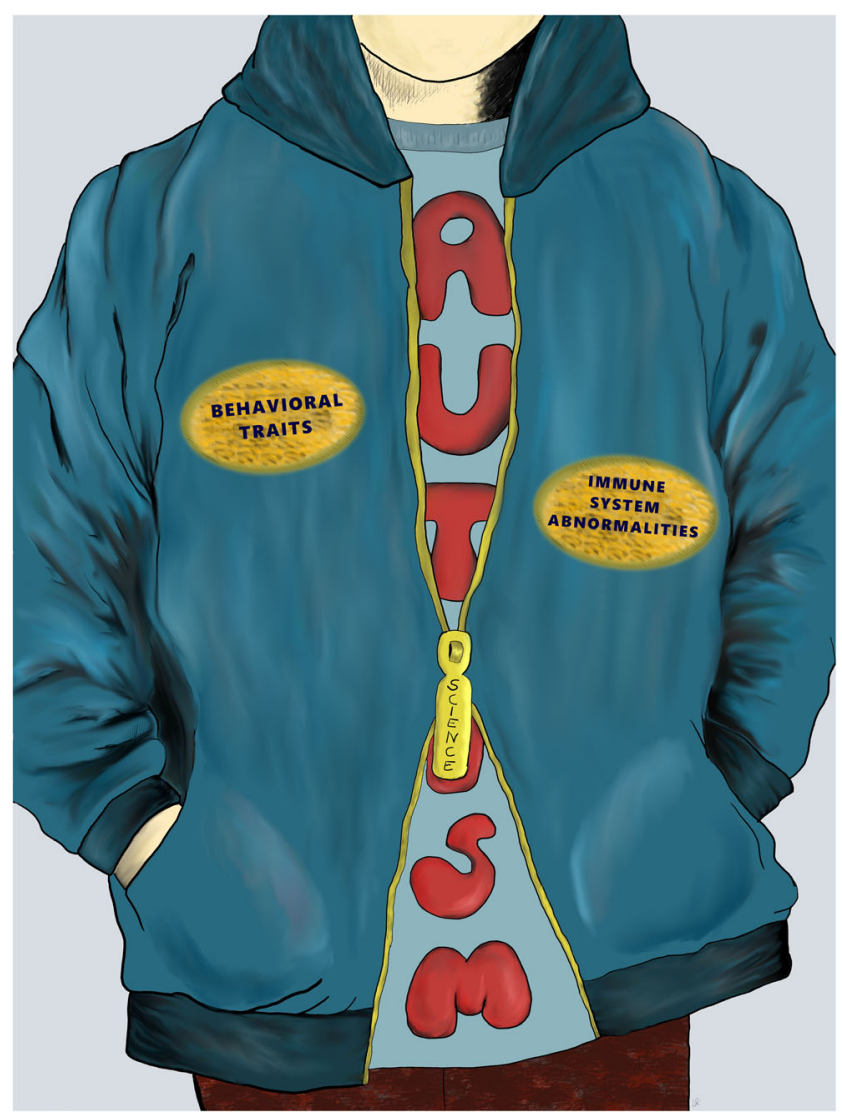

Fig. 1 A graphic "vision" of this article

of time (1991-2017) and advancements in ASD diagnostic ability and criteria make it difficult to compare results from early and current studies. The variety of psychological tools is of note as well, as an ASD diagnosis was not always confirmed with Autism Diagnostic Observation Schedule (ADOS) and Autism Diagnostic Interview-Revised (ADI$\mathrm{R}$ ), and several studies did not mention screening the control group for developmental disorders.

Out of 57 investigations that focused on cytokine and chemokine abnormalities, a detailed diagnosis of ASD was given only by 11 authors [140-142, 152, 153, 157, 159, 163, 179, $180,183]$, thus clinical picture of studied subjects might have varied greatly. Patients included in the analysis could have been diagnosed with autistic disorder, Asperger syndrome, or PDD-NOS (Table 2).

Moreover, the age of subjects often greatly varied; some studies included both pediatric and adult populations, which could alter results in a significant manner. A majority of the studies were carried out on young children. Some included only preschool age $[88,94,96,135,144,145,147,150$, $155,158,175,177,178]$, while others expanded inclusion criteria up to about 11 years [73, 89, 93, 142, 148, 157, 162, $163,165,168,170,172,181]$. Several studies focused solely on older children aged about 7-13 years [138, 139, 141, 146, 153, 160, 164, 166]. However, some investigators included 
wide-ranging age groups with not only children but also teenagers [91, 154, 156, 159, 167, 169, 171, 180, 183] and adults $[136,151]$. Only three studies were carried out solely on teenagers or adults [140, 176, 182].

While mainly all control subjects were age matched, only 33 studies compared gender-matched groups, which is highly important as biomarker profiles have been found to be gender specific [140].

Another source of bias could be different methodological approaches, as studies on peripheral blood used both plasma and serum, while investigations with PB-MNC were carried out with different stimulation conditions.

Multiple drugs are known to alter the cytokine profile, but 24 groups of investigators stated that patients either did not take any medication or were taking drugs that would not compromise study results $[89,91,94,138,141,144,145,147$, 150, 155, 160, 162, 164-166, 169-171, 174, 176, 181, 182, 185]. Several have stated that study subjects were taking psychotropic, antiepileptic, or other drugs that might be relevant [148, 151-153, 159, 168, 183]; however, almost half did not include any information on medication, which greatly impairs result interpretation.

Furthermore, ASD frequently occurs together with epilepsy, intellectual disability, ADHD, anxiety and behavior disorder, and in the course of several other diseases. The difference in cytokine profiles could be substantial as described by Jácome et al. [135] who compared ASD children with and without epilepsy. The exact data about ASD co-morbidities was frequently overlooked by investigators. Out of 57 summarized research studies on cytokine and chemokine abnormalities, 30 studies did not include any data on epilepsy, 47 on intellectual disability, and 49 on ADHD. For details, please see Table 2.

Further in-depth studies into ASD immunology could find that different behavioral traits are etiologically distinct and thus different approaches and therapeutic interventions should be undertaken. One third of conducted studies did not attempt to correlate biochemical abnormalities with behavioral traits. Observed concentrations of cytokines, chemokines, and growth factors were most frequently associated with ASD severity, impaired social interactions, and repetitive behaviors and interests. Only 3 studies, out of 26 that included psychological data, failed to detect any correlations (Table 3 ).

Out of multiple examined proteins, IL-1 and IL-6 turned out to be particularly interesting due to repeatability of the results concerning associated behavioral abnormalities. Probably, it could be partially attributed to the number of conducted studies in comparison to other examined molecules. IL-1 was explored by 14 groups of investigators [135, 137, 138, 144, 145, 150-152, 155, 163, 165, 166, 168, 176, $180]$, and IL- 6 by 16 of 26 [135, 138, 144, 145, 150-152, 155 , $163,166,167,170-172,176,180]$. IL-1, a key cytokine in the regulation of inflammatory pathway, was found relevant in several behavioral domains, including core ASD symptoms.
It was found to be positively correlated with impaired social sphere in two [150, 155] of five studies [138, 150, 155, 166, 177]. All studies evaluated social interactions based on ADOS and ADI-R apart from Napolioni et al. [138] who employed SRS. It is worth noticing that one study analyzed cytokines on mRNA level [166], while all the others examined protein concentration with enzyme-linked immunosorbent assays. It has not escaped our notice that Careaga et al. study [150] and Enstrom et al. study [155] were conducted on children with mean age of 3, while those who did not find any correlation to social sphere were carried out on older children $[138,166]$ or adults [138]. Surprisingly, no overwhelming evidence over IL-1 association with severity has been found. However, out of 24 studies that explored IL-1 links with behavioral abnormalities, only 4 tried to link it with ASD severity $[135,152$, 163,180 ] and 1 succeeded [152]. A related point to consider is poor methodological quality of that study: wide age range (221 years), inclusion of children with PDD (6/29 patients), and no exact data on medication taken by subjects. On the other hand, other studies had either small [135] or heterogeneous study groups [163, 181], along with children with Rett syndrome [180]. Regression turned out to be associated in two $[138,145]$ of four $[138,144,145,163]$ conducted studies in this area. The topic is worth exploring since one of the studies that denied abovementioned connection was carried out after stimulation [144] and the other one included children with PDD-NOS [163]. IL-6, a complex cytokine involved in inflammation and neural functions, was found to be upregulated in relation to social impairment in half $[150,155$, 167] of the conducted studies [138, 150, 155, 166, 167, 176]. Analogically to IL-1, IL-6 was found significant in younger children [150, 155] or in a large pediatric study group [167]. No correlation with cognition has been made by the same investigators who explored also IL-1 [138, 166, 177]. Intriguingly, three $[135,152,171]$ of four $[135,152,163,171]$ studies reported up-regulation of IL-6 in association with disease severity. Single studies have linked up-regulation of IL-1 and IL-6 with repetitive behaviors and interests [145], impaired communication [155], development [150], adaptive skills [138], aggression [150], hyperactivity and irritability [151], or lower IQ [138]. Despite vast studies of both IL-1 and IL-6, no associations with cognitive sphere have been reported so far. It is worth underlying that up-regulation of IL-1 or IL-6 and their connection to social sphere was significant in young individuals [150, 155]. It would be beneficial to examine large groups of children before psychological interventions, just after establishing diagnosis. We could suspect that those children would manifest the most prominent behavioral abnormalities and thus become an aim of further in-depth studies.

The search for potential biomarkers and their correlation with phenotypic variability should be the point of focus in ASD research and make a ground for future targeted therapies. Singh [334] hypothesized that an autoimmune autistic 
disorder might be identified and treated accordingly. However, his hypothesis involved mainly virus-induced autoimmunity. Several other interesting factors such as leptin, osteopontin, cell adhesion molecules, markers of oxidative stress, and neurotransmitters were reported to be relevant in ASD [335-340].

Not every study was in favor of an ASD immune pathogenesis. Stern et al. [117] concluded that only 2 out of 24 examined individuals had altered immune function, out of which 1 had common variable immune deficiency and routine immunologic examination would not benefit this group of patients. However, it is worth noticing that Stern et al. [117] also included children with PDD and the age of included patients varied from 3 to 17 years. For a full list of excluded correlations and a summary of studies conducted on peripheral blood, please refer to Table 3 .

Taken together, the presented data suggest a strong link between autism and immune dysfunction. Caution in drawing a conclusion should be preserved due to the lack of consistency in the studied populations, as the variety of co-existing symptoms and neurological comorbidities makes it difficult to completely synthesize all conducted studies. The association between immune system dysfunction and behavioral abnormalities, in at least a subset of individuals with ASD, suggests a potential role for immunomodulatory therapies as a causative treatment. Several investigators have already reported on the first clinical uses of stem cells in patients with ASD with promising results [317-319, 332]. Cellular therapies that take advantage of immunomodulatory properties of stem cells could address neurodevelopmental abnormalities on a cellular level. A summary of ongoing or unpublished clinical trials is presented in Supplementary Table 2.

It is noteworthy that in the future, we may be able to redefine ASD on the basis of molecular, immunological, and biochemical background and determine patients who could benefit from immunomodulatory approach.

\section{Compliance with ethical standards}

Conflict of interests D.G. is a part-time employee of the Polish Stem Cell Bank. Other authors have no conflicts of interest to declare.

Open Access This article is distributed under the terms of the Creative Commons Attribution 4.0 International License (http:// creativecommons.org/licenses/by/4.0/), which permits unrestricted use, distribution, and reproduction in any medium, provided you give appropriate credit to the original author(s) and the source, provide a link to the Creative Commons license, and indicate if changes were made.

\section{References}

1. World Health Organization (2013) International statistical classification of diseases and related health problems, 10th revision (ICD-10). World Health Organization, Geneva, 1992
2. American Psychiatric Association Neurodevelopmental disorders. In: Diagnostic and statistical manual of mental disorders, 5th edn. https://doi.org/10.1176/appi.books.9780890425596.dsm01. Accessed 29 May 2017

3. Coury DL, Swedo SE, Thurm AE, Miller DT, VeenstraVanderWeele JM, Carbone PS, Lounds Taylor J (2014) Treating the whole person with autism: the proceedings of the Autism Speaks National Autism Conference. Curr Probl Pediatr Adolesc Health Care 44(2):26-47

4. Lubetsky MJ, Handen BL, Lubetsky M, McGonigle JJ (2014) Systems of care for individuals with autism spectrum disorder and serious behavioral disturbance through the lifespan. Child Adolesc Psychiatr Clin N Am 23(1):97-110

5. Kennedy CH, Juárez AP, Becker A, Greenslade K, Harvey MT, Sullivan C, Tally B (2007) Children with severe developmental disabilities and behavioral disorders have increased special healthcare needs. Dev Med Child Neurol 49(12):926-930

6. Developmental Disabilities Monitoring Network Surveillance Year 2010 Principal Investigators, Centers for Disease Control and Prevention (2014) Prevalence of autism spectrum disorder among children aged 8 years - autism and developmental disabilities monitoring network, 11 sites, United States, 2010. MMWR Surveill Summ 63(2):1-21

7. Baxter AJ, Brugha TS, Erskine HE, Scheurer RW, Vos T, Scott JG (2015) The epidemiology and global burden of autism spectrum disorders. Psychol Med 45(3):601-613

8. Brynskikh A, Warren T, Zhu J, Kipnis J (2008) Adaptive immunity affects learning behavior in mice. Brain Behav Immun 22(6): 861-869. https://doi.org/10.1016/j.bbi.2007.12.008

9. Stubbs EG (1976) Autistic children exhibit undetectable hemagglutination inhibition antibody titers despite previous rubella vaccination. J Autism Child Schizophr 6(3):269-274

10. Onore CE, Schwartzer JJ, Careaga M, Berman RF, Ashwood P (2014) Maternal immune activation leads to activated inflammatory macrophages in offspring. Brain Behav Immun 38:220-226. https://doi.org/10.1016/j.bbi.2014.02.007

11. Luan R, Cheng H, Li L, Zhao Q, Liu H, Wu Z, Zhao L, Yang J et al (2015) Maternal lipopolysaccharide exposure promotes immunological functional changes in adult offspring CD4+ T cells. Am J Reprod Immunol 73(6):522-535. https://doi.org/10.1111/aji. 12364

12. Hsiao EY, McBride SW, Chow J, Mazmanian SK, Patterson PH (2012) Modeling an autism risk factor in mice leads to permanent immune dysregulation. Proc Natl Acad Sci U S A 109(31):1277612781. https://doi.org/10.1073/pnas.1202556109

13. Lucchina L, Depino AM (2014) Altered peripheral and central inflammatory responses in a mouse model of autism. Autism Res 7(2):273-289. https://doi.org/10.1002/aur.1338

14. Krakowiak P, Walker CK, Tancredi D, Hertz-Picciotto I, Van de Water J (2016) Autism-specific maternal anti-fetal brain autoantibodies are associated with metabolic conditions. Autism Res. https://doi.org/10.1002/aur.1657

15. Fox-Edmiston E, Van de Water J (2015) Maternal anti-fetal brain IgG autoantibodies and autism spectrum disorder: current knowledge and its implications for potential therapeutics. CNS Drugs 29(9):715-724. https://doi.org/10.1007/s40263-015-0279-2

16. Mazur-Kolecka B, Cohen IL, Gonzalez M, Jenkins EC, Kaczmarski W, Brown WT, Flory M, Frackowiak J (2014) Autoantibodies against neuronal progenitors in sera from children with autism. Brain Dev 36(4):322-329. https://doi.org/10.1016/j. braindev.2013.04.015

17. Nordahl CW, Braunschweig D, Iosif AM, Lee A, Rogers S, Ashwood P, Amaral DG, Van de Water J (2013) Maternal autoantibodies are associated with abnormal brain enlargement in a subgroup of children with autism spectrum disorder. Brain Behav Immun 30:61-65. https://doi.org/10.1016/j.bbi.2013.01.084 
18. Rossi CC, Fuentes J, Van de Water J, Amaral DG (2013) Brief report: Antibodies reacting to brain tissue in Basque Spanish children with autism spectrum disorder and their mothers. J Autism Dev Disord. https://doi.org/10.1007/s10803-013-1859-y

19. Rout UK, Mungan NK, Dhossche DM (2012) Presence of GAD65 autoantibodies in the serum of children with autism or ADHD. Eur Child Adolesc Psychiatry 21(3):141-147. https://doi. org/10.1007/s00787-012-0245-1

20. Singer HS, Morris CM, Gause CD, Gillin PK, Crawford S, Zimmerman AW (2008) Antibodies against fetal brain in sera of mothers with autistic children. J Neuroimmunol 194(1-2):165172

21. Martin LA, Ashwood P, Braunschweig D, Cabanlit M, Van de Water J, Amaral DG (2008) Stereotypies and hyperactivity in rhesus monkeys exposed to IgG from mothers of children with autism. Brain Behav Immun 22(6):806-816. https://doi.org/10. 1016/j.bbi.2007.12.007

22. Bauman MD, Iosif AM, Ashwood P, Braunschweig D, Lee A, Schumann CM, Van de Water J, Amaral DG (2013) Maternal antibodies from mothers of children with autism alter brain growth and social behavior development in the rhesus monkey. Transl Psychiatry 3(7):e278. https://doi.org/10.1038/tp.2013.47

23. Camacho J, Jones K, Miller E, Ariza J, Noctor S, Van de Water J, Martínez-Cerdeño V (2014) Embryonic intraventricular exposure to autism-specific maternal autoantibodies produces alterations in autistic-like stereotypical behaviors in offspring mice. Behav Brain Res 1(266):46-51. https://doi.org/10.1016/j.bbr.2014.02. 045

24. Heo Y, Zhang Y, Gao D, Miller VM, Lawrence DA (2011) Aberrant immune responses in a mouse with behavioral disorders. PLoS One 6(7):e20912. https://doi.org/10.1371/journal.pone. 0020912

25. Brown AS, Surcel HM, Hinkka-Yli-Salomäki S, CheslackPostava K, Bao Y, Sourander A (2015) Maternal thyroid autoantibody and elevated risk of autism in a national birth cohort. Prog Neuropsychopharmacol Biol Psychiatry 57:86-92. https://doi. org/10.1016/j.pnpbp.2014.10.010

26. Khaiman C, Onnuam K, Photchanakaew S, Chonchaiya W, Suphapeetiporn K (2015) Risk factors for autism spectrum disorder in the Thai population. Eur J Pediatr 174(10):1365-1372. https://doi.org/10.1007/s00431-015-2544-2

27. Andersen SL, Laurberg P, Wu CS, Olsen J (2014) Attention deficit hyperactivity disorder and autism spectrum disorder in children born to mothers with thyroid dysfunction: a Danish nationwide cohort study. BJOG 121(11):1365-1374. https://doi.org/10.1111/ $1471-0528.12681$

28. Lyall K, Ashwood P, Van de Water J, Hertz-Picciotto I (2014) Maternal immune-mediated conditions, autism spectrum disorders, and developmental delay. J Autism Dev Disord 44(7): 1546-1555. https://doi.org/10.1007/s10803-013-2017-2.

29. Xu G, Jing J, Bowers K, Liu B, Bao W (2014) Maternal diabetes and the risk of autism spectrum disorders in the offspring: a systematic review and meta-analysis. J Autism Dev Disord 44(4): 766-775. https://doi.org/10.1007/s10803-013-1928-2

30. Lyall K, Pauls DL, Spiegelman D, Ascherio A, Santangelo SL (2012) Pregnancy complications and obstetric suboptimality in association with autism spectrum disorders in children of the Nurses' Health Study II. Autism Res 5(1):21-30. https://doi.org/ 10.1002/aur.228

31. Keil A, Daniels JL, Forssen U, Hultman C, Cnattingius S, Söderberg KC, Feychting M, Sparen P (2010) Parental autoimmune diseases associated with autism spectrum disorders in offspring. Epidemiology 21(6):805-808. https://doi.org/10.1097/ EDE.0b013e3181f26e3f

32. Mostafa GA, Shehab AA (2010) The link of C4B null allele to autism and to a family history of autoimmunity in Egyptian autistic children. J Neuroimmunol 223(1-2):115-119. https://doi. org/10.1016/j.jneuroim.2010.03.025

33. Atladóttir HO, Pedersen MG, Thorsen P, Mortensen PB, Deleuran B, Eaton WW, Parner ET (2009) Association of family history of autoimmune diseases and autism spectrum disorders. Pediatrics 124(2):687-694. https://doi.org/10.1542/peds.2008-2445

34. Mouridsen SE, Rich B, Isager T, Nedergaard NJ (2007) Autoimmune diseases in parents of children with infantile autism: a case-control study. Dev Med Child Neurol 49(6):429-432

35. Croen LA, Grether JK, Yoshida CK, Odouli R, Van de Water J (2005) Maternal autoimmune diseases, asthma and allergies, and childhood autism spectrum disorders: a case-control study. Arch Pediatr Adolesc Med 159(2):151-157

36. Lauritsen MB, Pedersen CB, Mortensen PB (2005) Effects of familial risk factors and place of birth on the risk of autism: a nationwide register-based study. J Child Psychol Psychiatry 46(9):963-971

37. Comi AM, Zimmerman AW, Frye VH, Law PA, Peeden JN (1999) Familial clustering of autoimmune disorders and evaluation of medical risk factors in autism. J Child Neurol 14(6):388-394

38. Wu S, Ding Y, Wu F, Li R, Xie G, Hou J, Mao P (2015) Family history of autoimmune diseases is associated with an increased risk of autism in children: a systematic review and meta-analysis. Neurosci Biobehav Rev 55:322-332. https://doi.org/10.1016/j. neubiorev.2015.05.004

39. Chen SW, Zhong XS, Jiang LN, Zheng XY, Xiong YQ, Ma SJ, Qiu M, Huo ST et al (2016) Maternal autoimmune diseases and the risk of autism spectrum disorders in offspring: a systematic review and meta-analysis. Behav Brain Res 296:61-69. https:// doi.org/10.1016/j.bbr.2015.08.035

40. Mostafa GA, Shehab AA, Al-Ayadhi LY (2013) The link between some alleles on human leukocyte antigen system and autism in children. J Neuroimmunol 255(1-2):70-74. https://doi.org/10. 1016/j.jneuroim.2012.10.002

41. Trajkovski V, Spiroski M (2015) DNA typing of HLA-A, -C, -B, AND -DRB1 in the children with autism in the Republic of Macedonia. Bratisl Lek Listy 116(1):14-19

42. Lee LC, Zachary AA, Leffell MS, Newschaffer CJ, Matteson KJ, Tyler JD, Zimmerman AW (2006) HLA-DR4 in families with autism. Pediatr Neurol 35(5):303-307

43. Torres AR, Sweeten TL, Cutler A, Bedke BJ, Fillmore M, Stubbs EG, Odell D (2006) The association and linkage of the HLA-A2 class I allele with autism. Hum Immunol 67(4-5):346-351

44. Torres AR, Maciulis A, Stubbs EG, Cutler A, Odell D (2002) The transmission disequilibrium test suggests that HLA-DR4 and DR13 are linked to autism spectrum disorder. Hum Immunol 63(4):311-316

45. Warren RP, Odell JD, Warren WL, Burger RA, Maciulis A, Daniels WW, Torres AR (1996) Strong association of the third hypervariable region of HLA-DR beta 1 with autism. J Neuroimmunol 67(2):97-102

46. Puangpetch A, Suwannarat P, Chamnanphol M, Koomdee N, Ngamsamut N, Limsila P, Sukasem C (2015) Significant association of HLA-B alleles and genotypes in Thai children with autism spectrum disorders: a case-control study. Dis Markers: 724935. https://doi.org/10.1155/2015/724935

47. Al-Hakbany M, Awadallah S, Al-Ayadhi L (2014) The relationship of HLA class I and II alleles and haplotypes with autism: a case control study. Autism Res Treat: 242048. https://doi.org/10. 1155/2014/242048

48. Chien YL, Wu YY, Chen CH, Gau SS, Huang YS, Chien WH, Hu FC, Chao YL (2012) Association of HLA-DRB1 alleles and neuropsychological function in autism. Psychiatr Genet 22(1):46-49. https://doi.org/10.1097/YPG.0b013e32834915ae

49. Guerini FR, Bolognesi E, Chiappedi M, Ghezzo A, Canevini MP, Mensi MM, Vignoli A, Agliardi C et al (2015) An HLA-G(*)14bp 
insertion/deletion polymorphism associates with the development of autistic spectrum disorders. Brain Behav Immun 44:207-212. https://doi.org/10.1016/j.bbi.2014.10.002.

50. Johnson WG, Buyske S, Mars AE, Sreenath M, Stenroos ES, Williams TA, Stein R, Lambert GH (2009) HLA-DR4 as a risk allele for autism acting in mothers of probands possibly during pregnancy. Arch Pediatr Adolesc Med 163(6):542-546. https:/ doi.org/10.1001/archpediatrics.2009.74

51. Torres AR, Sweeten TL, Johnson RC, Odell D, Westover JB, Bray-Ward P, Ward DC, Davies CJ et al (2016) Common genetic variants found in HLA and KIR immune genes in autism spectrum disorder. Front Neurosci 10:463

52. Piras IS, Haapanen L, Napolioni V, Sacco R, Van de Water J, Persico AM (2014) Anti-brain antibodies are associated with more severe cognitive and behavioral profiles in Italian children with autism spectrum disorder. Brain Behav Immun 38:91-99. https:// doi.org/10.1016/j.bbi.2013.12.020

53. Braunschweig D, Duncanson P, Boyce R, Hansen R, Ashwood P, Pessah IN, Hertz-Picciotto I, Van de Water J (2012) Behavioral correlates of maternal antibody status among children with autism. J Autism Dev Disord 42(7):1435-1445. https://doi.org/10.1007/ s10803-011-1378-7

54. Mostafa GA, Al-Ayadhi LY (2012) The relationship between the increased frequency of serum antineuronal antibodies and the severity of autism in children. Eur J Paediatr Neurol 16(5):464-468. https://doi.org/10.1016/j.ejpn.2011.12.010

55. Rossi CC, Van de Water J, Rogers SJ, Amaral DG (2011) Detection of plasma autoantibodies to brain tissue in young children with and without autism spectrum disorders. Brain Behav Immun 25(6):1123-1135. https://doi.org/10.1016/j.bbi.2011.02. 011

56. Wills S, Rossi CC, Bennett J, Martinez Cerdeño V, Ashwood P, Amaral DG, Van de Water J (2011) Further characterization of autoantibodies to GABAergic neurons in the central nervous system produced by a subset of children with autism. Mol Autism 2: 5. https://doi.org/10.1186/2040-2392-2-5

57. Goines P, Haapanen L, Boyce R, Duncanson P, Braunschweig D, Delwiche L, Hansen R, Hertz-Picciotto I et al (2011) Autoantibodies to cerebellum in children with autism associate with behavior. Brain Behav Immun 25(3):514-523. https://doi. org/10.1016/j.bbi.2010.11.017

58. Wills S, Cabanlit M, Bennett J, Ashwood P, Amaral DG, Van de Water J (2009) Detection of autoantibodies to neural cells of the cerebellum in the plasma of subjects with autism spectrum disorders. Brain Behav Immun 23(1):64-74. https://doi.org/10.1016/j. bbi.2008.07.007

59. Cabanlit M, Wills S, Goines P, Ashwood P, Van de Water J (2007) Brain-specific autoantibodies in the plasma of subjects with autistic spectrum disorder. Ann N Y Acad Sci 1107:92-103. https://doi. org/10.1196/annals.1381.010

60. Connolly AM, Chez M, Streif EM, Keeling RM, Golumbek PT, Kwon JM, Riviello JJ, Robinson RG et al (2006) Brain-derived neurotrophic factor and autoantibodies to neural antigens in sera of children with autistic spectrum disorders, Landau-Kleffner syndrome, and epilepsy. Biol Psychiatry 59(4):354-363

61. Singer HS, Morris CM, Williams PN, Yoon DY, Hong JJ, Zimmerman AW (2006) Antibrain antibodies in children with autism and their unaffected siblings. J Neuroimmunol 178(1-2): $149-155$

62. Singh VK, Warren RP, Odell JD, Warren WL, Cole P (1993) Antibodies to myelin basic protein in children with autistic behavior. Brain Behav Immun 7(1):97-103

63. Mostafa GA, Al-Ayadhi LY (2011) Increased serum levels of antiganglioside M1 auto-antibodies in autistic children: relation to the disease severity. J Neuroinflammation 8:39. https://doi.org/10. 1186/1742-2094-8-39
64. Jones KL, Croen LA, Yoshida CK, Heuer L, Hansen R, Zerbo O, DeLorenze GN, Kharrazi M et al (2017) Autism with intellectual disability is associated with increased levels of maternal cytokines and chemokines during gestation. Mol Psychiatry 22(2):273-279. https://doi.org/10.1038/mp.2016.77

65. Krakowiak P, Goines PE, Tancredi DJ, Ashwood P, Hansen RL, Hertz-Picciotto I, Van de Water J (2017) Neonatal cytokine profiles associated with autism spectrum disorder. Biol Psychiatry 81(5):442-451. https://doi.org/10.1016/j.biopsych.2015.08.007

66. Zerbo O, Yoshida C, Grether JK, Van de Water J, Ashwood P, Delorenze GN, Hansen RL, Kharrazi M et al (2014) Neonatal cytokines and chemokines and risk of autism spectrum disorder: the Early Markers for Autism (EMA) study: a case-control study. J Neuroinflammation 11:113. https://doi.org/10.1186/1742-209411-113

67. Abdallah MW, Mortensen EL, Greaves-Lord K, Larsen N, Bonefeld-Jørgensen EC, Nørgaard-Pedersen B, Hougaard DM, Grove J (2013) Neonatal levels of neurotrophic factors and risk of autism spectrum disorders. Acta Psychiatr Scand 128(1):6169. https://doi.org/10.1111/acps.12020

68. Abdallah MW, Larsen N, Grove J, Bonefeld-Jørgensen EC, Nørgaard-Pedersen B, Hougaard DM, Mortensen EL (2013) Neonatal chemokine levels and risk of autism spectrum disorders: findings from a Danish historic birth cohort follow-up study. Cytokine 61(2):370-376. https://doi.org/10.1016/j.cyto.2012.11. 015

69. Abdallah MW, Pearce BD, Larsen N, Greaves-Lord K, NørgaardPedersen B, Hougaard DM, Mortensen EL, Grove J (2012) Amniotic fluid MMP-9 and neurotrophins in autism spectrum disorders: an exploratory study. Autism Res 5(6):428-433. https:// doi.org/10.1002/aur.1254

70. Abdallah MW, Larsen N, Mortensen EL, Atladóttir HÓ, Nørgaard-Pedersen B, Bonefeld-Jørgensen EC, Grove J, Hougaard DM (2012) Neonatal levels of cytokines and risk of autism spectrum disorders: an exploratory register-based historic birth cohort study utilizing the Danish Newborn Screening Biobank. J Neuroimmunol 252(1-2):75-82. https://doi.org/10. 1016/j.jneuroim.2012.07.013

71. Goines PE, Croen LA, Braunschweig D, Yoshida CK, Grether J, Hansen R, Kharrazi M, Ashwood P et al (2011) Increased midgestational IFN- $\gamma$, IL-4 and IL- 5 in women bearing a child with autism: a case-control study. Mol Autism 2:13. https://doi. org/10.1186/2040-2392-2-13

72. Nelson PG, Kuddo T, Song EY, Dambrosia JM, Kohler S, Satyanarayana G, Vandunk C, Grether JK et al (2006) Selected neurotrophins, neuropeptides, and cytokines: developmental trajectory and concentrations in neonatal blood of children with autism or Down syndrome. Int J Dev Neurosci 24(1):73-80

73. El-Ansary A, Hassan WM, Qasem H, Das UN (2016) Identification of biomarkers of impaired sensory profiles among autistic patients. PLoS One 11(11):e0164153. https://doi.org/10. 1371/journal.pone.0164153

74. Rose D, Ashwood P (2014) Potential cytokine biomarkers in autism spectrum disorders. Biomark Med 8(9):1171-1181. https:// doi.org/10.2217/bmm.14.39

75. Anderson GM (2015) Autism biomarkers: challenges, pitfalls and possibilities. J Autism Dev Disord 45(4):1103-1113. https://doi. org/10.1007/s10803-014-2225-4

76. Chatterjee P, Chiasson VL, Bounds KR, Mitchell BM (2014) Regulation of the anti-inflammatory cytokines interleukin- 4 and interleukin-10 during pregnancy. Front Immunol 5:253. https:// doi.org/10.3389/fimmu.2014.00253

77. Holmes VA, Wallace JM, Gilmore WS, McFaul P, Alexander HD (2003) Plasma levels of the immunomodulatory cytokine interleukin-10 during normal human pregnancy: a longitudinal study. Cytokine 21(6):265-269 
78. Stubbs EG, Crawford ML (1977) Depressed lymphocyte responsiveness in autistic children. J Autism Child Schizophr 7(1):49-55

79. Warren RP, Margaretten NC, Pace NC, Foster A (1986) Immune abnormalities in patients with autism. J Autism Dev Disord 16(2): 189-197

80. Denney DR, Frei BW, Gaffney GR (1996) Lymphocyte subsets and interleukin-2 receptors in autistic children. J Autism Dev Disord 26(1):87-97

81. Yonk LJ, Warren RP, Burger RA, Cole P, Odell JD, Warren WL, White E, Singh VK (1990) CD4+ helper T cell depression in autism. Immunol Lett 25(4):341-345

82. Ashwood P, Corbett BA, Kantor A, Schulman H, Van de Water J, Amaral DG (2011) In search of cellular immunophenotypes in the blood of children with autism. PLoS One 6(5):e19299. https://doi. org/10.1371/journal.pone.0019299

83. Ferrante P, Saresella M, Guerini FR, Marzorati M, Musetti MC, Cazzullo AG (2003) Significant association of HLA A2-DR11 with CD4 naive decrease in autistic children. Biomed Pharmacother 57(8):372-374

84. Warren RP, Yonk J, Burger RW, Odell D, Warren WL (1995) DRpositive T cells in autism: association with decreased plasma levels of the complement C4B protein. Neuropsychobiology 31(2):5357

85. Warren RP, Yonk LJ, Burger RA, Cole P, Odell JD, Warren WL, White E, Singh VK (1990) Deficiency of suppressor-inducer (CD4+CD45RA+) T cells in autism. Immunol Invest 19(3):245251

86. Mostafa GA, Shehab AA, Fouad NR (2010) Frequency of CD4+ CD25high regulatory T cells in the peripheral blood of Egyptian children with autism. J Child Neurol 25(3):328-335

87. Ahmad SF, Zoheir KM, Ansari MA, Nadeem A, Bakheet SA, AlAyadhi LY, Alzahrani MZ, Al-Shabanah OA, Al-Harbi MM, Attia SM (2017) Dysregulation of Th1, Th2, Th17, and T regulatory cell-related transcription factor signaling in children with autism. Mol Neurobiol 54(6):4390-4400. https://doi.org/10.1007/s12035016-9977-0

88. Gupta S, Aggarwal S, Rashanravan B, Lee T (1998) Th1- and Th2-like cytokines in CD4+ and CD8+ T cells in autism. J Neuroimmunol 85(1):106-109. https://doi.org/10.1016/S01655728(98)00021-6

89. Al-Ayadhi LY, Mostafa GA (2013) Elevated serum levels of macrophage-derived chemokine and thymus and activationregulated chemokine in autistic children. J Neuroinflammation 10:72. https://doi.org/10.1186/1742-2094-10-72

90. López-Cacho JM, Gallardo S, Posada M, Aguerri M, Calzada D, Mayayo T, Lahoz C, Cárdaba B (2016) Characterization of immune cell phenotypes in adults with autism spectrum disorders. J Investig Med 64(7):1179-1185. https://doi.org/10.1136/jim-2016000070

91. Saresella M, Marventano I, Guerini FR, Mancuso R, Ceresa L, Zanzottera M, Rusconi B, Maggioni E et al (2009) An autistic endophenotype results in complex immune dysfunction in healthy siblings of autistic children. Biol Psychiatry 66(10):978-984. https://doi.org/10.1016/j.biopsych.2009.06.020

92. Tabarkiewicz J, Pogoda K, Karczmarczyk A, Pozarowski P, Giannopoulos K (2015) The role of IL-17 and Th17 lymphocytes in autoimmune diseases. Arch Immunol Ther Exp (Warsz) 63(6): 435-449. https://doi.org/10.1007/s00005-015-0344-z

93. Al-Ayadhi LY, Mostafa GA (2012) Elevated serum levels of interleukin-17A in children with autism. J Neuroinflammation 9: 158

94. Akintunde ME, Rose M, Krakowiak P, Heuer L, Ashwood P, Hansen R, Hertz-Picciotto I, Van de Water J (2015) Increased production of IL-17 in children with autism spectrum disorders and co-morbid asthma. J Neuroimmunol 286:33-41. https://doi. org/10.1016/j.jneuroim.2015.07.003
95. Choi GB, Yim YS, Wong H, Kim S, Kim H, Kim SV, Hoeffer CA, Littman DR et al (2016) The maternal interleukin-17a pathway in mice promotes autism-like phenotypes in offspring. Science 351(6276):933-939. https://doi.org/10.1126/science.aad0314

96. Onore C, Enstrom A, Krakowiak P, Hertz-Picciotto I, Hansen R, Van de Water J, Ashwood P (2009) Decreased cellular IL-23 but not IL-17 production in children with autism spectrum disorders. J Neuroimmunol 216(1-2):126-129. https://doi.org/10.1016/j. jneuroim.2009.09.005

97. Enstrom A, Onore C, Hertz-Picciotto I, Hansen R, Croen L, Van De Water J, Ashwood P (2003) Detection of IL-17 and IL-23 in plasma samples of children with autism. Am J Biochem Biotechnol 4(2):114-120

98. Kim SN, Jo GH, Kim HA, Heo Y (2016) Aberrant IgG isotype generation in mice with abnormal behaviors. J Immunotoxicol 13(1):92-96. https://doi.org/10.3109/1547691X.2015.1014581

99. Young JG, Caparulo BK, Shaywitz BA, Johnson WT, Cohen DJ (1977) Childhood autism. Cerebrospinal fluid examination and immunoglobulin levels. J Am Acad Child Psychiatry 16(1):174179

100. Warren RP, Odell JD, Warren WL, Burger RA, Maciulis A, Daniels WW, Torres AR (1997) Brief report: immunoglobulin A deficiency in a subset of autistic subjects. J Autism Dev Disord 27(2):187-192

101. Wasilewska J, Kaczmarski M, Stasiak-Barmuta A, Tobolczyk J, Kowalewska E (2012) Low serum IgA and increased expression of CD23 on B lymphocytes in peripheral blood in children with regressive autism aged 3-6 years old. Arch Med Sci 8(2):324 331. https://doi.org/10.5114/aoms.2012.28561.

102. Santaella ML, Varela Y, Linares N, Disdier OM (2008) Prevalence of autism spectrum disorders in relatives of patients with selective immunoglobulin A deficiency. P R Health Sci J 27(3):204-208

103. Heuer L, Ashwood P, Schauer J, Goines P, Krakowiak P, HertzPicciotto I, Hansen R, Croen LA et al (2008) Reduced levels of immunoglobulin in children with autism correlates with behavioral symptoms. Autism Res 1(5):275-283. https://doi.org/10.1002/ aur.42

104. Heuer LS, Rose M, Ashwood P, Van de Water J (2012) Decreased levels of total immunoglobulin in children with autism are not a result of B cell dysfunction. J Neuroimmunol 251(1-2):94-102. https://doi.org/10.1016/j.jneuroim.2012.07.001

105. Trajkovski V, Ajdinski L, Spiroski M (2004) Plasma concentration of immunoglobulin classes and subclasses in children with autism in the Republic of Macedonia: retrospective study. Croat Med J 45(6):746-749

106. Trajkovski V, Petlichovski A, Efinska-Mladenovska O, Trajkov D, Arsov T, Strezova A, Ajdinski L, Spiroski M (2008) Higher plasma concentration of food-specific antibodies in persons with autistic disorder in comparison to their siblings. Focus Autism Other Dev Disabl 23:176-185

107. Spiroski M, Trajkovski V, Trajkov D, Petlichkovski A, EfinskaMladenovska O, Hristomanova S, Djulejic E, Paneva M et al (2009) Family analysis of immunoglobulin classes and subclasses in children with autistic disorder. Bosn J Basic Med Sci 9(4):283289

108. Croonenberghs J, Wauters A, Devreese K, Verkerk R, Scharpe S, Bosmans E, Egyed B, Deboutte D et al (2002) Increased serum albumin, gamma globulin, immunoglobulin $\mathrm{IgG}$, and $\mathrm{IgG} 2$ and IgG4 in autism. Psychol Med 32(8):1457-1463

109. Enstrom A, Krakowiak P, Onore C, Pessah IN, Hertz-Picciotto I, Hansen RL, Van de Water JA, Ashwood P (2009) Increased IgG4 levels in children with autism disorder. Brain Behav Immun 23(3): 389-395. https://doi.org/10.1016/j.bbi.2008.12.005

110. Hollander E, DelGiudice-Asch G, Simon L, Schmeidler J, Cartwright C, DeCaria CM, Kwon J, Cunningham-Rundles C 
et al (1999) B lymphocyte antigen D8/17 and repetitive behaviors in autism. Am J Psychiatry 156(2):317-320

111. Harel L, Mukamel M, Zeharia A, Kodman Y, Prais D, Uziel Y, Zabriskie JB, Amir J (2007) Presence of D8/17 B-cell marker in patients with poststreptococcal reactive arthritis. Rheumatol Int 27(8):695-698

112. Weisz JL, McMahon WM, Moore JC, Augustine NH, Bohnsack JF, Bale JF, Johnson MB, Morgan JF et al (2004) D8/17 and CD19 expression on lymphocytes of patients with acute rheumatic fever and Tourette's disorder. Clin Diagn Lab Immunol 11(2):330-336

113. Niehaus DJ, Knowles JA, van Kradenberg J, du Toit W, Kaminer D, Seedat S, Daniels W, Cotton M et al (1999) D8/17 in obsessivecompulsive disorder and trichotillomania. S Afr Med J 89(7):755756

114. Swedo SE, Leonard HL, Mittleman BB, Allen AJ, Rapoport JL, Dow SP, Kanter ME, Chapman F et al (1997) Identification of children with pediatric autoimmune neuropsychiatric disorders associated with streptococcal infections by a marker associated with rheumatic fever. Am J Psychiatry 154(1):110-112

115. Sharpe MA, Gist TL, Baskin DS (2013) B-lymphocytes from a population of children with autism spectrum disorder and their unaffected siblings exhibit hypersensitivity to thimerosal. J Toxicol. https://doi.org/10.1155/2013/801517

116. Wei H, Malik M, Sheikh AM, Merz G, Ted Brown W, Li X (2011) Abnormal cell properties and down-regulated FAK-Src complex signaling in B lymphoblasts of autistic subjects. Am J Pathol 179(1):66-74. https://doi.org/10.1016/j.ajpath.2011.03.034

117. Stern L, Francoeur MJ, Primeau MN, Sommerville W, Fombonne E, Mazer BD (2005) Immune function in autistic children. Ann Allergy Asthma Immunol 95(6):558-565

118. Cooper MA, Fehniger TA, Caligiuri MA (2001) The biology of human natural killer-cell subsets. Trends Immunol 22(11):633640

119. Papamichail M, Perez SA, Gritzapis AD, Baxevanis CN (2004) Natural killer lymphocytes: biology, development, and function. Cancer Immunol Immunother 53(3):176-186

120. Zitvogel L (2002) Dendritic and natural killer cells cooperate in the control/switch of innate immunity. J Exp Med 195(3):F9-14

121. Enk J, Mandelboim O (2014) The role of natural cytotoxicity receptors in various pathologies: emphasis on type I diabetes. Front Immunol 5:4

122. Galuppo M, Giacoppo S, Sessa E, Bramanti P, Mazzon E (2014) Are natural killer cells involved in multiple sclerosis etiology? Evidences from NKp46/NCR1 receptor modulation in an observational study. J Neurol Sci 345(1-2):248-251

123. Sperner-Unterweger B, Whitworth A, Kemmler G, Hilbe W, Thaler J, Weiss G, Fleischhacker WW (1999) T-cell subsets in schizophrenia: a comparison between drug-naive first episode patients and chronic schizophrenic patients. Schizophr Res 38(1): $61-70$

124. Lit L, Gilbert DL, Walker W, Sharp FR (2007) A subgroup of Tourette's patients overexpress specific natural killer cell genes in blood: a preliminary report. Am J Med Genet B Neuropsychiatr Genet 144B(7):958-963

125. Fiumara A, Sciotto A, Barone R, D'Asero G, Munda S, Parano E, Pavone L (1999) Peripheral lymphocyte subsets and other immune aspects in Rett syndrome. Pediatr Neurol 21(3):619-621

126. Warren RP, Foster A, Margaretten NC (1987) Reduced natural killer cell activity in autism. J Am Acad Child Adolesc Psychiatry 26(3):333-335

127. Enstrom AM, Lit L, Onore CE, Gregg JP, Hansen RL, Pessah IN, Hertz-Picciotto I, Van de Water JA et al (2009) Altered gene expression and function of peripheral blood natural killer cells in children with autism. Brain Behav Immun 23(1):124-133

128. Vojdani A, Mumper E, Granpeesheh D, Mielke L, Traver D, Bock K, Hirani K, Neubrander J et al (2008) Low natural killer cell cytotoxic activity in autism: the role of glutathione, IL-2 and IL15. J Neuroimmunol 205(1-2):148-154

129. Gregg JP, Lit L, Baron CA, Hertz-Picciotto I, Walker W, Davis RA, Croen LA, Ozonoff S et al (2008) Gene expression changes in children with autism. Genomics 91(1):22-29

130. Torres AR, Westover JB, Gibbons C, Johnson RC, Ward DC (2012) Activating killer-cell immunoglobulin-like receptors (KIR) and their cognate HLA ligands are significantly increased in autism. Brain Behav Immun 26(7):1122-1127

131. Guerini FR, Bolognesi E, Chiappedi M, Manca S, Ghezzo A, Agliardi C, Zanette M, Littera R et al (2014) Activating KIR molecules and their cognate ligands prevail in children with a diagnosis of ASD and in their mothers. Brain Behav Immun 36: 54-60

132. Ivarsson MA, Michaëlsson J, Fauriat C (2014) Activating killer cell Ig-like receptors in health and disease. Front Immunol 5:184

133. Kuśnierczyk P (2013) Killer cell immunoglobulin-like receptor gene associations with autoimmune and allergic diseases, recurrent spontaneous abortion, and neoplasms. Front Immunol 4:8

134. Siniscalco D, Mijatovic T, Bosmans E, Cirillo A, Kruzliak P, Lombardi VC, De Meirleir K, Antonucci N (2016) Decreased numbers of CD57+CD3- cells identify potential innate immune differences in patients with autism spectrum disorder. In Vivo 30(2):83-89

135. Jácome IMC, Morales Chacòn LM, Vera Cuesta H, Maragoto Rizo C, Whilby Santiesteban M, Ramos Hernandez L, Noris García E, González Fraguela ME et al (2016) Peripheral inflammatory markers contributing to comorbidities in autism. Behav Sci (Basel) 6(4). https://doi.org/10.3390/bs6040029

136. Pecorelli A, Cervellati F, Belmonte G, Montagner G, Waldon P, Hayek J, Gambari R, Valacchi G (2016) Cytokines profile and peripheral blood mononuclear cells morphology in Rett and autistic patients. Cytokine 77:180-188. https://doi.org/10.1016/j.cyto. 2015.10.002

137. Rose D, Van de Water J, Ashwood P (2016) Unique immune profiles in children with autism who experience gastrointestinal co-morbidity (Abstract \# 1787). Brain Behav Immun 57:e23-e24. https://doi.org/10.1016/j.bbi.2016.07.080.

138. Napolioni V, Ober-Reynolds B, Szelinger S, Corneveaux JJ, Pawlowski T, Ober-Reynolds S, Kirwan J, Persico AM et al (2013) Plasma cytokine profiling in sibling pairs discordant for autism spectrum disorder. J Neuroinflammation 10:38. https://doi. org/10.1186/1742-2094-10-38

139. Manzardo AM, Henkhaus R, Dhillon S, Butler MG (2012) Plasma cytokine levels in children with autistic disorder and unrelated siblings. Int J Dev Neurosci 30(2):121-127. https://doi.org/10. 1016/j.ijdevneu.2011.12.003

140. Schwarz E, Guest PC, Rahmoune H, Wang L, Levin Y, Ingudomnukul E, Ruta L, Kent L et al (2011) Sex-specific serum biomarker patterns in adults with Asperger's syndrome. Mol Psychiatry 16(12):1213-1220. https://doi.org/10.1038/mp.2010. 102

141. Suzuki K, Matsuzaki H, Iwata K, Kameno Y, Shimmura C, Kawai S, Yoshihara Y, Wakuda T et al (2011) Plasma cytokine profiles in subjects with high-functioning autism spectrum disorders. PLoS One 6(5):e20470. https://doi.org/10.1371/journal.pone.0020470

142. Bryn V, Aass HC, Skjeldal OH, Isaksen J, Saugstad OD, Ormstad $\mathrm{H}$ (2017) Cytokine profile in autism spectrum disorders in children. J Mol Neurosci 61(1):1-7. https://doi.org/10.1007/s12031016-0847-z

143. Tostes MH, Teixeira HC, Gattaz WF, Brandão MA, Raposo NR (2012) Altered neurotrophin, neuropeptide, cytokines and nitric oxide levels in autism. Pharmacopsychiatry 45(6):241-243. https://doi.org/10.1055/s-0032-1301914

144. Ashwood P, Krakowiak P, Hertz-Picciotto I, Hansen R, Pessah IN, Van de Water J (2011) Altered T cell responses in children with 
autism. Brain Behav Immun 25(5):840-849. https://doi.org/10. 1016/j.bbi.2010.09.002

145. Ashwood P, Krakowiak P, Hertz-Picciotto I, Hansen R, Pessah I, Van de Water J (2011) Elevated plasma cytokines in autism spectrum disorders provide evidence of immune dysfunction and are associated with impaired behavioral outcome. Brain Behav Immun 25(1):40-45. https://doi.org/10.1016/j.bbi.2010.08.003

146. Malik M, Sheikh AM, Wen G, Spivack W, Brown WT, Li X (2011) Expression of inflammatory cytokines, Bcl2 and cathepsin $\mathrm{D}$ are altered in lymphoblasts of autistic subjects. Immunobiology 216(1-2):80-85. https://doi.org/10.1016/j.imbio.2010.03.001

147. Ashwood P, Schauer J, Pessah IN, Van de Water J (2009) Preliminary evidence of the in vitro effects of BDE- 47 on innate immune responses in children with autism spectrum disorders. $\mathrm{J}$ Neuroimmunol 208(1-2):130-135. https://doi.org/10.1016/j. jneuroim.2008.12.012

148. Molloy CA, Morrow AL, Meinzen-Derr J, Schleifer K, Dienger K, Manning-Courtney P, Altaye M, Wills-Karp M (2006) Elevated cytokine levels in children with autism spectrum disorder. J Neuroimmunol 172(1-2):198-205

149. Singh VK, Warren RP, Odell JD, Cole P (1991) Changes of soluble interleukin-2, interleukin-2 receptor, T8 antigen, and interleukin-1 in the serum of autistic children. Clin Immunol Immunopathol 61(3):448-455

150. Careaga M, Rogers S, Hansen RL, Amaral DG, Van de Water J, Ashwood P (2017) Immune endophenotypes in children with autism spectrum disorder. Biol Psychiatry 81(5):434-441. https:// doi.org/10.1016/j.biopsych.2015.08.036

151. Jyonouchi H, Geng L, Davidow AL (2014) Cytokine profiles by peripheral blood monocytes are associated with changes in behavioral symptoms following immune insults in a subset of ASD subjects: an inflammatory subtype? J Neuroinflammation 11:187

152. Ricci S, Businaro R, Ippoliti F, Lo Vasco VR, Massoni F, Onofri E, Troili GM, Pontecorvi V et al (2013) Altered cytokine and BDNF levels in autism spectrum disorder. Neurotox Res 24(4): 491-501. https://doi.org/10.1007/s12640-013-9393-4

153. Jyonouchi H, Geng L, Streck DL, Toruner GA (2012) Immunological characterization and transcription profiling of peripheral blood $(\mathrm{PB})$ monocytes in children with autism spectrum disorders (ASD) and specific polysaccharide antibody deficiency (SPAD): case study. J Neuroinflammation 9:4. https://doi.org/10. 1186/1742-2094-9-4

154. Jyonouchi H, Geng L, Streck DL, Toruner GA (2011) Children with autism spectrum disorders (ASD) who exhibit chronic gastrointestinal (GI) symptoms and marked fluctuation of behavioral symptoms exhibit distinct innate immune abnormalities and transcriptional profiles of peripheral blood (PB) monocytes. J Neuroimmunol 238(1-2):73-80. https://doi.org/10.1016/j. jneuroim.2011.07.001

155. Enstrom AM, Onore CE, Van de Water JA, Ashwood P (2010) Differential monocyte responses to TLR ligands in children with autism spectrum disorders. Brain Behav Immun 24(1):64-71

156. Jyonouchi H, Geng L, Cushing-Ruby A, Quraishi H (2008) Impact of innate immunity in a subset of children with autism spectrum disorders: a case control study. J Neuroinflammation 5: 52. https://doi.org/10.1186/1742-2094-5-52

157. Jyonouchi H, Geng L, Ruby A, Reddy C, Zimmerman-Bier B (2005) Evaluation of an association between gastrointestinal symptoms and cytokine production against common dietary proteins in children with autism spectrum disorders. J Pediatr 146(5): 605-610

158. Jyonouchi H, Geng L, Ruby A, Zimmerman-Bier B (2005) Dysregulated innate immune responses in young children with autism spectrum disorders: their relationship to gastrointestinal symptoms and dietary intervention. Neuropsychobiology 51(2): $77-85$
159. Jyonouchi H, Sun S, Le H (2001) Proinflammatory and regulatory cytokine production associated with innate and adaptive immune responses in children with autism spectrum disorders and developmental regression. J Neuroimmunol 120(1-2):170-179

160. Singh VK (1996) Plasma increase of interleukin-12 and interferon-gamma. Pathological significance in autism. J Neuroimmunol 66(1-2):143-145

161. Sweeten TL, Posey DJ, McDougle CJ (2003) High blood monocyte counts and neopterin levels in children with autistic disorder. Am J Psychiatry 160(9):1691-1693

162. Ahmad SF, Nadeem A, Ansari MA, Bakheet SA, Attia SM, Zoheir KM, Al-Ayadhi LY, Alzahrani MZ et al (2017) Imbalance between the anti- and pro-inflammatory milieu in blood leukocytes of autistic children. Mol Immunol 82:57-65. https://doi.org/10.1016/j. molimm.2016.12.019

163. Guloksuz SA, Abali O, Aktas Cetin E, Bilgic Gazioglu S, Deniz G, Yildirim A, Kawikova I, Guloksuz S, Leckman JF (2017) Elevated plasma concentrations of S100 calcium-binding protein $\mathrm{B}$ and tumor necrosis factor alpha in children with autism spectrum disorders. Rev Bras Psiquiatr 39(3):195-200. https://doi.org/ 10.1590/1516-4446-2015-1843

164. Han YM, Cheung WK, Wong CK, Sze SL, Cheng TW, Yeung MK, Chan AS (2017) Distinct cytokine and chemokine profiles in autism spectrum disorders. Front Immunol 8:11. https://doi.org/ 10.3389/fimmu.2017.00011

165. El-Ansary AK, Ben Bacha AG, Al-Ayadhi LY (2011) Proinflammatory and proapoptotic markers in relation to mono and di-cations in plasma of autistic patients from Saudi Arabia. J Neuroinflammation 8:142. https://doi.org/10.1186/1742-2094-8142

166. Makinodan M, Iwata K, Ikawa D, Yamashita Y, Yamamuro K, Toritsuka M, Kimoto S, Okumura K et al (2017) Tumor necrosis factor-alpha expression in peripheral blood mononuclear cells correlates with early childhood social interaction in autism spectrum disorder. Neurochem Int 104:1-5. https://doi.org/10.1016/j.neuint. 2016.12.005.

167. Ferguson BJ, Marler S, Altstein LL, Lee EB, Mazurek MO, McLaughlin A, Macklin EA, McDonnell E et al (2016) Associations between cytokines, endocrine stress response, and gastrointestinal symptoms in autism spectrum disorder. Brain Behav Immun 58:57-62. https://doi.org/10.1016/j.bbi.2016.05. 009

168. Barbosa IG, Rodrigues DH, Rocha NP, Sousa LF, Vieira EL, Simões-E-Silva AC, Kummer A, Teixeira AL (2015) Plasma levels of alarmin IL-33 are unchanged in autism spectrum disorder: a preliminary study. J Neuroimmunol 278:69-72. https://doi. org/10.1016/j.jneuroim.2014.11.021

169. Tonhajzerova I, Ondrejka I, Mestanik M, Mikolka P, Hrtanek I, Mestanikova A, Bujnakova I, Mokra D (2015) Inflammatory activity in autism spectrum disorder. Adv Exp Med Biol 861:93-98. https://doi.org/10.1007/5584_2015_145

170. Tsilioni I, Taliou A, Francis K, Theoharides TC (2015) Children with autism spectrum disorders, who improved with a luteolincontaining dietary formulation, show reduced serum levels of TNF and IL-6. Transl Psychiatry 5:e647. https://doi.org/10.1038/ tp.2015.142

171. Yang CJ, Liu CL, Sang B, Zhu XM, Du YJ (2015) The combined role of serotonin and interleukin-6 as biomarker for autism. Neuroscience 284:290-296. https://doi.org/10.1016/j. neuroscience.2014.10.011

172. El-Ansary A, Al-Ayadhi L (2014) GABAergic/glutamatergic imbalance relative to excessive neuroinflammation in autism spectrum disorders. J Neuroinflammation 11:189. https://doi.org/10. 1186/s12974-014-0189-0 
173. El-Ansary A, Al-Ayadhi L (2012) Neuroinflammation in autism spectrum disorders. J Neuroinflammation 9:265. https://doi.org/ 10.1186/1742-2094-9-265

174. Ashwood P, Krakowiak P, Hertz-Picciotto I, Hansen R, Pessah IN, Van de Water J (2011) Associations of impaired behaviors with elevated plasma chemokines in autism spectrum disorders. J Neuroimmunol 232(1-2):196-199. https://doi.org/10.1016/j. jneuroim.2010.10.025

175. Onore C, Van de Water J, Ashwood P (2012) Decreased levels of EGF in plasma of children with autism spectrum disorder. Autism Res Treat: 205362. https://doi.org/10.1155/2012/205362

176. Emanuele E, Orsi P, Boso M, Broglia D, Brondino N, Barale F, di Nemi SU, Politi P (2010) Low-grade endotoxemia in patients with severe autism. Neurosci Lett 471(3):162-165. https://doi.org/10. 1016/j.neulet.2010.01.033

177. Ashwood P, Enstrom A, Krakowiak P, Hertz-Picciotto I, Hansen RL, Croen LA, Ozonoff S, Pessah IN et al (2008) Decreased transforming growth factor betal in autism: a potential link between immune dysregulation and impairment in clinical behavioral outcomes. J Neuroimmunol 204(1-2):149-153. https://doi.org/ 10.1016/j.jneuroim.2008.07.006

178. Enstrom A, Onore C, Hertz-Picciotto I, Hansen R, Croen L, Van de Water J, Ashwood P (2008) Detection of IL-17 and IL-23 in plasma samples of children with autism. Am J Biochem Biotechnol 4(2):114-120

179. Grigorenko EL, Han SS, Yrigollen CM, Leng L, Mizue Y, Anderson GM, Mulder EJ, de Bildt A et al (2008) Macrophage migration inhibitory factor and autism spectrum disorders. Pediatrics 122(2):e438-e445. https://doi.org/10.1542/peds.20073604

180. Al-Ayadhi LY (2005) Pro-inflammatory cytokines in autistic children in central Saudi Arabia. Neurosciences (Riyadh) 10(2):155158

181. Sweeten TL, Posey DJ, Shankar S, McDougle CJ (2004) High nitric oxide production in autistic disorder: a possible role for interferon-gamma. Biol Psychiatry 55(4):434-437

182. Croonenberghs J, Bosmans E, Deboutte D, Kenis G, Maes M (2002) Activation of the inflammatory response system in autism. Neuropsychobiology 45(1):1-6

183. Jyonouchi H, Sun S, Itokazu N (2002) Innate immunity associated with inflammatory responses and cytokine production against common dietary proteins in patients with autism spectrum disorder. Neuropsychobiology 46(2):76-84

184. Jyonouchi H, Geng L, Waynne R, Rose S, Frye R (2017) An association between IL-1 $\beta$ production and mitochondrial functions in patients with autism spectrum disorders (abstract 671). J Allergy Clin Immunol 139(2):AB213. https://doi.org/10.1016/j. jaci.2016.12.689

185. Kajizuka M, Miyachi T, Matsuzaki H, Iwata K, Shinmura C, Suzuki K, Suda S, Tsuchiya KJ et al (2010) Serum levels of platelet-derived growth factor BB homodimers are increased in male children with autism. Prog Neuropsychopharmacol Biol Psychiatry 34(1):154-158. https://doi.org/10.1016/j. pnpbp.2009.10.017

186. Ginhoux F, Jung S (2014) Monocytes and macrophages: developmental pathways and tissue homeostasis. Nat Rev Immunol 14(6): 392-404. https://doi.org/10.1038/nri3671

187. Swirski FK, Hilgendorf I, Robbins CS (2014) From proliferation to proliferation: monocyte lineage comes full circle. Semin Immunopathol 36(2):137-148. https://doi.org/10.1007/s00281013-0409-1

188. Amoruso A, Sola D, Rossi L, Obeng JA, Fresu LG, Sainaghi PP, Pirisi M, Brunelleschi S (2016) Relation among anti-rheumatic drug therapy, CD14(+)CD16(+) blood monocytes and disease activity markers (DAS28 and US7 scores) in rheumatoid arthritis: a pilot study. Pharmacol Res 107:308-314. https://doi.org/10.1016/ j.phrs.2016.03.034

189. Saresella M, Marventano I, Calabrese E, Piancone F, Rainone V, Gatti A, Alberoni M, Nemni R et al (2014) A complex proinflammatory role for peripheral monocytes in Alzheimer's disease. $\mathrm{J}$ Alzheimers Dis 38(2):403-413. https://doi.org/10.3233/JAD131160.

190. Grozdanov V, Bliederhaeuser C, Ruf WP, Roth V, FundelClemens K, Zondler L, Brenner D, Martin-Villalba A et al (2014) Inflammatory dysregulation of blood monocytes in Parkinson's disease patients. Acta Neuropathol 128(5):651-663. https://doi.org/10.1007/s00401-014-1345-4

191. Benarroch EE (2013) Microglia: multiple roles in surveillance, circuit shaping, and response to injury. Neurology 81(12):1079-1088

192. Koyama R, Ikegaya Y (2015) Microglia in the pathogenesis of autism spectrum disorders. Neurosci Res. https://doi.org/10. 1016/j.neures.2015.06.005

193. Takano T (2015) Role of microglia in autism: recent advances. Dev Neurosci 37(3):195-202

194. Réus GZ, Fries GR, Stertz L, Badawy M, Passos IC, Barichello T, Kapczinski F, Quevedo J (2015) The role of inflammation and microglial activation in the pathophysiology of psychiatric disorders. Neuroscience 300:141-154

195. Yamamuro K, Kimoto S, Rosen KM, Kishimoto T, Makinodan M (2015) Potential primary roles of glial cells in the mechanisms of psychiatric disorders. Front Cell Neurosci 9:154

196. Suzuki K, Sugihara G, Ouchi Y, Nakamura K, Futatsubashi M, Takebayashi K, Yoshihara Y, Omata K et al (2013) Microglial activation in young adults with autism spectrum disorder. JAMA Psychiatry 70(1):49-58

197. Morgan JT, Chana G, Abramson I, Semendeferi K, Courchesne E, Everall IP (2012) Abnormal microglial-neuronal spatial organization in the dorsolateral prefrontal cortex in autism. Brain Res 1456:72-81

198. Morgan JT, Chana G, Pardo CA, Achim C, Semendeferi K, Buckwalter J, Courchesne E, Everall IP (2010) Microglial activation and increased microglial density observed in the dorsolateral prefrontal cortex in autism. Biol Psychiatry 68(4):368-376. https://doi.org/10.1016/j.biopsych.2010.05.024

199. Tetreault NA, Hakeem AY, Jiang S, Williams BA, Allman E, Wold BJ, Allman JM (2012) Microglia in the cerebral cortex in autism. J Autism Dev Disord 42(12):2569-2584. https://doi.org/10.1007/ s10803-012-1513-0

200. Rodriguez JI, Kern JK (2011) Evidence of microglial activation in autism and its possible role in brain underconnectivity. Neuron Glia Biol 7(2-4):205-213. https://doi.org/10.1017/ S1740925X12000142

201. Belmonte MK, Allen G, Beckel-Mitchener A, Boulanger LM, Carper RA, Webb SJ (2004) Autism and abnormal development of brain connectivity. J Neurosci 24(42):9228-9231

202. Chen SK, Tvrdik P, Peden E, Cho S, Wu S, Spangrude G, Capecchi MR (2010) Hematopoietic origin of pathological grooming in Hoxb8 mutant mice. Cell 141(5):775-785. https:// doi.org/10.1016/j.cell.2010.03.055

203. Laskaris LE, Di Biase MA, Everall I, Chana G, Christopoulos A, Skafidas E, Cropley VL, Pantelis C (2016) Microglial activation and progressive brain changes in schizophrenia. Br J Pharmacol 173(4):666-680. https://doi.org/10.1111/bph.13364

204. Chew LJ, Fusar-Poli P, Schmitz T (2013) Oligodendroglial alterations and the role of microglia in white matter injury: relevance to schizophrenia. Dev Neurosci 35(2-3):102-129. https://doi.org/10. $1159 / 000346157$

205. Wohleb ES, Delpech JC (2017) Dynamic cross-talk between microglia and peripheral monocytes underlies stress-induced neuroinflammation and behavioral consequences. Prog 
Neuropsychopharmacol Biol Psychiatry 79(Pt A):40-48. https:// doi.org/10.1016/j.pnpbp.2016.04.013

206. Pepe G, Calderazzi G, De Maglie M, Villa AM, Vegeto E (2014) Heterogeneous induction of microglia M2a phenotype by central administration of interleukin-4. J Neuroinflammation 11:211. https://doi.org/10.1186/s12974-014-0211-6

207. Tomita M, Khan RL, Blehm BH, Santoro TJ (2004) The potential pathogenetic link between peripheral immune activation and the central innate immune response in neuropsychiatric systemic lupus erythematosus. Med Hypotheses 62(3):325-335

208. Ameis SH, Catani M (2015) Altered white matter connectivity as a neural substrate for social impairment in autism spectrum disorder. Cortex 62:158-181. https://doi.org/10.1016/j.cortex.2014.10.014

209. Chang YS, Owen JP, Desai SS, Hill SS, Arnett AB, Harris J, Marco EJ, Mukherjee P (2014) Autism and sensory processing disorders: shared white matter disruption in sensory pathways but divergent connectivity in social-emotional pathways. PLoS One 9(7):e103038. https://doi.org/10.1371/journal.pone.0103038

210. Li X, Chauhan A, Sheikh AM, Patil S, Chauhan V, Li XM, Ji L, Brown T et al (2009) Elevated immune response in the brain of autistic patients. J Neuroimmunol 207(1-2):111-116

211. Vargas DL, Nascimbene C, Krishnan C, Zimmerman AW, Pardo CA (2005) Neuroglial activation and neuroinflammation in the brain of patients with autism. Ann Neurol 57(1):67-81

212. Wei H, Zou H, Sheikh AM, Malik M, Dobkin C, Brown WT, Li X (2011) IL-6 is increased in the cerebellum of autistic brain and alters neural cell adhesion, migration and synaptic formation. $\mathrm{J}$ Neuroinflammation 8:52. https://doi.org/10.1186/1742-2094-8-52

213. Zimmerman AW, Jyonouchi H, Comi AM, Connors SL, Milstien S, Varsou A, Heyes MP (2005) Cerebrospinal fluid and serum markers of inflammation in autism. Pediatr Neurol 33(3):195-201

214. Tani Y, Fernell E, Watanabe Y, Kanai T, Långström B (1994) Decrease in 6R-5,6,7,8-tetrahydrobiopterin content in cerebrospinal fluid of autistic patients. Neurosci Lett 181(1-2):169-172

215. Zhao HX, Yin SS, Fan JG (2015) High plasma neopterin levels in Chinese children with autism spectrum disorders. Int J Dev Neurosci 41:92-97. https://doi.org/10.1016/j.ijdevneu.2015.02. 002

216. Messahel S, Pheasant AE, Pall H, Ahmed-Choudury J, SungumPaliwal RS, Vostanis P (1998) Urinary levels of neopterin and biopterin in autism. Neurosci Lett 241:17-20

217. Harrison KL, Pheasant AE (1995) Analysis of urinary pterins in autism. Biochem Soc Trans 23(4):603S

218. Eto I, Bandy MD, Butterworth CE Jr (1992) Plasma and urinary levels of biopterin, neopterin, and related pterins and plasma levels of folate in infantile autism. J Autism Dev Disord 22(2):295-308

219. Frye RE, DeLatorre R, Taylor HB, Slattery J, Melnyk S, Chowdhury N, James SJ (2013) Metabolic effects of sapropterin treatment in autism spectrum disorder: a preliminary study. Transl Psychiatry 3:e237. https://doi.org/10.1038/tp.2013.14

220. Klaiman C, Huffman L, Masaki L, Elliott GR (2013) Tetrahydrobiopterin as a treatment for autism spectrum disorders: a double-blind, placebo-controlled trial. J Child Adolesc Psychopharmacol 23(5):320-328. https://doi.org/10.1089/cap. 2012.0127

221. Frye RE, Huffman LC, Elliott GR (2010) Tetrahydrobiopterin as a novel therapeutic intervention for autism. Neurotherapeutics 7(3): 241-249. https://doi.org/10.1016/j.nurt.2010.05.004

222. Danfors T, von Knorring AL, Hartvig P, Langstrom B, Moulder R, Stromberg B, Torstenson R, Wester U et al (2005) Tetrahydrobiopterin in the treatment of children with autistic disorder: a double-blind placebo-controlled crossover study. J Clin Psychopharmacol 25(5):485-489

223. Fernell E, Watanabe Y, Adolfsson I, Tani Y, Bergström M, Hartvig P, Lilja A, von Knorring AL et al (1997) Possible effects of tetrahydrobiopterin treatment in six children with autism — clinical and positron emission tomography data: a pilot study. Dev Med Child Neurol 39(5):313-318

224. Komori H, Matsuishi T, Yamada S, Yamashita Y, Ohtaki E, Kato H (1995) Cerebrospinal fluid biopterin and biogenic amine metabolites during oral R-THBP therapy for infantile autism. J Autism Dev Disord 25(2): 183-193

225. Schnetz-Boutaud NC, Anderson BM, Brown KD, Wright HH, Abramson RK, Cuccaro ML, Gilbert JR, Pericak-Vance MA et al (2009) Examination of tetrahydrobiopterin pathway genes in autism. Genes Brain Behav 8(8):753-757. https://doi.org/10. 1111/j.1601-183X.2009.00521.x

226. Young AM, Campbell E, Lynch S, Suckling J, Powis SJ (2011) Aberrant NF-kappaB expression in autism spectrum condition: a mechanism for neuroinflammation. Front Psychiatry 2:27. https:// doi.org/10.3389/fpsyt.2011.00027

227. Chez MG, Dowling T, Patel PB, Khanna P, Kominsky M (2007) Elevation of tumor necrosis factor-alpha in cerebrospinal fluid of autistic children. Pediatr Neurol 36(6):361-365. https://doi.org/10. 1016/j.pediatrneurol.2007.01.012

228. Song R, Yu D, Yoon J, Park J (2015) Valproic acid attenuates the expression of pro-inflammatory cytokines lipopolysaccharidetreated canine peripheral blood mononuclear cells (in vitro) and in a canine endotoxemia model (in vivo). Vet Immunol Immunopathol. https://doi.org/10.1016/j.vetimm.2015.06.012

229. Choi JE, Widjaja F, Careaga M, Bent S, Ashwood P, Hendren RL (2014) Change in plasma cytokine levels during risperidone treatment in children with autism. J Child Adolesc Psychopharmacol 24(10):586-589. https://doi.org/10.1089/cap.2013.0108

230. Suda S, Katsura K, Kanamaru T, Saito M, Katayama Y (2013) Valproic acid attenuates ischemia-reperfusion injury in the rat brain through inhibition of oxidative stress and inflammation. Eur J Pharmacol 707(1-3):26-31. https://doi.org/10.1016/j. ejphar.2013.03.020

231. Ximenes JC, de Oliveira Gonçalves D, Siqueira RM, Neves KR, Santos Cerqueira G, Correia AO, Félix FH, Leal LK et al (2013) Valproic acid: an anticonvulsant drug with potent antinociceptive and anti-inflammatory properties. Naunyn Schmiedebergs Arch Pharmacol 386(7):575-587. https://doi.org/10.1007/s00210-0130853-4

232. Pardo CA, Farmer CA, Thurm A, Shebl FM, Ilieva J, Kalra S, Swedo S (2017) Serum and cerebrospinal fluid immune mediators in children with autistic disorder: a longitudinal study. Mol Autism. 8(1). https://doi.org/10.1186/s13229-016-0115-7

233. Hsiao EY (2014) Gastrointestinal issues in autism spectrum disorder. Harv Rev Psychiatry 22(2):104-111. https://doi.org/10. 1097/HRP.0000000000000029

234. Ashwood P, Wakefield AJ (2006) Immune activation of peripheral blood and mucosal CD3+ lymphocyte cytokine profiles in children with autism and gastrointestinal symptoms. J Neuroimmunol 173(1-2):126-134

235. Ashwood P, Anthony A, Torrente F, Wakefield AJ (2004) Spontaneous mucosal lymphocyte cytokine profiles in children with autism and gastrointestinal symptoms: mucosal immune activation and reduced counter regulatory interleukin-10. J Clin Immunol 24(6):664-673

236. Luna RA, Oezguen N, Balderas M, Venkatachalam A, Runge JK, Versalovic J, Veenstra-VanderWeele J, Anderson GM et al (2016) Distinct microbiome-neuroimmune signatures correlate with functional abdominal pain in children with autism spectrum disorder. Cell Mol Gastroenterol Hepatol 3(2):218-230. https://doi.org/10. 1016/j.jcmgh.2016.11.008

237. DeFelice ML, Ruchelli ED, Markowitz JE, Strogatz M, Reddy KP, Kadivar K, Mulberg AE, Brown KA (2003) Intestinal cytokines in children with pervasive developmental disorders. Am J Gastroenterol 98(8):1777-1782 
238. Furlano RI, Anthony A, Day R, Brown A, McGarvey L, Thomson MA, Davies SE, Berelowitz M et al (2001) Colonic CD8 and gamma delta T-cell infiltration with epithelial damage in children with autism. J Pediatr 138(3):366-372

239. Ashwood P, Anthony A, Pellicer AA, Torrente F, Walker-Smith JA, Wakefield AJ (2003) Intestinal lymphocyte populations in children with regressive autism: evidence for extensive mucosal immunopathology. J Clin Immunol 23(6):504-517

240. Torrente F, Ashwood P, Day R, Machado N, Furlano RI, Anthony A, Davies SE, Wakefield AJ et al (2002) Small intestinal enteropathy with epithelial IgG and complement deposition in children with regressive autism. Mol Psychiatry 7(4):375-382 334

241. Bashir S, Al-Ayadhi LY (2014) Effect of camel milk on thymus and activation-regulated chemokine in autistic children: doubleblind study. Pediatr Res 75(4):559-563. https://doi.org/10.1038/ pr.2013.248

242. Shenoy S, Arnold S, Chatila T (2000) Response to steroid therapy in autism secondary to autoimmune lymphoproliferative syndrome. J Pediatr 136(5):682-687

243. Feasby T, Banwell B, Benstead T, Bril V, Brouwers M, Freedman M, Hahn A, Hume $\mathrm{H}$ et al (2007) Guidelines on the use of intravenous immune globulin for neurologic conditions. Transfus Med Rev 21(2 Suppl 1):S57-107

244. Plioplys AV (1998) Intravenous immunoglobulin treatment of children with autism. J Child Neurol. 13(2):79-82

245. Gupta S, Aggarwal S, Heads C (1996) Dysregulated immune system in children with autism: beneficial effects of intravenous immune globulin on autistic characteristics. J Autism Dev Disord 26(4):439-452

246. DelGiudice-Asch G, Simon L, Schmeidler J, CunninghamRundles C, Hollander E (1999) Brief report: a pilot open clinical trial of intravenous immunoglobulin in childhood autism. J Autism Dev Disord 29(2):157-160

247. Boris M, Goldblatt A, Edelson SM (2005) Improvement in children with autism treated with intravenous gamma globulin. J Nutr Environ Med 15:169-176

248. Schneider CK, Melmed RD, Barstow LE, Enriquez FJ, RangerMoore J, Ostrem JA (2006) Oral human immunoglobulin for children with autism and gastrointestinal dysfunction: a prospective, open-label study. J Autism Dev Disord 36(8):1053-1064

249. Handen BL, Melmed RD, Hansen RL, Aman MG, Burnham DL, Bruss JB, McDougle CJ (2009) A double-blind, placebocontrolled trial of oral human immunoglobulin for gastrointestinal dysfunction in children with autistic disorder. J Autism Dev Disord 39(5):796-805. https://doi.org/10.1007/s10803-0080687-y

250. Svecova D (2016) IVIG therapy in pemphigus vulgaris has corticosteroid-sparing and immunomodulatory effects. Australas J Dermatol 57(2):141-144. https://doi.org/10.1111/ajd.12422

251. Cantarini L, Rigante D, Vitale A, Napodano S, Sakkas LI, Bogdanos DP, Shoenfeld Y (2015) Intravenous immunoglobulins (IVIG) in systemic sclerosis: a challenging yet promising future. Immunol Res 61(3):326-337

252. Klehmet J, Goehler J, Ulm L, Kohler S, Meisel C, Meisel A, Harms H (2015) Effective treatment with intravenous immunoglobulins reduces autoreactive T-cell response in patients with CIDP. J Neurol Neurosurg Psychiatry 86(6):686-691. https://doi. org/10.1136/jnnp-2014-307708

253. Issekutz AC, Rowter D, Miescher S, Käsermann F (2015) Intravenous IgG (IVIG) and subcutaneous IgG (SCIG) preparations have comparable inhibitory effect on $\mathrm{T}$ cell activation, which is not dependent on IgG sialylation, monocytes or B cells. Clin Immunol 160(2):123-132. https://doi.org/10.1016/j.clim.2015. 05.003

254. Durandy A, Kaveri SV, Kuijpers TW, Basta M, Miescher S, Ravetch JV, Rieben R (2009) Intravenous immunoglobulins- understanding properties and mechanisms. Clin Exp Immunol 158(Suppl 1):2-13. https://doi.org/10.1111/j.1365-2249.2009. 04022.x

255. Dussault N, Ducas E, Racine C, Jacques A, Paré I, Côté S, Néron S (2008) Immunomodulation of human B cells following treatment with intravenous immunoglobulins involves increased phosphorylation of extracellular signalregulated kinases 1 and 2. Int Immunol. 20(11):13691379. https://doi.org/10.1093/intimm/dxn090

256. Duffy FH, Shankardass A, McAnulty GB, Eksioglu YZ, Coulter D, Rotenberg A, Als H (2014) Corticosteroid therapy in regressive autism: a retrospective study of effects on the Frequency Modulated Auditory Evoked Response (FMAER), language, and behavior. BMC Neurol 14:70. https://doi.org/10.1186/1471-2377-14-70

257. Golla S, Sweeney JA (2014) Corticosteroid therapy in regressive autism: Preliminary findings from a retrospective study. BMC Med 12:79. https://doi.org/10.1186/1741-7015-12-79

258. Stefanatos GA, Grover W, Geller E (1995) Case study: corticosteroid treatment of language regression in pervasive developmental disorder. J Am Acad Child Adolesc Psychiatry 34(8):1107-1111

259. Buitelaar JK, van Engeland H, de Kogel KH, de Vries H, van Hooff JA, van Ree JM (1992) The use of adrenocorticotrophic hormone (4-9) analog ORG 2766 in autistic children: effects on the organization of behavior. Biol Psychiatry 31(11):1119-1129

260. LeClerc S, Easley D (2015) Pharmacological therapies for autism spectrum disorder: a review. P T 40(6):389-397

261. Obuchowicz E, Bielecka-Wajdman AM, Paul-Samojedny M, Nowacka M (2017) Different influence of antipsychotics on the balance between pro- and anti-inflammatory cytokines depends on glia activation: an in vitro study. Cytokine 94:37-44. https:// doi.org/10.1016/j.cyto.2017.04.004

262. MacDowell KS, García-Bueno B, Madrigal JL, Parellada M, Arango C, Micó JA, Leza JC (2013) Risperidone normalizes increased inflammatory parameters and restores anti-inflammatory pathways in a model of neuroinflammation. Int $\mathrm{J}$ Neuropsychopharmacol 16(1):121-135. https://doi.org/10.1017/ S1461145711001775

263. Seki Y, Kato TA, Monji A, Mizoguchi Y, Horikawa H, Sato-Kasai M, Yoshiga D, Kanba S (2013) Pretreatment of aripiprazole and minocycline, but not haloperidol, suppresses oligodendrocyte damage from interferon- $\gamma$-stimulated microglia in co-culture model. Schizophr Res 151(1-3):20-28. https://doi.org/10.1016/j. schres.2013.09.011

264. Sugino H, Futamura T, Mitsumoto Y, Maeda K, Marunaka Y (2009) Atypical antipsychotics suppress production of proinflammatory cytokines and up-regulate interleukin-10 in lipopolysaccharide-treated mice. Prog Neuropsychopharmacol Biol Psychiatry 33(2):303-307. https://doi.org/10.1016/j.pnpbp. 2008.12.006

265. Kato T, Monji A, Hashioka S, Kanba S (2007) Risperidone significantly inhibits interferon-gamma-induced microglial activation in vitro. Schizophr Res 92(1-3):108-115

266. Sobiś J, Rykaczewska-Czerwińska M, Świętochowska E, Gorczyca P (2015) Therapeutic effect of aripiprazole in chronic schizophrenia is accompanied by anti-inflammatory activity. Pharmacol Rep 67(2):353-359. https://doi.org/10.1016/j.pharep. 2014.09.007

267. Cazzullo CL, Sacchetti E, Galluzzo A, Panariello A, Adorni A, Pegoraro M, Bosis S, Colombo F et al (2002) Cytokine profiles in schizophrenic patients treated with risperidone: a 3-month follow-up study. Prog Neuropsychopharmacol Biol Psychiatry 26(1):33-39

268. Erbağci AB, Herken H, Köylüoglu O, Yilmaz N, Tarakçioglu M (2001) Serum IL-1beta, sIL-2R, IL-6, IL-8 and TNF-alpha in schizophrenic patients, relation with 
symptomatology and responsiveness to risperidone treatment. Mediators Inflamm 10(3):109-115

269. Kim DJ, Kim W, Yoon SJ, Go HJ, Choi BM, Jun TY, Kim YK (2001) Effect of risperidone on serum cytokines. Int J Neurosci 111(1-2):11-19

270. Tobiasova Z, van der Lingen KH, Scahill L, Leckman JF, Zhang Y, Chae W, McCracken JT, McDougle CJ et al (2011) Risperidone-related improvement of irritability in children with autism is not associated with changes in serum of epidermal growth factor and interleukin-13. J Child Adolesc Psychopharmacol 21(6):555-564. https://doi.org/10.1089/cap. 2010.0134

271. Troost PW, Lahuis BE, Steenhuis MP, Ketelaars CE, Buitelaar JK, van Engeland H, Scahill L, Minderaa RB et al (2005) Long-term effects of risperidone in children with autism spectrum disorders: a placebo discontinuation study. J Am Acad Child Adolesc Psychiatry 44(11):1137-1144

272. Soares A, Shiozawa P, Trevizol AP, Paula CS, Lowenthal R, Cordeiro Q (2016) Effects of augmentation agents in autistic disorder patients treated with risperidone: a systematic review and a meta-analysis. Trends Psychiatry Psychother 38(2):114-116. https://doi.org/10.1590/2237-6089-2015-0068

273. Ghanizadeh A, Tordjman S, Jaafari N (2015) Aripiprazole for treating irritability in children \& adolescents with autism: a systematic review. Indian J Med Res 142(3):269-275. https://doi.org/ 10.4103/0971-5916.166584

274. Deb S, Farmah BK, Arshad E, Deb T, Roy M, Unwin GL (2014) The effectiveness of aripiprazole in the management of problem behaviour in people with intellectual disabilities, developmental disabilities and/or autistic spectrum disorder-a systematic review. Res Dev Disabil. 35(3):711-725. https://doi.org/10.1016/j. ridd.2013.12.004

275. Arikawa M, Kakinuma Y, Noguchi T, Todaka H, Sato T (2016) Donepezil, an acetylcholinesterase inhibitor, attenuates LPSinduced inflammatory response in murine macrophage cell line RAW 264.7 through inhibition of nuclear factor kappa B translocation. Eur J Pharmacol 789:17-26. https://doi.org/10.1016/j. ejphar.2016.06.053

276. Chen T, Hou R, Xu S, Wu C (2015) Donepezil regulates 1-methyl4-phenylpyridinium-induced microglial polarization in Parkinson's disease. ACS Chem Neurosci 6(10):1708-1714. https://doi.org/10.1021/acschemneuro.5b00026

277. Hwang J, Hwang H, Lee HW, Suk K (2010) Microglia signaling as a target of donepezil. Neuropharmacology 58(7):1122-1129. https://doi.org/10.1016/j.neuropharm.2010.02.003

278. Karvat G, Kimchi T (2014) Acetylcholine elevation relieves cognitive rigidity and social deficiency in a mouse model of autism. Neuropsychopharmacology 39(4):831-840. https://doi.org/10. 1038/npp.2013.274

279. Kim JW, Seung H, Kwon KJ, Ko MJ, Lee EJ, HA O, Choi CS, Kim KC et al (2014) Subchronic treatment of donepezil rescues impaired social, hyperactive, and stereotypic behavior in valproic acid-induced animal model of autism. PLoS One 9(8):e104927. https://doi.org/10.1371/journal.pone.0104927

280. Richardson C, Gard PR, Klugman A, Isaac M, Tabet N (2013) Blood pro-inflammatory cytokines in Alzheimer's disease in relation to the use of acetylcholinesterase inhibitors. Int J Geriatr Psychiatry 28(12):1312-1317. https://doi.org/10.1002/gps.3966

281. Hardan AY, Handen BL (2002) A retrospective open trial of adjunctive donepezil in children and adolescents with autistic disorder. J Child Adolesc Psychopharmacol 12(3):237-241

282. Sahu JK, Gulati S, Sapra S, Arya R, Chauhan S, Chowdhury MR, Gupta N, Kabra M et al (2013) Effectiveness and safety of donepezil in boys with fragile $\mathrm{X}$ syndrome: a double-blind, randomized, controlled pilot study. J Child Neurol 28(5):570-575. https://doi.org/10.1177/0883073812449381
283. Handen BL, Johnson CR, McAuliffe-Bellin S, Murray PJ, Hardan AY (2011) Safety and efficacy of donepezil in children and adolescents with autism: neuropsychological measures. J Child Adolesc Psychopharmacol 21(1):43-50. https://doi.org/10.1089/ cap. 2010.0024

284. Mattei D, Djodari-Irani A, Hadar R, Pelz A, de Cossío LF, Goetz T, Matyash M, Kettenmann $\mathrm{H}$ et al (2014) Minocycline rescues decrease in neurogenesis, increase in microglia cytokines and deficits in sensorimotor gating in an animal model of schizophrenia. Brain Behav Immun 38:175-184. https://doi.org/10.1016/j.bbi. 2014.01.019

285. Pardo CA, Buckley A, Thurm A, Lee LC, Azhagiri A, Neville DM, Swedo SE (2013) A pilot open-label trial of minocycline in patients with autism and regressive features. J Neurodev Disord 5(1):9. https://doi.org/10.1186/1866-1955-5-9

286. Ghaleiha A, Alikhani R, Kazemi MR, Mohammadi MR, Mohammadinejad P, Zeinoddini A, Hamedi M, Shahriari M et al (2016) Minocycline as adjunctive treatment to risperidone in children with autistic disorder: a randomized, double-blind placebocontrolled trial. J Child Adolesc Psychopharmacol 26(9):784-791

287. https://clinicaltrials.gov/ - accessed 2017/09/30

288. Tohmi M, Tsuda N, Zheng Y, Mizuno M, Sotoyama H, Shibuya M, Kawamura M, Kakita A et al (2007) The cellular and behavioral consequences of interleukin-1 alpha penetration through the blood-brain barrier of neonatal rats: a critical period for efficacy. Neuroscience 150(1):234-250

289. Zalcman S, Murray L, Dyck DG, Greenberg AH, Nance DM (1998) Interleukin-2 and -6 induce behavioral-activating effects in mice. Brain Res 811(1-2):111-121

290. Raison CL, Borisov AS, Majer M, Drake DF, Pagnoni G, Woolwine BJ, Vogt GJ, Massung B et al (2009) Activation of central nervous system inflammatory pathways by interferon-alpha: relationship to monoamines and depression. Biol Psychiatry 65(4):296-303. https://doi.org/10.1016/j.biopsych.2008.08.010

291. Taylor JL, Grossberg SE (1998) The effects of interferon-alpha on the production and action of other cytokines. Semin Oncol 25(1 Suppl 1):23-29

292. Scagnolari C, Antonelli G (2013) Antiviral activity of the interferon $\alpha$ family: biological and pharmacological aspects of the treatment of chronic hepatitis C. Expert Opin Biol Ther 13(5):693711. https://doi.org/10.1517/14712598.2013.764409

293. Tarhini AA, Gogas H, Kirkwood JM (2012) IFN- $\alpha$ in the treatment of melanoma. J Immunol 189(8):3789-3793. https://doi.org/ 10.4049/jimmunol.1290060

294. Kovacs D, Kovacs P, Eszlari N, Gonda X, Juhasz G (2016) Psychological side effects of immune therapies: symptoms and pathomechanism. Curr Opin Pharmacol 29:97-103. https://doi. org/10.1016/j.coph.2016.06.008

295. Lee DW, Gardner R, Porter DL, Louis CU, Ahmed N, Jensen M, Grupp SA, Mackall CL (2014) Current concepts in the diagnosis and management of cytokine release syndrome. Blood 124(2): 188-195. https://doi.org/10.1182/blood-2014-05-552729

296. Wu H, Wang X, Gao J, Liang S, Hao Y, Sun C, Xia W, Cao Y, Wu L (2017) Fingolimod (FTY720) attenuates social deficits, learning and memory impairments, neuronal loss and neuroinflammation in the rat model of autism. Life Sci 173:43-54. https://doi.org/10. 1016/j.lfs.2017.01.012

297. Caprnda M, Kubatka P, Gazdikova K, Gasparova I, Valentova V, Stollarova N, La Rocca G, Kobyliak N, Dragasek J, Mozos I, Prosecky R, Siniscalco D, Büsselberg D, Rodrigo L, Kruzliak P (2017) Immunomodulatory effects of stem cells: therapeutic option for neurodegenerative disorders. Biomed Pharmacother 91: 60-69. https://doi.org/10.1016/j.biopha.2017.04.034

298. Nauta AJ, Fibbe WE (2007) Immunomodulatory properties of mesenchymal stromal cells. Blood 110(10):3499-3506 
299. Dominici M, Le Blanc K, Mueller I, Slaper-Cortenbach I, Marini F, Krause D, Deans R, Keating A, Prockop DJ, Horwitz E (2006) Minimal criteria for defining multipotent mesenchymal stromal cells. The International Society for Cellular Therapy position statement. Cytotherapy 8(4):315-317. https://doi.org/10.1080/ 14653240600855905

300. Lee M, Jeong SY, Ha J, Kim M, Jin HJ, Kwon SJ, Chang JW, Choi SJ, Oh W, Yang YS, Kim JS, Jeon HB (2014) Low immunogenicity of allogeneic human umbilical cord blood-derived mesenchymal stem cells in vitro and in vivo. Biochem Biophys Res Commun 446(4):983-989. https://doi.org/10.1016/j.bbrc.2014. 03.051

301. Patterson PH (2011) Modeling autistic features in animals. Pediatr Res 69(5 Pt 2):34R-40R

302. Wei H, Ma Y, Liu J, Ding C, Jin G, Wang Y, Hu F, Yu L (2016) Inhibition of IL- 6 trans-signaling in the brain increases sociability in the BTBR mouse model of autism. Biochim Biophys Acta 1862(10):1918-1925. https://doi.org/10.1016/j.bbadis.2016.07.013

303. Careaga M, Schwartzer J, Ashwood P (2015) Inflammatory profiles in the BTBR mouse: how relevant are they to autism spectrum disorders? Brain Behav Immun 43:11-16. https://doi.org/10. 1016/j.bbi.2014.06.006

304. Onore CE, Careaga M, Babineau BA, Schwartzer JJ, Berman RF, Ashwood P (2013) Inflammatory macrophage phenotype in BTBR T+tf/J mice. Front Neurosci 7:158. https://doi.org/10. 3389/fnins.2013.00158

305. Segal-Gavish H, Karvat G, Barak N, Barzilay R, Ganz J, Edry L, Aharony I, Offen D et al (2016) Mesenchymal stem cell transplantation promotes neurogenesis and ameliorates autism related behaviors in BTBR mice. Autism Res 9(1):17-32. https://doi.org/10. 1002/aur.1530

306. Perets N, Segal-Gavish H, Gothelf Y, Barzilay R, Barhum Y, Abramov N, Hertz S, Morozov D et al (2017) Long term beneficial effect of neurotrophic factors-secreting mesenchymal stem cells transplantation in the BTBR mouse model of autism. Behav Brain Res 331:254-260. https://doi.org/10.1016/j.bbr. 2017.03.047

307. Barzilay R, Ganz J, Sadan O, Ben-Zur T, Bren Z, Hinden N, Taler M, Lev N et al (2013) Mesenchymal stem cells protect from subchronic phencyclidine insult in vivo and counteract changes in astrocyte gene expression in vitro. Eur Neuropsychopharmacol 23(9): 1115-1123. https://doi.org/10.1016/j.euroneuro.2012.10.002

308. Barzilay R, Sadan O, Melamed E, Offen D (2009) Comparative characterization of bone marrow-derived mesenchymal stromal cells from four different rat strains. Cytotherapy 11(4):435-442. https://doi.org/10.1080/14653240902849796

309. Ha S, Park H, Mahmood U, Ra JC, Suh YH, Chang KA (2017) Human adipose-derived stem cells ameliorate repetitive behavior, social deficit and anxiety in a VPA-induced autism mouse model. Behav Brain Res 317:479-484. https://doi.org/10.1016/j.bbr. 2016.10.004

310. Hegyi B, Környei Z, Ferenczi S, Fekete R, Kudlik G, Kovács KJ, Madarász E, Uher F (2014) Regulation of mouse microglia activation and effector functions by bone marrow-derived mesenchymal stem cells. Stem Cells Dev 23(21):2600-2612. https://doi.org/ 10.1089/scd.2014.0088

311. Zanier ER, Pischiutta F, Riganti L, Marchesi F, Turola E, Fumagalli S, Perego C, Parotto E et al (2014) Bone marrow mesenchymal stromal cells drive protective M2 microglia polarization after brain trauma. Neurotherapeutics 11(3):679-695. https://doi. org/10.1007/s13311-014-0277-y

312. Ma T, Gong K, Ao Q, Yan Y, Song B, Huang H, Zhang X, Gong Y (2013) Intracerebral transplantation of adipose-derived mesenchymal stem cells alternatively activates microglia and ameliorates neuropathological deficits in Alzheimer's disease mice. Cell Transplant 22(Suppl 1):S113-S126
313. Giunti D, Parodi B, Usai C, Vergani L, Casazza S, Bruzzone S, Mancardi G, Uccelli A (2012) Mesenchymal stem cells shape microglia effector functions through the release of CX3CL1. Stem Cells 30(9):2044-2053

314. Ooi YY, Dheen ST, Tay SS (2015) Paracrine effects of mesenchymal stem cells-conditioned medium on microglial cytokines expression and nitric oxide production. Neuroimmunomodulation 22(4):233-242. https://doi.org/10.1159/000365483.

315. Blondheim NR, Levy YS, Ben-Zur T et al (2006) Human mesenchymal stem cells express neural genes, suggesting a neural predisposition. Stem Cells Dev 15(2):141-164

316. Lalu MM, McIntyre L, Pugliese C, Fergusson D, Winston BW, Marshall JC, Granton J, Stewart DJ (2013) Canadian Critical Care Trials Group. Safety of cell therapy with mesenchymal stromal cells (SafeCell): a systematic review and meta-analysis of clinical trials. PLoS One 7(10):e47559. https://doi.org/10.1371/journal. pone.0047559.

317. Sharma A, Badhe P, Gokulchandran N, Kulkarni P, Mishra P, Shetty A, Sane H (2013) An improved case of autism as revealed by PET CT scan in patient transplanted with autologous bone marrow derived mononuclear cells. J Stem Cell Res Ther 3:139

318. Sharma A, Gokulchandran N, Sane H, Nagrajan A, Paranjape A, Kulkarni P, Shetty A, Mishra P, Kali M, Biju H, Badhe P (2013) Autologous bone marrow mononuclear cell therapy for autism: an open label proof of concept study. Stem Cells Int: 623875. https:// doi.org/10.1155/2013/623875

319. Lv YT, Zhang Y, Liu M, Qiuwaxi JN, Ashwood P, Cho SC, Huan Y, Ge RC et al (2013) Transplantation of human cord blood mononuclear cells and umbilical cord-derived mesenchymal stem cells in autism. J Transl Med 11:196. https://doi.org/10.1186/14795876-11-196

320. Bradstreet JJ, Sych N, Antonucci N, Klunnik M, Ivankova O, Matyashchuk I, Demchuk M, Siniscalco D (2014) Efficacy of fetal stem cell transplantation in autism spectrum disorders: an openlabeled pilot study. Cell Transplant 23(Suppl 1):S105-S112

321. Shroff G (2017) Human embryonic stem cells in the treatment of autism: a case series. Innov Clin Neurosci 14(3-4):12-16

322. Schira J, Falkenberg H, Hendricks M, Waldera-Lupa DM, Kögler G, Meyer HE, Müller HW, Stühler K (2015) Characterization of regenerative phenotype of unrestricted somatic stem cells (USSC) from human umbilical cord blood (hUCB) by functional secretome analysis. Mol Cell Proteomics 14(10):2630-2643. https://doi.org/10.1074/mcp.M115.049312

323. Divya MS, Roshin GE, Divya TS, Rasheed VA, Santhoshkumar TR, Elizabeth KE, James J, Pillai RM (2012) Umbilical cord blood-derived mesenchymal stem cells consist of a unique population of progenitors co-expressing mesenchymal stem cell and neuronal markers capable of instantaneous neuronal differentiation. Stem Cell Res Ther 3(6):57. https://doi.org/10.1186/scrt148

324. Wang M, Yang Y, Yang D, Luo F, Liang W, Guo S, Xu J (2009) The immunomodulatory activity of human umbilical cord bloodderived mesenchymal stem cells in vitro. Immunology 126(2): 220-232. https://doi.org/10.1111/j.1365-2567.2008.02891.x

325. Cohen SB, Perez-Cruz I, Fallen P, Gluckman E, Madrigal JA (1999) Analysis of the cytokine production by cord and adult blood. Hum Immunol 60(4):331-336

326. Gluckman E, Broxmeyer HA, Auerbach AD, Friedman HS, Douglas GW, Devergie A, Esperou H, Thierry D et al (1989) Hematopoietic reconstitution in a patient with Fanconi's anemia by means of umbilical-cord blood from an HLA-identical sibling. N Engl J Med 321(17):1174-1178

327. Sun JM, Kurtzberg J (2015) Cord blood for brain injury. Cytotherapy 17(6):775-785. https://doi.org/10.1016/j.jcyt.2015.03.004

328. Englander ZA, Sun J, Case L, Mikati MA, Kurtzberg J, Song AW (2015) Brain structural connectivity increases concurrent with functional improvement: evidence from diffusion tensor MRI in 
children with cerebral palsy during therapy. Neuroimage Clin 7: 315-324. https://doi.org/10.1016/j.nicl.2015.01.002

329. Sun JM, Grant GA, McLaughlin C, Allison J, Fitzgerald A, Waters-Pick B, Kurtzberg J (2015) Repeated autologous umbilical cord blood infusions are feasible and had no acute safety issues in young babies with congenital hydrocephalus. Pediatr Res 78(6): 712-716. https://doi.org/10.1038/pr.2015.161

330. Saha A, Buntz S, Scotland P, Xu L, Noeldner P, Patel S, Wollish A, Gunaratne A et al (2016) A cord blood monocyte-derived cell therapy product accelerates brain remyelination. JCI Insight 1(13):e86667

331. Drobyshevsky A, Cotten CM, Shi Z, Luo K, Jiang R, Derrick M, Tracy ET, Gentry T et al (2015) Human umbilical cord blood cells ameliorate motor deficits in rabbits in a cerebral palsy model. Dev Neurosci 37(4-5):349-362. https://doi.org/10.1159/000374107.

332. Dawson G, Sun JM, Davlantis KS, Murias M, Franz L, Troy J, Simmons R, Sabatos-DeVito M et al (2017) Autologous cord blood infusions are safe and feasible in young children with autism spectrum disorder: results of a single-center phase I open-label trial. Stem Cells Transl Med 6(5):1332-1339. https://doi.org/10. 1002/sctm.16-0474

333. Gillberg C, Fernell E (2014) Autism plus versus autism pure. J Autism Dev Disord 44(12):3274-3276

334. Sing (2009) Phenotypic expression of autoimmune autistic disorder (AAD): a major subset of autism Ann Clin Psychiatry 21(3): $148-61$

335. Nadeem A, Ahmad SF, Bakheet SA, Al-Harbi NO, Al-Ayadhi LY, Attia SM, Zoheir KM (2017) Toll-like receptor 4 signaling is associated with upregulated NADPH oxidase expression in peripheral $\mathrm{T}$ cells of children with autism. Brain Behav Immun 61: 146-154. https://doi.org/10.1016/j.bbi.2016.12.024

336. Patel AB, Tsilioni I, Leeman SE, Theoharides TC (2016) Neurotensin stimulates sortilin and mTOR in human microglia inhibitable by methoxyluteolin, a potential therapeutic target for autism. Proc Natl Acad Sci U S A 113(45):E7049-E7058. https:// doi.org/10.1073/pnas.1604992113

337. Alabdali A, Al-Ayadhi L, El-Ansary A (2014) Association of social and cognitive impairment and biomarkers in autism spectrum disorders. J Neuroinflammation 11:4. https://doi.org/10.1186/ 1742-2094-11-4

338. Al-Ayadhi LY, Mostafa GA (2011) Increased serum osteopontin levels in autistic children: relation to the disease severity. Brain Behav Immun 25(7):1393-1398. https://doi.org/10.1016/j.bbi. 2011.04.006

339. Ikawa D, Makinodan M, Iwata K, Ohgidani M, Kato TA, Yamashita Y, Yamamuro K, Kimoto S, Toritsuka M, Yamauchi T, Fukami SI, Yoshino H, Okumura K, Tanaka T, Wanaka A, Owada Y, Tsujii M, Sugiyama T, Tsuchiya K, Mori N, Hashimoto R, Matsuzaki H, Kanba S, Kishimoto T (2017) Microglia-derived neuregulin expression in psychiatric disorders. Brain Behav Immun 61:375-385. https://doi.org/10.1016/j.bbi.2017.01.003

340. Onore CE, Nordahl CW, Young GS, Van de Water JA, Rogers SJ, Ashwood P (2012) Levels of soluble platelet endothelial cell adhesion molecule-1 and P-selectin are decreased in children with autism spectrum disorder. Biol Psychiatry 72(12):1020-1025. https://doi.org/10.1016/j.biopsych.2012.05.004 